\title{
REGENERATION AND AUTOTOMY IN THE \\ BLACK WIDOW SPIDER, \\ Latrodectus variolus Walckenaer.
}

\section{By}

JOHN BROOKES RANDALL

A DISSERTATION PRESENTED TO THE GRADUATE COUNCLL OF THE UNIVERSITY OF FLORIDA

IN PARTIAL FULFILLNENT OF THE REQUIRENENTS FOR THE DEGREE OF DOCTOR OF PHILOSOPHY

\author{
UNI VERSITY OF FLORIDA
}


This dissertation is dedicated to my mother, Norma B. Randall, who taught me the values of study and striving to

REGENERATION AND AUTOTOMY IN THE

BLACK WIDOW SPIDER,

Latrodectus variolus Walckenaer.

By

JOHN BROOKES RANDALL

A DISSERTATION PRESENTED TO THE GRADUATE COUNCIL OF THE UNIVERSITY OF FLORIDA

IN PARTIAL FULFILLMENT OF THE REQUIREIENTS FOR THE DEGPEE OF DOCTOR OF PHILOSOPHY 


\section{ACKNOWIEDGEVIENTS}

I would like to express my sincere appreciation to Dr. H. L. Cromroy for his continual advice, encouragement and friendship throughout the course of this study and for furnishing me with the space and materials required to complete this work.

I would especially like to thank Dr. Herbert Oberlander of the Insect Attractants, Behavior and Basic Biology Research Laboratory, USDA, Gainesville, Florida for his continual counsel, encouragement and friendship and for his valuable assistance in the preparation of the dissertation.

I would also like to acknowledge Dr. J. Nation and $\mathrm{Dr}$. J. Reiskind as members of my supervisory committee for their advice and encouragement. I would also like to thank Dr. D. L. Silhacek, also of the USDA Gainesville lab, for employing me in his laboratory and Dr. M. S. Mayer of the same laboratory for his help in assessing some of the data I collected.

My sincere thanks go to my parents, Mr. and Mrs. John A. Fandall of Millersville, Maryland, and to Col. and Mrs. Charles Foreman of HcLean, Virginia, for their continual support and encouragement in seeing that my family was never without necessities. 
Finally, I wish to thank my wife Carol who worked hard at a not so desirable job so that I could complete my graduate studies. Without her support, love and encouragement this goal could never have been attained. 
TABLE OF CONTENTS

Page

ACKNOWLEDGEMENTS . . . . . . . . . . . . . . . . . . iii

LIST OF TABLES . . . . . . . . . . . . . . . . . viii

LIST OF FIGUPES • . • . . . . . . . . . . . . . . . ix

KEY TO SYMBOLS AND ABBREVIATIONS . . . . . . . . . . xix

ABSTRACT . . . . . . . . . . . . . . . . . xiii

INTRODUCTION . . . . . . . . . . . . . . . . . . . . . I I

LITERATURE REVIEW . . . . . . . . . . . . . . . . 3

Regeneration . . . . . . . . . . . . 3

Crustacea . . . . . . . . . . . . . . 4

Insecta . . . . . . . . . . . . . . 4

Arachnida . . . . . . . . . . . . 10

Autotomy . . . . . . . . . . . . . . . 11

Crustacea . . . . . . . . . . . . 12

Insecta . . . . . . . . . . . . . 13

Arachnida . . . . . . . . . . . . 13

L. Variolus and the Morphology of

Arachnid Palpal Organ and Legs . . . . . . . 14

METHODS AND MATERIALS . . . . . . . . . . . . . 20

L. variolus . . . . . . . . . . . . . 20

Histology . . . . . . . . . . . . . . . . 21

Amputation and Ligature . . . . . . . . . . 21 
RESULTS . . . . . . . . . . . . . . . . . . . . . . . 25

The Palpal Organ of L. variolus . . . . . . 25

Development of the Papal Organ . . . . . 25

Amputation of the Pre-penultimate Palp . . 30

Amputation at the mid-tarsus . . . . 30

Amputation at the tibia-tarsus joint . . 30

Amputation at the patella-tibia

joint. . . . . . . . . . . . .

32

Amputation at the femur-patelia

joint . . . . . . . . . . . . . .

35

Amputation at the mid-femur and at

the trochanter-femur joint. . . . . .

35

Amputation at the coxa-trochanter

joint . . . . . . . . . . . . . .

36

Amputation of the penultimate palp . . . . 39

Amputation at the mid-tarsus . . . . . 39

Amputation at the tibia-tarsus joint . . 39

Damage to the Palpal tarsus . . . . . 39

Amputation at the patella-tibia joint... 41

Amputation at the coxa-trochanter

joint. . . . . . . . . . . . . .

Ligature of Pre-penultimate and Penultimate Palps . . . . . . . . . . . . . . .

Ligature at mid-femur of Pre-penultimate palp . . . . . . . . . . . . .

Ligature at the tibia-tarsus joint of Penultimate $\mathrm{Palp} \cdot$. . . . . . . . . .

Ligature at mid-femur of Penultimate

Palp . . . . . . . . . . . . .

Regeneration and Autotomy in Legs of L. variolus 
Amputation of the Legs . . . . . . . . . . 44

Amputation at the mid-telotarsus . . . . 44

Amputation at the mid-basitarsus . . . 46

Amputation at the mid-tibia and at

the patella-tibia joint... . . . . 46

Amputation at the femur-patella joint . . 48

Amputation at mid-femur . . . . . . . 48

Amputation at the trochanter-femur joint. $\quad 50$

Amputation at the coxa-trochanter joint . 50

Amputation at the Proximal Margin of

the Coxa. . . . . . . . . . . . 50

Localized Injury to the Femur . . . . . . 50

Ligature of the Legs . . . . . . . . . . 54

Ligature at the mid-basitarsus . . . . 54

Ligature at the mid-tibia . . . . . . 56

Ligature at the patella . . . . . . . 56

Ligature at the mid-femur . . . . . . 58

External Force Applied to the Autotomy

Plane of the Leg. . . . . . . . . . 58

Summary of Results . . . . . . . . . . . 58

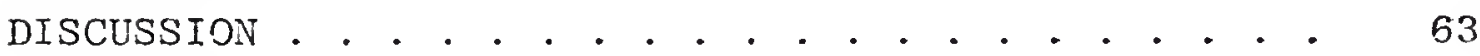

Regeneration . . . . . . . . . . . . . . 63

Autotomy . . . . . . . . . . . . . . . 68

APPENDIX 1 - Fixation, Dehydration and Embedding • . 74

APPENDIX 2 - Hallory's Triple Stain Technique • • . 76

LITERATURE CITED . • . . . . . . . . . . . . . . 77

SUPPLEMENTARY BIBLIOGRAPHY . . • • • . • . . • . . 82

BIOGRAPHICAL SKETCH . . . . . . . . . . . . . . . 85 


\section{LIST OF TABLES}

Table

Page

1 Summary of the amputation experiments performed on pre-penultimate male I. variolus palps . . . 38

2 Summary of the amputation experiments performed on penultimate male $\underline{L}$. variolus palps . . . .

3 Summary of ligature experiments performed on the palps of pre-penultimate and penultimate

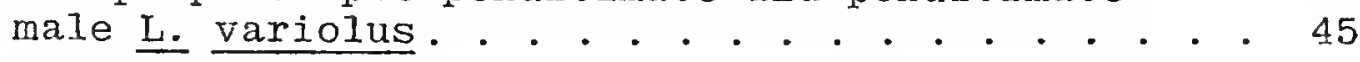

4 Summary of the amputation experiments performed on the legs of $\underline{\text { L. }}$ variolus. . . . . . . . . . 53

5 Summary of ligature and external pressure experiments performed on the legs of L. variolus. . . . 60 


\section{LIST OF FIGURES}

Figure

Page

1

The developmental gradient model for

regeneration and duplication . . . . . . .

The polar coordinate model for regener-

Schematic diagram of the autotomy mechanism of spiders . . . . . . . . . . . . . .

Comparative morphology of the spider leg

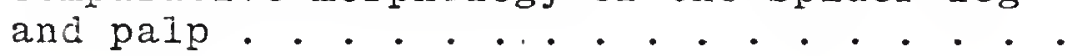

The development of the male palpal organ and identification of some of the major parts of the adult organ . . . . . . . .

Restraint apparatus used in amputation and ligation experiments . . . . . . . .

Ligature in place on the leg of $\underline{L}$. variolus Pre-penultimate palp of a male $\underline{L}$. variolus

12 Differentiation of the developing palpal organ at 24 - 36 hours into the penultimate instar. . . . . . . . . . . . . .

13 Differentiation of the developing palpal organ at 48 - 72 hours into the penultimate instar........ . . . . . . . . .

14 Differentiation of the developing palpal organ approximately four days prior to the adult molt. . . . . . . . . . . . . . 
Results of amputation of the pre-penultimate palp at the tibia-tarsus joint . . . . . .

Histology of regenerate palp following amputation at the tibia-tarsus joint . . . . .

Results of amputation of the pre-penultimate palp at the patella-tibia joint.......

Histology of regenerate palp following amputation at the patella-tibia joint...... palp at the femur patella-joint.......

Results of amputation of the pre-penultimate palp at the mid-femur and trochanter-femur joint.

23 Results of amputation of the pre-penultimate palp at the coxa-trochanter joint . . . . .

24 Results of amputation of the penultimate palp at the mid-tarsus.

Results of amputation of the penultimate palp at the tibia-tarsus joint... . . . . .

Results of damage (puncture) to the tarsus of the penultimate palp . . . . . . . . .

27 Results of amputation of the penultimate palp at the patella-tibia joint . . . . . . .

Results of amputation of the penultimate palp at the coxa-trochanter joint . . . . . . .

Results of amputation of the leg at the midtelotarsus 
Results of amputation of the leg at the femurpatella joint. . . . . . . . . . . . .

Results of amputation of the leg at the midfemur

Results of amputation of the leg at the

Results of amputation of the leg at the coxatrochanter joint

Results of amputation of the leg at the proximal margin of the coxa. . . . . . .

Results of localized injury to the femur of

the leg

Results of ligation of the leg at the midbasitarsus

Results of ligation of the leg at the midtibia

Results of ligation of the leg at the patella

Results of ligation of the leg at the mid-

femur. . . . . . . . . . . . . . .

42 Comparison of the regenerative capacities of the pre-penultimate and penultimate palps

of the male L. variolus . . . . . . . .

43 Healing of the wound produced by amputation of the pre-penultimate palp at the tibia-tarsus joint

44 The open wound of an autotomized leg after localized injury to the femur of the leg.

A comparison of the autotomy, healing and regeneration of the legs injured by amputation and ligation . . . . . . . . . . 


\section{KEY TO SYMBOLS AND ABBREVIATIONS}

\begin{tabular}{|c|c|}
\hline$A I$ & alveolus \\
\hline btar & basitarsus \\
\hline $\mathrm{Cd}$ & conductor \\
\hline & $\operatorname{coxa}$ \\
\hline $\begin{array}{l}\mathrm{Cx} . \mathrm{ms} \\
\mathrm{Cm}\end{array}$ & $\begin{array}{l}\text { coxal muscle } \\
\text { cymbium }\end{array}$ \\
\hline D. $1 \mathrm{~b}$ & dorsal lobe \\
\hline Em & embolus \\
\hline Fm & femur \\
\hline $\mathrm{Fd}$ & fundus \\
\hline Haem & haematodocha (basal) \\
\hline Inv & invagination \\
\hline M. a & median apophysis \\
\hline $\mathrm{Nv}$ & nerve \\
\hline Pat & patella \\
\hline Ptar & pretarsus \\
\hline P.S & receptaculum seminis \\
\hline $\mathrm{Scl}$ & sclerite \\
\hline $\operatorname{Tar}$ & tarsus \\
\hline ttar & telotarsus \\
\hline $\begin{array}{l}\text { T.a } \\
\text { Tib }\end{array}$ & $\begin{array}{l}\text { terminal apophysis } \\
\text { tibia }\end{array}$ \\
\hline $\operatorname{Tr}$ & Trochanter \\
\hline$V . I b$ & ventral lobe \\
\hline-- & amputation \\
\hline 1 & Iigation \\
\hline
\end{tabular}


Abstract of Dissertation Presented to the Graduate Council of the University of Plorida in Partial Fulfillment of the Requirements for the Degree of Doctor of Philosophy

\section{REGENERATION AND AUTOTOMY IN THE BLACK \\ WIDOW SPIDER, Latrodectus variolus \\ walckenaer}

by

JOHN BROOKES RANDALL

August 1979

Chairman: Dr. Harvey I. Cromroy

Major Department: Entomology and Nematology

The restoration of lost body parts by regeneration has been extensively investigated in arthropods. Crustaceans, insects and to a lesser degree arachnids have been utilized to study this phenomenon. The loss of an appendage most readily occurs at a predetermined plane of weakness, termed the autotomy plane, as a mechanism of escape or severence of a badly damaged limb. The mechanism of autotomy is believed to be initiated by a nervous reflex. Past researchers state that the capacity for arthropod regeneration is greatest at the autotomy plane.

Amputation and Iigature of the developing male palpal organ and the legs were used to determine whether regeneration occurring in the black widow spider, Latrodectus variolus Walckenaer complied with the developmental gradient of regeneration. The occurrence of autotomy in this species was also documented. 
The ability of the pre-penultimate palp to regenerate and subsequently produce a normal adult palpal organ was confined to injury to the distal portion of the palp. Amputation of more proximal segments of the male palp during the pre-penultimate stage did not result in normal adult palps two molts later. Amputation of or severe damage to the tibia and tarsus of the penultimate male palp most often resulted in the death of the spider. No regeneration occurred following amputation or ligature of penultimate palps.

Amputation indicated the most proximal point from which regeneration of the leg could occur was the mid-point of the femur. Proximal to that point no regeneration was observed. Autotomy following amputation was not observed. The regeneration observed in the palps and legs of I. variolus complied with the developmental gradient and polar coordinate models Eor regeneration.

Ligature of the legs resulted in autotomy when applied at and proximal to the mid-point of the tibia, increasing in frrequency as more proximal segments were ligatured. Autotomy always occurred at the coxa-trochanter joint. No regeneration of the iscs occurred following autotomy.

The evidence strongly suggests that autotomy in the legs was initiated by a wound factor (currently hypothetical) released after injury and the dose of which may be related to the size and duration of the wound. 


\section{INTRODUCT ION}

In their evolution from annelid-like ancestors arthropods had to sacrifice some advantages in order to become more specialized and complex. Although their greater complexity does not allow for the regeneration of large body parts, such as an entire head, arthropods have retained the ability to regenerate appendages. When arthropods gained the protection of an exoskeleton it became necessary for them to molt in order to grow. Likewise, molting was required for arthropod regeneration to occur. The rigid exoskeleton, clearly segmented, provides for qualitative and quantitative measurement of regeneration. For this reason arthropods, especially crustaceans, insects and to a lesser extent the arachnids, have been the subject of considerable research into the mysteries of regeneration.

Unlike the crustacea that continue to grow and molt after reaching maturity, insects, once sexually mature, lose the ability to molt and thereby their ability to regenerate lost parts. The majority of spiders, like insects, cease molting after maturity is attained. Exceptions to this include the mygalomorph spiders (i.e. tarantulas) that continue to molt after maturation and can live up to 25 years. 
The black widow spider has been the subject of much study in past years. A species of black widow spider, Latrodectus variolus Walckenaer, was used in this investigation to establish the regenerative capacitites of the developing male palpal organ and legs. The occurrence of autotomy in this species was also studied. The results establish three alternatives, besides death, to the injury exhibited by L. variolus; healing with no regeneration, regeneration or autotomy.

The following literature review provides background information on arthropod regeneration and autotomy as well as on the development of the palpal organ of a male black widow spider. 


\section{LITERATURE REVIEW}

\section{$\underline{\text { Regeneration }}$}

Regeneration, the restoration of lost parts, has been described by many authors. Goss (1965) views regeneration as a physiological process, not simply anatomical growth, with the primary objective of re-establishing the functional efficiency of the organism. Thus, regeneration is stimulated by the physiological demands for increased function caused by the loss of a body part. Goss defines qualitative regeneration as that process which occurs to replace a lost limb, as this is the only way efficiency can be restored in a structure that has a single function. Quantitative regeneration is the method by which compound organs, such as a Iiver, would be restored.

Wolpert (1974) considers regeneration as the re-establishment of the positional field of cells followed by the reinterpreting of positional values. This can be attained by either of two methods. (1) Epimorphosis involves growth from the cut surface of the wound to provide new positional values for the regenerating portion. (2) Morphallaxis establishes a new boundary region at the cut surface and new positional values are assigned within the existing adjacent tissues. Morphallaxis does not involve growth. 


\section{$\underline{\text { Crustacea }}$}

Crustaceans have been utilized extensively in the study of regeneration (Agar, 1930; Bliss, 1960; Emmel, 1910; Needham, 1945, 1947, 1949, 1950, 1953; Paul, 1914; Wilson, 1903; Wood and Wood, 1932). Crabs, lobsters and crayfish have been examined extensively because of their convenient size, availability, and possession of a preformed breakage plane (Bliss, 1960). With the possible exception of mouthparts, decapods seem to be able to regenerate all types of appendages. It is believed that in crustacea the peripheral nerve supply in the region of amputation exerts a local effect favoring limb regeneration. This, coupled with neurosecretory hormones which inhibit the molt-promoting Y-organs are responsible together for the regenerative capacity in these animals (Bliss, 1960).

\section{$\underline{\text { Insecta }}$}

Among the insects used in regeneration experimentation, cockroaches have been studied most extensively. Bohn (1965, 1972, 1974a, 1974b, 1974c) used Leucophaea maderae in experiments which indicated that the integumental tissues that separate adjacent legs were required for the regeneration of the leg. Regeneration of a leg occurred only when both the basal sclerites anterior to and a membraneous area posterior to the coxa were in contact with each other. Bohn confirmed these results through transplantation experiments (Bohn, 1974b). Bohn (1965) found that a V-shaped wedge cut from the tibia of 
Leucophaea resulted in the next instar developing a lateral regenerate at the site of injury.

Scientists working on different insects described various proximal limits for leg regeneration. Penzlin (1963) (Periplaneta) reported regeneration after removal of most of the basal sclerites (episternum and epimeron). Bulliere (1967) and Urvoy (1963) (Blabera craniffer Burm.) found the proximal limit of regeneration between the coxa and trochantin and praecoxa and trochantin respectively.

Luscher (1948) reported regeneration of the leg of Rhodnius occurring as far back as the coxa-trochanter joint. In 1933 Bodenstein reported regeneration after removing the entire leg and surrounding tissues in larval Vanessa urticae Raupen (Lepidoptera). Bodenstein (1955) not only discovered that Periplaneta americana could regenerate the entire leg after amputation at the trochanter-femur joint, but also found that ecdysone was required for initiating and sustaining the progression of regeneration. Adult periplaneta could be made to regenerate through parabiotic fusion with nymphs and by transplantation of active prothoracic glands. It was Bodenstein's feeling that "wound factors" produced at the site and time of injury played a minor role, if any, in the initiation of regeneration. Needham (1947) argues that a wound factor may in fact reduce the regenerative power since after autotomy of limbs in the crustacean Asellus aquaticus if the remaining tissues are mechanically damaged there is a reduction in the animal's regenerative capacity. 
O'Farrell and Stock (1953) investigated regeneration of the metathoracic leg of Blattella germanica, and found that when the leg was amputated at the proximal autotomy plane (between the trochanter and femur) either a completely differentiated regenerate or an undifferentiated papilla resulted, a complete regenerate appeared at the second molt following amputation. They also described a "critical period" during the first instar before which amputation resulted in a complete regenerate with a delay in the first ecdysis following surgery and after which the papilla was produced with no delay in ecdysis. The ability of $\underline{B}$. germanica to regenerate a complete leg persisted until the last molt. Repeated regeneration of the same leg prolonged development and caused additional molts but the adults resulting from such supermolts were normal in size and appearance. When reared at $25^{\circ} \mathrm{C}$, repeated regeneration of $\mathrm{B}$. germanica initiated early in development resulted in more supermolts than if initiated later. Most of the experimental insects reared at $30^{\circ} \mathrm{C}$ metamorphosed without supermolts.

Regeneration in insects has also been studied through experimentation on the imaginal discs of developing larvae. Bryant (1971) performed in situ experiments bisecting the leg discs of Drosophila melanogaster. He found that the upper portion of a bisected disc, still attached to the larval epidermis, regenerated; whereas the lower half of the disc, unattached from the larval epidermis, duplicated itself.

Partial bisection of leg discs resulted in branched legs where one branch was complete and the other branch a 
double half. Bryant interpreted these results to mean that regeneration occurred from one cut edge and duplication from the other. From this work Bryant proposed a gradient of developmental capacity and its response to bisection (Fig. I). Later Bryant (1975) found that when an imaginal disc was cut into three pieces those fragments with their cut edge facing away from the center of the disc underwent regeneration, while fragments with their cut edge facing toward the center of the disc underwent duplication. The presence of the center of the disc was not a prerequisite for regeneration. Fragments with two cut edges on the same side of the center would exhibit regeneration at one edge and duplication at the other.

French et al. (1976) proposed the polar coordinate model for regeneration based on information from cockroach and amphibian limb regeneration and insect imaginal disc regeneration. Their model is a two-dimensional system allowing the assignment of specific positional information to an epimorphic field. One coordinate defines the circumferential position of a cell by twelve meridinal points numbered clockwise one to twelve. Letters A to $E$ define the proximaldistal position of a cell. proximal structures are at the peripherg and distal structures are at the center of the mode1 (Fig. 2).

They also proposed two rules for the behavior of cells in an epimorphic field. The rule of intercalation states that when normally non-adjacent positional values in either 

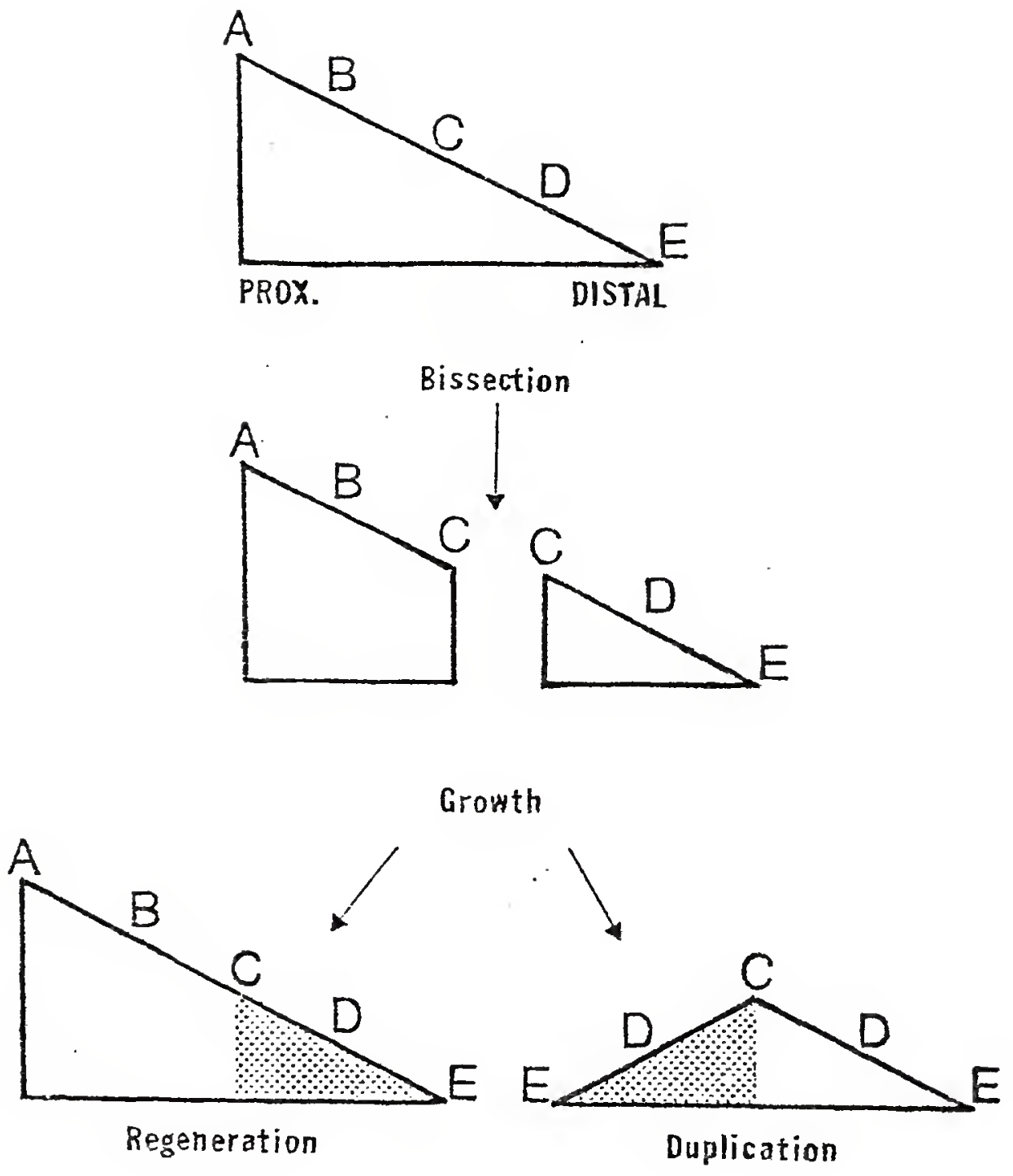

Fig. 1. The developmental gradient model for regeneration and duplication (Bryant, 1971). 


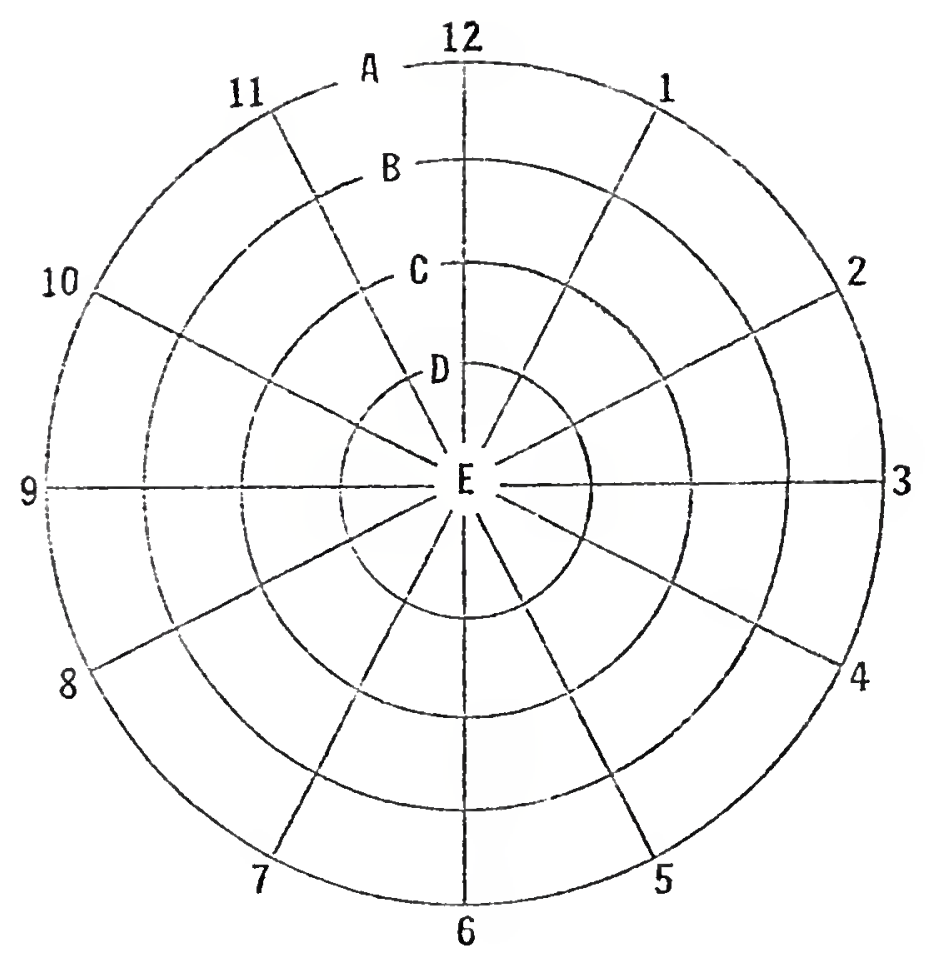

Fig. 2. The polar coordinate model for regeneration (French et a1., 1976). 
the circular or radial sequence come into contact in a graft or through wound healing, growth occurs at that junction until the cells with intermediate positional values have been intercalated.

The second is the complete circle rule for distal transplantation. The entire circular sequence at a particular level may undergo distal transplantation to produce cells with all the more central (distal) positional values. This rule pertains to Bryant's gradient of developmental capacity (Fig. 1) and means that when amputation occurs along the proximal-distal sequence of positional values the proximal level remaining can regenerate only those positional values distal to it.

\section{$\underline{\text { Arachnida }}$}

Regeneration in arachnids has been little studied (Bonnet, 1930; Friedrich, 1906; Schultz, 1898; Vachon, 1941; Wagner, 1887). The most extensive of these studies was carried out by Bonnet working on Dolomedes fimbriatus (Clerck) (Pisauridae). Bonnet (1930) reported that D. fimbriatus could regenerate from one to all eight legs, taking three molts to re-establish normal size.

Bonnet also performed regeneration experiments on developing male palps and concluded that if the loss of part or all of a palp occurred no later than the preantepenultimate instar (three more molts before maturation) the male could fully regenerate the palp. Palps injured or lost later than 
the preantepenultimate stage would not regenerate completely. When injured at the prepenultimate stage the palps were sometimes perfectly formed at maturation but were too short so that the animals could not come to normal copulation.

Vachon (1941) reported that the leg segments of the same regenerating leg were not necessarily all at the same stage, distal segments being "older" than proximal ones.

\section{Autotomy}

Several terms have been used to describe the loss of an arthropod limb; they include: 1) autotomy, 2) autospasy and 3) autotilly (Bliss, 1960). Autotomy is the ability of an animal to cast off its own appendage at a pre-determined breakage plane by a well developed, usually unisegmental reflex. Autospasy has been defined as the separation of a limb at a predetermined plane of weakness when the limb is subjected to force by an outside agent against the resistance provided by the animal's weight or efforts to escape. Autotilly is the severence of the limb at a predetermined plane of weakness through use of the mouthparts, claws, or legs of the animal itself.

The point common to all three definitions is the "predetermined plane of weakness," also termed breaking joint, autotomy plane, plane of least resistance, and locus of weakness or separation (B1iss, 1960).

Injury or amputation distal to the plane of weakness often causes the entire limb to detach. In most arthropods 
no muscles cross the autotomy plane (Needham, 1965). An exception to this was described by Parry (1957) where the M. Flexor femoris longus of the spider Tegenaria atrica Koch (Agelenidae) passes from the coxa, through the trochanter to attach to the femur. The autotomy plane of $\underline{T}$ atrica is at the coxa-trochanter joint.

Autotomy occurs as the result of a nervous reflex initiated by injury to the limb (Goss, 1965). Goss also stated that the capacity for regeneration of lost appendages in arthropods is greatest at the autotomic breakage plane.

\section{Crustacea}

Some crustaceans possess an autotomy plane but no reflex of autotomy. In others (i.e. Homarus americanus) autotomy only occurs in the first paix of thoracic legs or chelae. Autospasy and autotilly may occur in the other limbs as the plane of weakness exists but the autotomy reflex is absent in those legs (Wood and Wood, 1932). When Wood and Food studied 15 species of crabs they found autotomy exhibited in all five pairs of legs.

The stimulus for autotomy may occur when injury is sustained to an appendage distal to the plane of weakness. Hodge (1956) demonstrated in the crab Gecarcinus lateralis that autotomy never resulted from injury to the dactyl, the most distal segment of the walking leg, but did occur with greater frequency as more proximal segments were injured. This was also demonstrated by Needham (1947) for Asellus aquaticus and on several species of Brachyura (Wood and Wood, 
1932). This may be related to the fact that the leg nerve does not extend beyond the proximal area of the propus, the next proximal segment to the dactyl (Bliss, 1960).

Bliss also reported that acetylcholine reduces the frequency of autotomy when injected into a crustacean and that acetylcholine antagonists (i.e. atropine) facilitate autotomy.

\section{Insecta}

O'Farrell and Stock (1953) found regeneration when the leg of $B$. germanica was removed at the autotomy plane, between the trochanter and femur. The same plane of weakness has been described for mantids, phasmids, and grasshoppers (BIiss, 1960). A second locus of separation was reported at the tibia-tarsus joint of B. germanica by Woodruff (1937). A true autotomy reflex was described for Achaeta domesticus L. by BrousseGaury (1958).

Autotomy is even well developed in Tipulidae and opiliones (arachnida) where regeneration is impossible (Needham, 1965). The ability to escape has value regardless of the ability to replace the appendage lost in escape.

\section{Arachnida}

Autotomy has been examined in spiders (Bonnet, 1930; Parry, 1957; Yood, 1926). Unlike crustaceans and insects, spiders autotomize their legs at a functional joint, the coxatrochanter joint (Parry, 1957). Bliss (1960) stated that among the true arachnids, including the spiders, there is autospasy but not autotomy. Wood and Wood (1932) reported the 
absence of a plane of weakness in scorpions, ticks and Limulus.

Wood (1926) after a detailed morphological study of the exoskeleton and musculature of scorpions, harvestman, and twelve species of spiders, reported no autotomizing mechanism existed in those animals. Severence of the legs did, however, occur at a point in the limb directly correlated with a definite structural weakness in the exoskeleton and musculature. Wood reported that the spider itself removed the injured leg by grasping it with its mouthparts (autotilly) and concluded that autotomy as an automatic reflex did not exist in arachnids. Parry (1957) reported findings contrary to Wood's 1926 report when he described the mechanism by which Tegenaria atrica autotomizes its legs. Parry found that in T. atrica the coxal muscles were all inserted onto a ring of sclerites that fit into a groove in the proximal rim of the trochanter. The joint fractures when the coxal muscles contract pulling the articular membrane proximally also causing the sclerites to converge leaving only a small hole that rapidly seals with. clotting blood (Fig. 3).

L. variolus and the Morphology of Arachnid Legs and Palpal Organ

The biology of the black widow spider has been well documented (Baerg, 1923; Bhatnagar and Rempe1, 1962; Burt, 1935; Chamberlin and Ivie, 1935; Deevey, 1949; Hagstrum, 1968; Jellison and Philip, 1935; Kaston, 1937, 1954, 1963, 1968, 1970; Lawson, 1933; Levi, 1958; McCrone, 1968; Rempe1, 1957; 


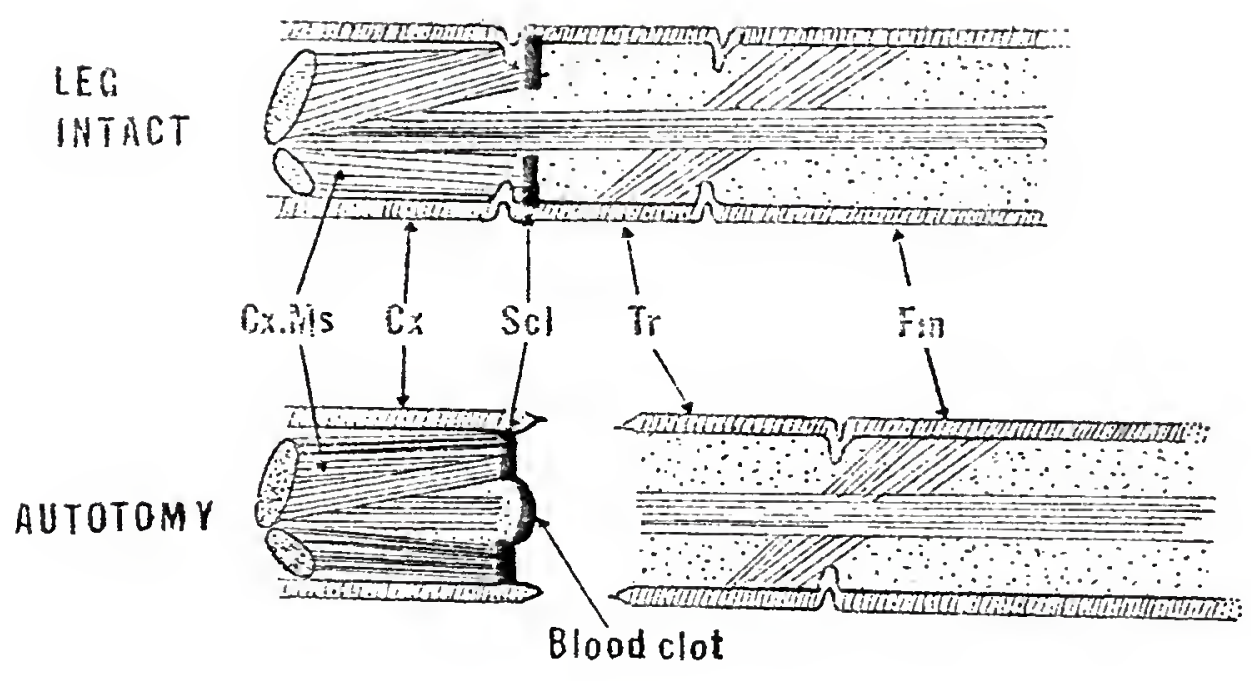

Fig. 3. Schematic diagram of the autotomy mechanism in spiders.

LEG

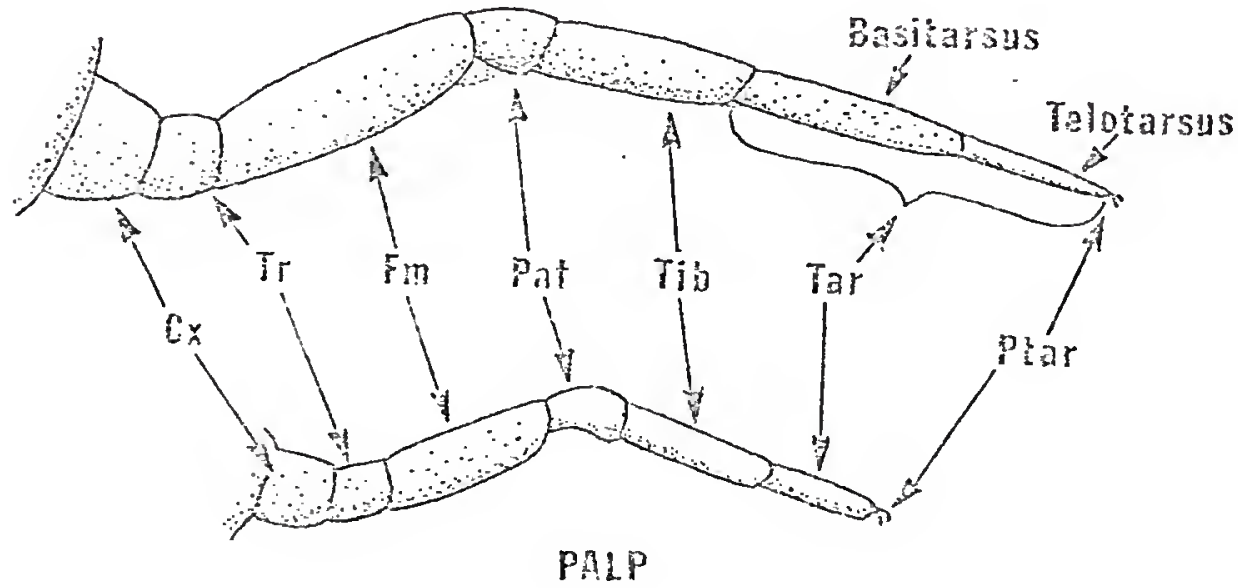

Fig. 4. Comparative morphology of the spider leg and palp. 
Ross and Smith, 1979). There are three species of North American black widow spider: Latrodectus mactans (Fabr.) and $L$. variolus Walckenaer in the eastern U. S. and only L. hesperus Chamberlin and Ivie in the western U. S.

The adult female L. variolus has a black cephalothorax and legs. There is a row or mid-dorsal red spots on the abdomen and three pairs of diagonal white stripes on each side with a narrow white stripe encircling the anterior dorsum of the abdomen. The hourglass mark on the ventarl abdomen is divided, the two halves seaparated (Kaston, 1970). In some cases half or the entire hourglass mark may be completely absent (Kaston, 1954). The male L. variolus is colored like the female but with broader white stripes. Female black widows may be as much as 160 times larger than the males by weight (Kaston, 1970).

The range for the number of days spent in each instar for L. variolus as reported by Kaston (1970) for instars one through five are: 1 to 33,5 to 30,6 to 48,6 to 76 , and 7 to 76,124 (sic) days respectively.

The pedipalp of a spider is morphologically similar to the spider leg with the exception that the tarsus of the leg is subdivided into a long basal part called the basitarsus (also metatarsus of 1 -tar) and a shorter distal part called the telotarsus (also tarsus or 2-tar) (Fig. 4). The tarsal subunits of the leg are not true segments as exhibited by the consistent absence of interconnecting muscles (Snodgrass, 1965) The development of the male palpal organ of L. curacavien-

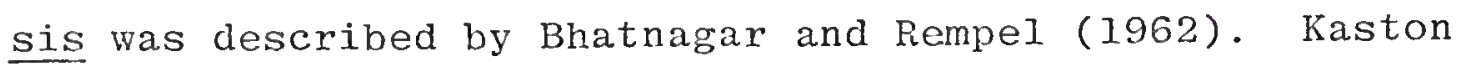


(1970) disputes the species Bhatnagar and Rempel studied was

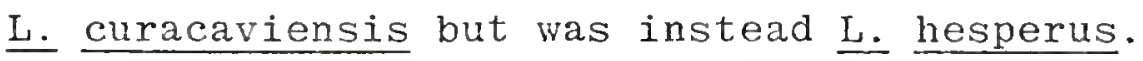

The pedipalps of newly emerged male and female spiciers are indistinguishable (Fig. 5A). The development of the papal organ, the male copulatory organ, is first recognizable when the palpal tarsus becomes slightly swollen (Fig. 5B). The swelling usually first appears in the antepenultimate (pre-penultimate) instar but has been observed as early as the preantepenultimate instar. When the male reaches the penultimate instar, the palps become very large and bulbous (Fig. 5C). Inside the bulbous palp the palpal organ is developing.

Like insect imaginal discs the origin of the palpal organ is the hypodermis (Bhatnagar and Rempel, 1962).

At the first swelling of the male palp the cells that give rise to the pretarsus increase in size and number and form a mass having dorsal and ventral lobes. During this stage the muscle tendons associated with the tarsal claws lose their connections and the new claw secreted by hypodermal cells is immobile and passive. The large number of blood cells in the tarsus may indicate the swelling was caused by hydrostatic pressure.

With the next molt the penultimate palp, now extremely bulbous, continues the internal morphogenesis of the copulatory organ. The receptaculum seminis, the sperm storage tube consisting of the fundus, reservoir and ejaculatory duct, can be seen as an invagination of the ventral lobe. Later in 


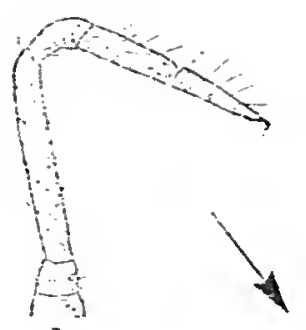

A
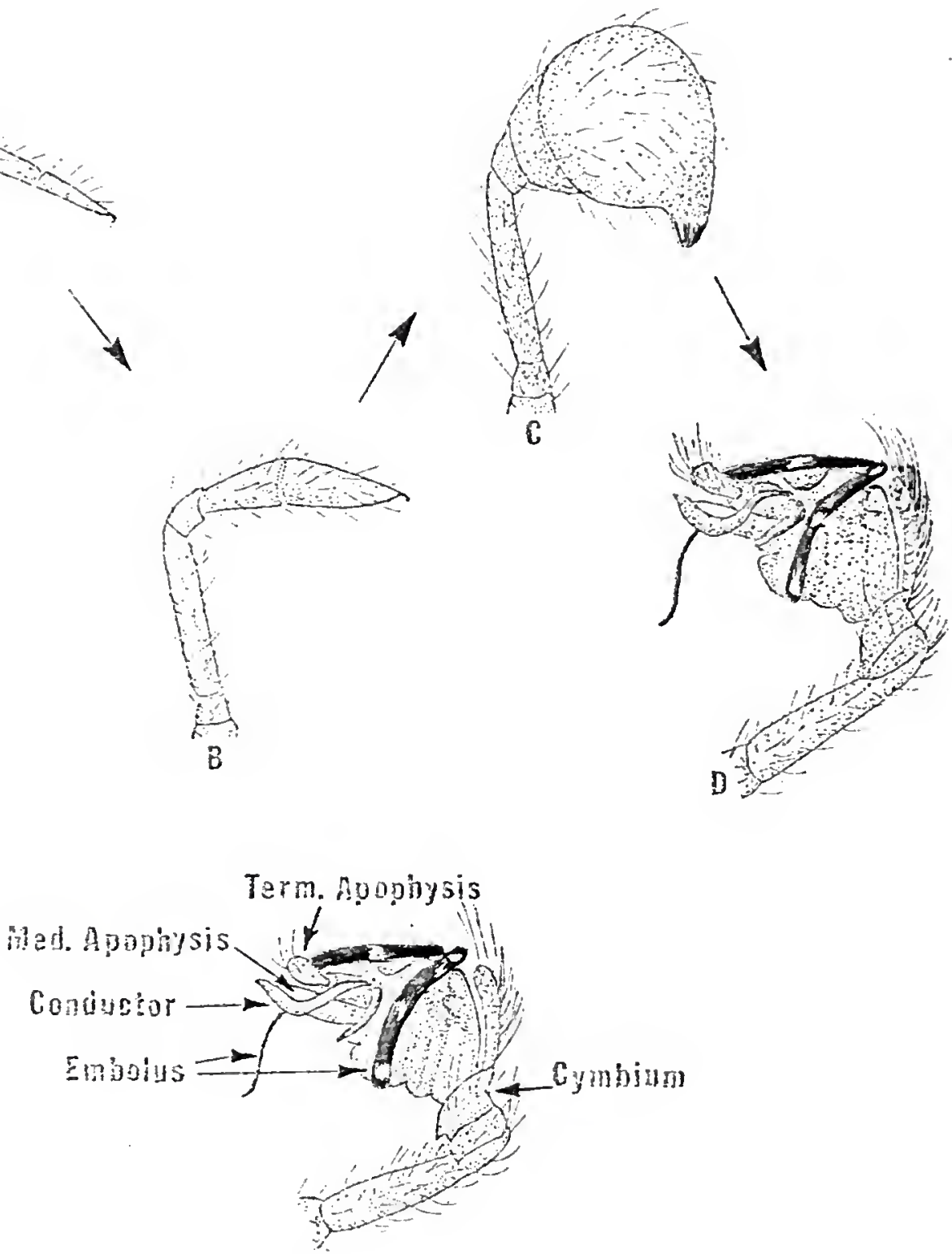

Fig. 5. The development of the male palpal organ and identification of some of the major parts of the adult organ. 
the instar the base of the developing organ is joined to the tarsus by a small neck of cells destined to become the basal haematodocha. The haematodocha is a folded membrane within the alveolus of the mature palp that forms an articulation between the cymbium and the sclerotized portion of the genital bulb and becomes distended during copulation due to increased hemolymph pressure. The formation of the small neck of cells represents the pretarsus becoming withdrawn into the tarsus. The tarsus will develop into the cymbium which holds the receptaculum seminis and its accessory sclerties within the alveolus. Toward the end of the penultimate instar the developing palpal organ can be seen through the tarsal wall. At the final molt the adult palpal organ appears (Fig. 5D).

Based on the above information experimental objectives for the present research were established for investigation of regeneration and autotomy in the legs and palpal organ of L. variolus. Experiments were designed to determine and compare the regenerative capacities and autotomic responses of pre-penultimate and penultimate male palps resulting from injury by amputation and Iigation. Another series of experiments was performed to discover the regenerative capacity and autotomic responses of the legs of immature L. variolus resulting from injury by amputation, ligature and local segmental injury. The results of the above experiments would then allow for the comparison of the regenerative capacities of the developing palpal organ and legs since these parts of a spider are morphologically homologous. 
METHODS AND MATERIALS

\section{L. variolus}

Latrodectus variolus was chosen as the subject of experimentation because of its availability, and the fact that of the three North American species its newly emerged spiderlings are the largest and they hatch and emerge in the shortest time (Kaston, 1970). Adult female L. variolus were acquired from Tempe, Arizona, and maintained in the laboratory on a diet of cabbage looper (Trichoplusia ni (Hubner)) Iarvae. Egg sacs constructed by the adult females were removed to separate containers until the emergence of young. The newly emerged spiderlings, considered to be in the second instar, were separated into numbered, $35 \times 10 \mathrm{~mm}$ polystyrene culture dishes. Spiderlings were maintained at room temperature and fed adult Drosophila melanogaster. Exuvia were removed from the rearing containers following each molt thus insuring against mistakes in instar identification. Pre-penultimate and penultimate males, third and fourth instar respectively, identified by the noticable swelling of the palpal tarsus were separated from the primary rearing colony for experimentation. Fourth and fifth instar female L. variolus were used primarily for leg regeneration experiments. 


\section{Histology}

Spiders used in histological studies were fixed in alcoholic Bouin's fixative for 4 to 24 hours before being transferred to the dehydration series. Dehydration was followed by infiltration and embedding in paraffin (Appendix 1). Embedded material was sectioned on a rotary microtome at six to ten microns, mounted on glass slides and stained using Mallory's Triple stain technique (Appendix 2). Slides were then examined and photographed through a compound microscope.

\section{Amputation and Ligature}

Amputation and ligature procedures were carried out with the aid of a dissecting microscope. Due to the possible effects of anesthesia on the postoperative physiology of the immature spiders no anesthesia was used. Unanesthetized spiders were placed in an apparatus I fabriçated (Fig. 6) specifically to restrain while not damaging the spiders for the duration of the procedures. The apparatus was designed to hold the spider in a foam rubber sandwich with the appendages to be operated on exposed. The foam rubber allowed the fragile spiders to be firmly held without injury. From control studies it was determined that holding the spiders in the apparatus for as long as three minutes (twice the upper limit for actual procedures) in no way altered the development of the young $\underline{L}$. variolus. It took $40-90$ seconds for the amputation and ligature procedures, including the time for removal and return of the spider to its rearing container. 
Pre-penultimate and penultimate male palps were amputated at various points from the mid-tarsus (most distal) to the coxa-trochanter joint (most proximal). Likewise, one of the first pair of legs was cut at various points from the mid-telotarsus (most distal) to the proximal margin of the coxa (most proximal). Amputations and other cuts were made with microscissors with the exception of cuts made at the proximal margin of the coxa in which case specially fabricated microscalpels were used.

In all cases only one palp or leg was injured leaving the corresponding appendage to develop normally to serve as a standard with which to compare the results of the operations. Comparisons were made only with the uninjured corresponding appendage of the same animal.

Wounds made during amputation were not sealed with any foreign substance; healing was left up to the spiders.

Ligatures were made with sterile, 7-0 Ethicon braided silk suturing thread. Overhand knots were pre-tied with forceps leaving a loop approximately one to two millimeters in diamster. With a spider in the restraint the loop was slipped over the leg, positioned and tightened (Fig. 7). The free ends were trimmed close to the knot with microscissors. Ligatures were placed at various points on the leg from the mid-basitarsus (most distal) to the mid-femur (most proximal) and at the mid-femur of pre-penultimate and penultimate palps and at the tibia-tarsus joint of penultimate palps. 


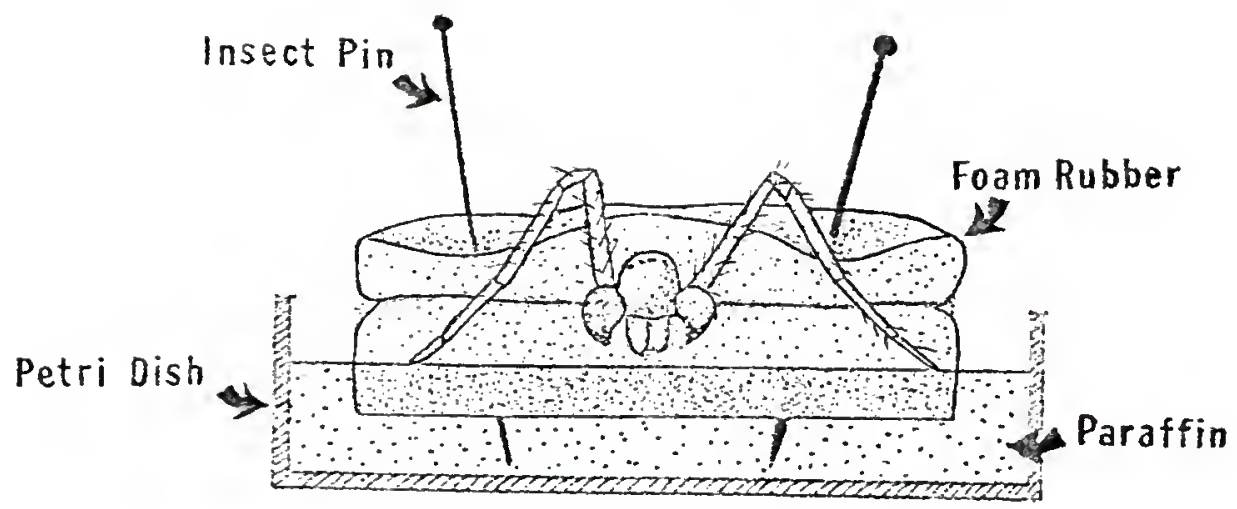
Fig. 6 . Pestraint apparatus used in amputation and 1 igation
experiments.

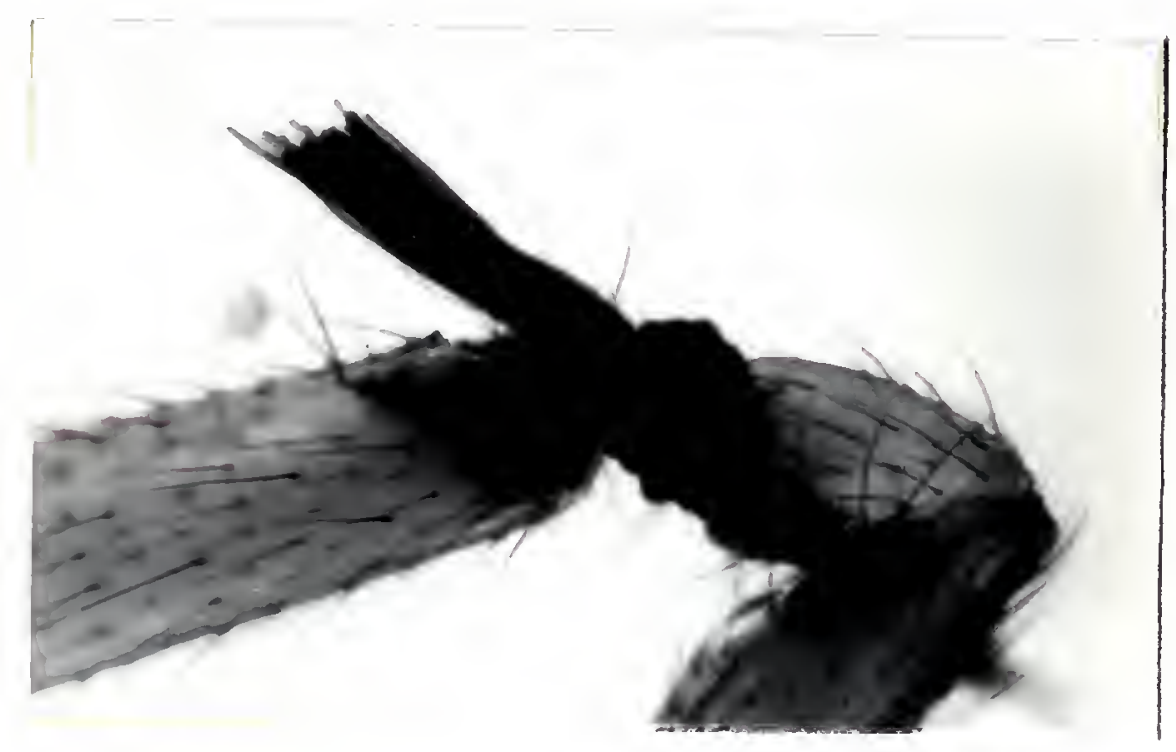

Fig. 7. Ligature in place on the leg of L. variolus. 
The possibility existed that the manipulation of the spiders during amputation and ligature might also cause injury at other parts of the leg, especially at the plane of weakness. The legs were pulled with forceps in a preIiminary experiment to establish the plane of weakness in the leg and palps (coxa-trochanter joint) and to simulate autotomy at that point. An experiment was conducted to tax the coxa-trochanter joint by pulling steadily on the leg until the articulating membrane between the coxa and trochanter split releasing some hemolymph. The leak in the membrane at that point and at no other joint along the leg, indicated that the autotomy plane had been taxed beyond normal limits while leaving the leg intact.

Bohn (1965) had removed a V-shaped wedge of tissue from the tibia of $\mathrm{L}$. maderae resulting in a leg regenerating from the site of injury. A similar experiment was performed on L. variolus by removal of a section of tissue from the femur of a leg. 
RESULTS

The Palpal Organ of L. variolus

The pre-penultimate and penultimate palps of $\underline{L}$. variolus males were sectioned to establish the morphogenesis of normally developing palps and thereby set a standard with which to compare the results of subsequent amputation and regeneration of the palps.

Development of the Palpal Organ

The internal morphogenesis of the palpal organ of $\underline{L}$. variolus is very similar to that described for L. curacavienSis (or L. hesperus) by Bhatnagar and Rempel (1962).

The pre-penultimate palp exhibited a slight swelling, most pronounced at the tibia-tarsus joint (Fig. 8). At this stage the palp contains the pretarsal primordia now rapidly proliferating into the dorsal and ventral lobes of the developing organ (Fig. 9). The cell mass changes configuration very little after 48 to 72 hours of development (Fig. 10).

After the next molt the slightly swollen pre-penultimate palp becomes extremely bulbous (Fig. 11). With the onset of the penultimate instar morphogenesis increases so that the developing palpal structures can be identified (Figs. 12 and 13). Near the end of the penultimate instar genital bulb structures are welI differentiated within the palp (Fig. I4) 

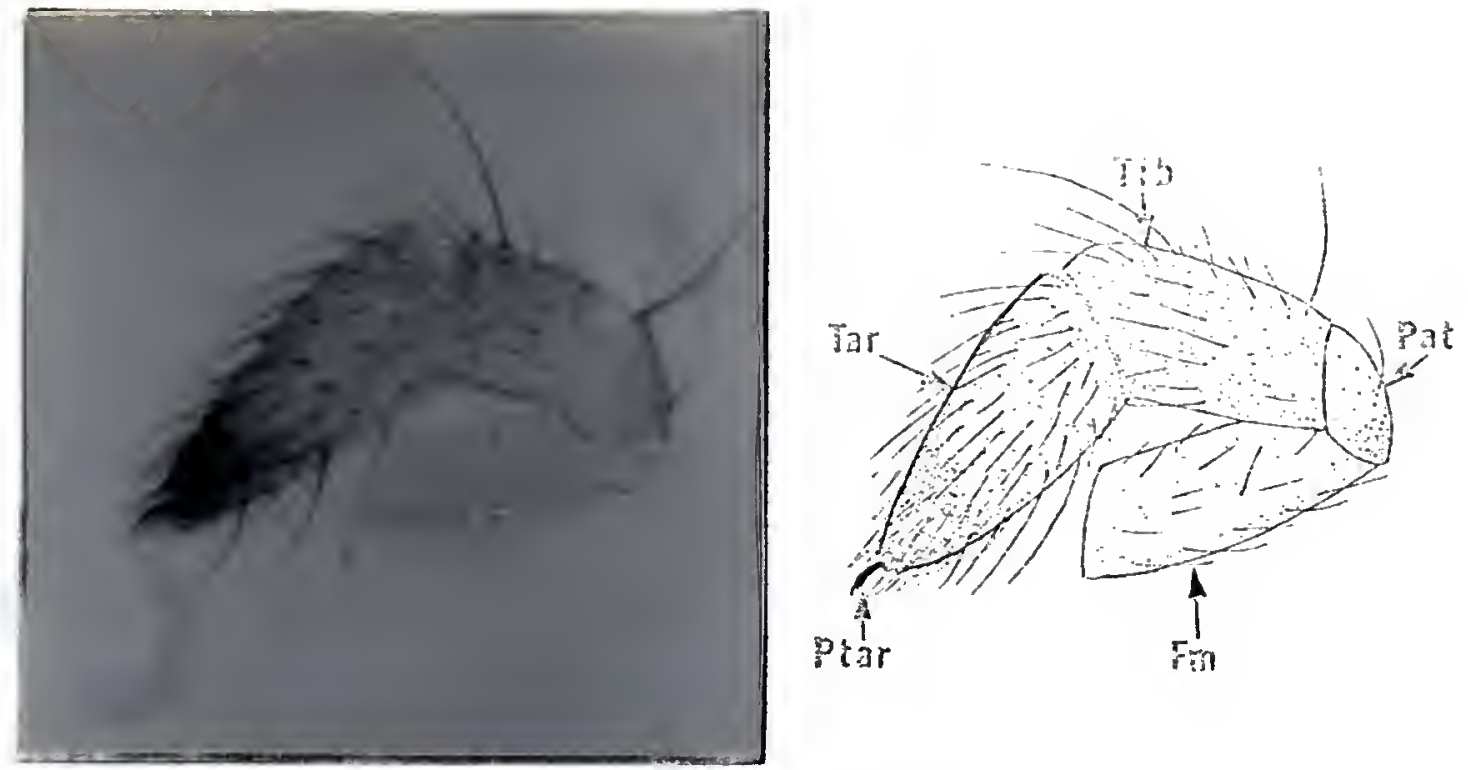

Fig. 8. Pre-penultimate palp of a male L. variolus.
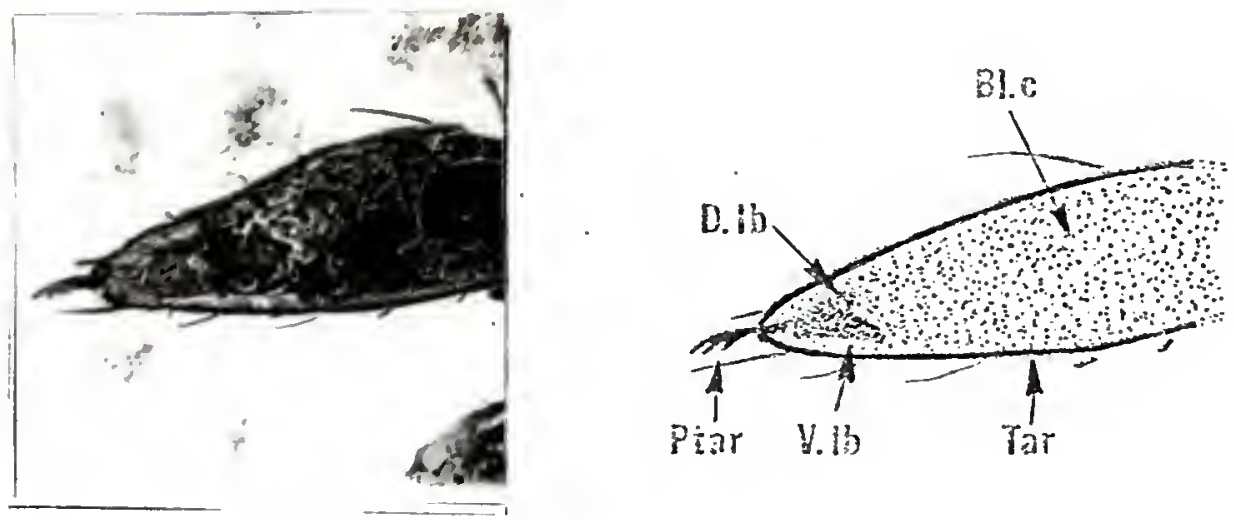

Fig. 9. Early proliferation of pretarsal primordia. 

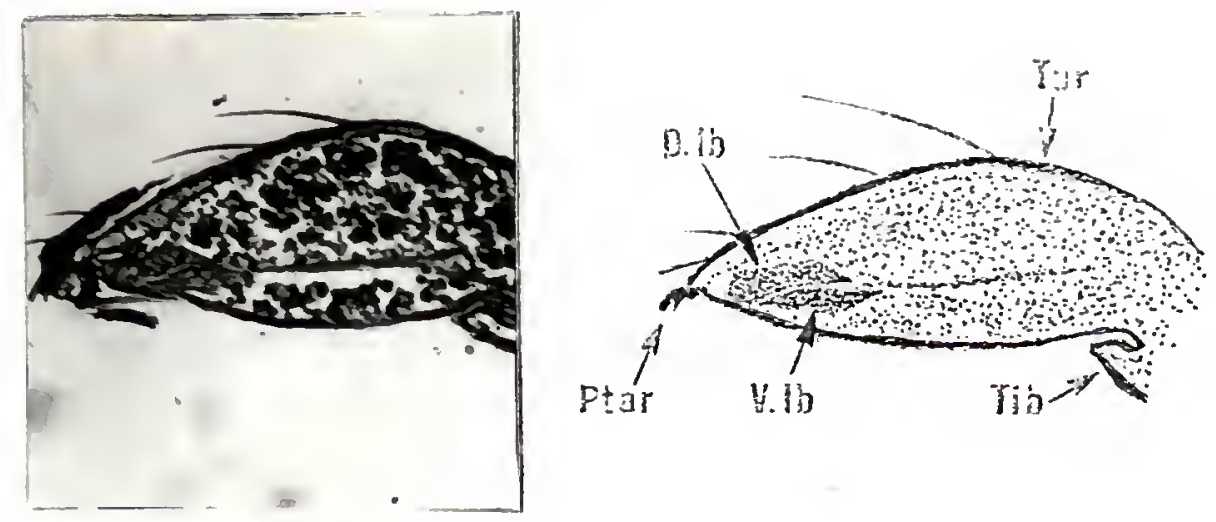

Fig. 10. Pretarsal cells 48-72 hours of development.
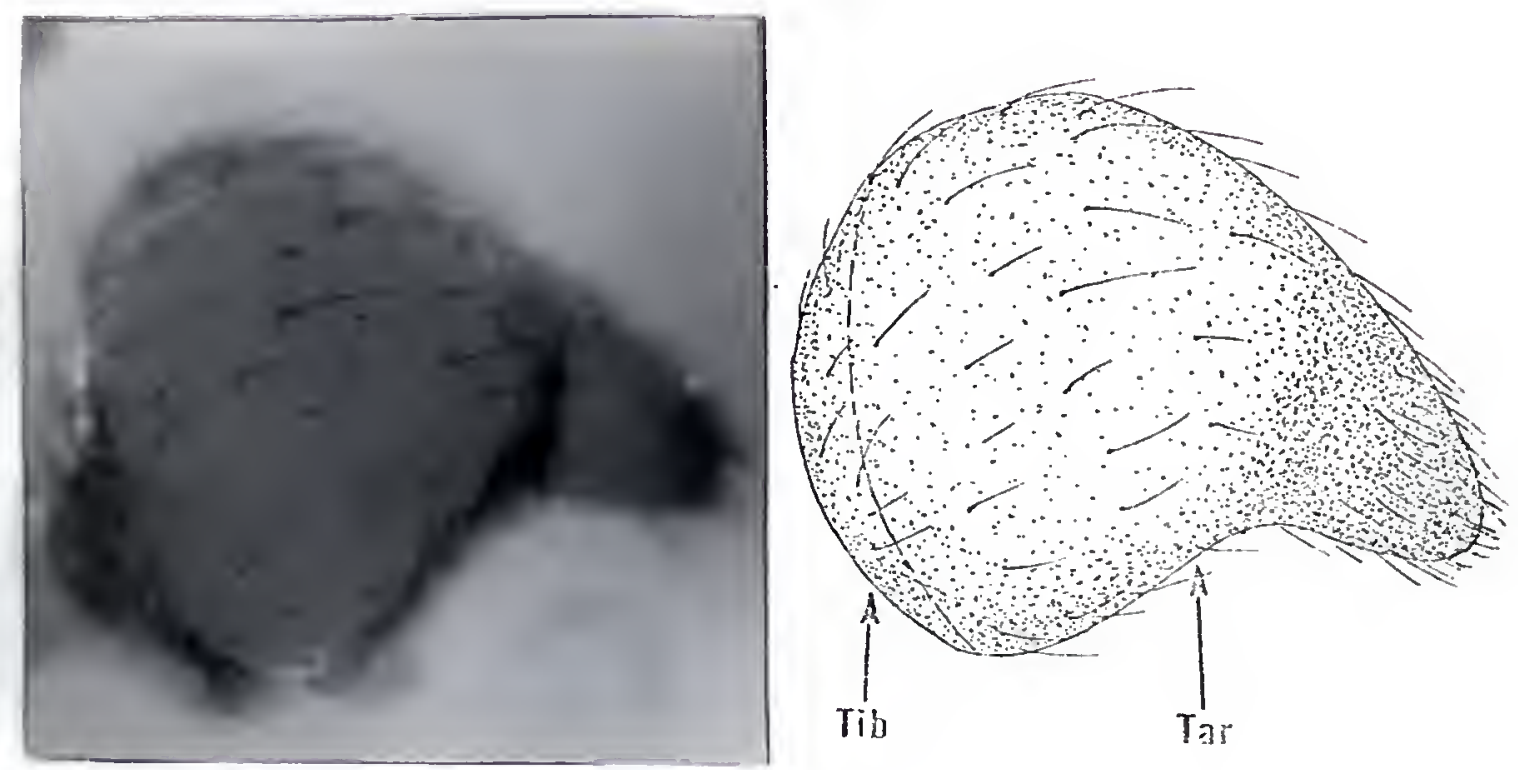

Fig. 11. Penultimate palp of a male I. variolus. 

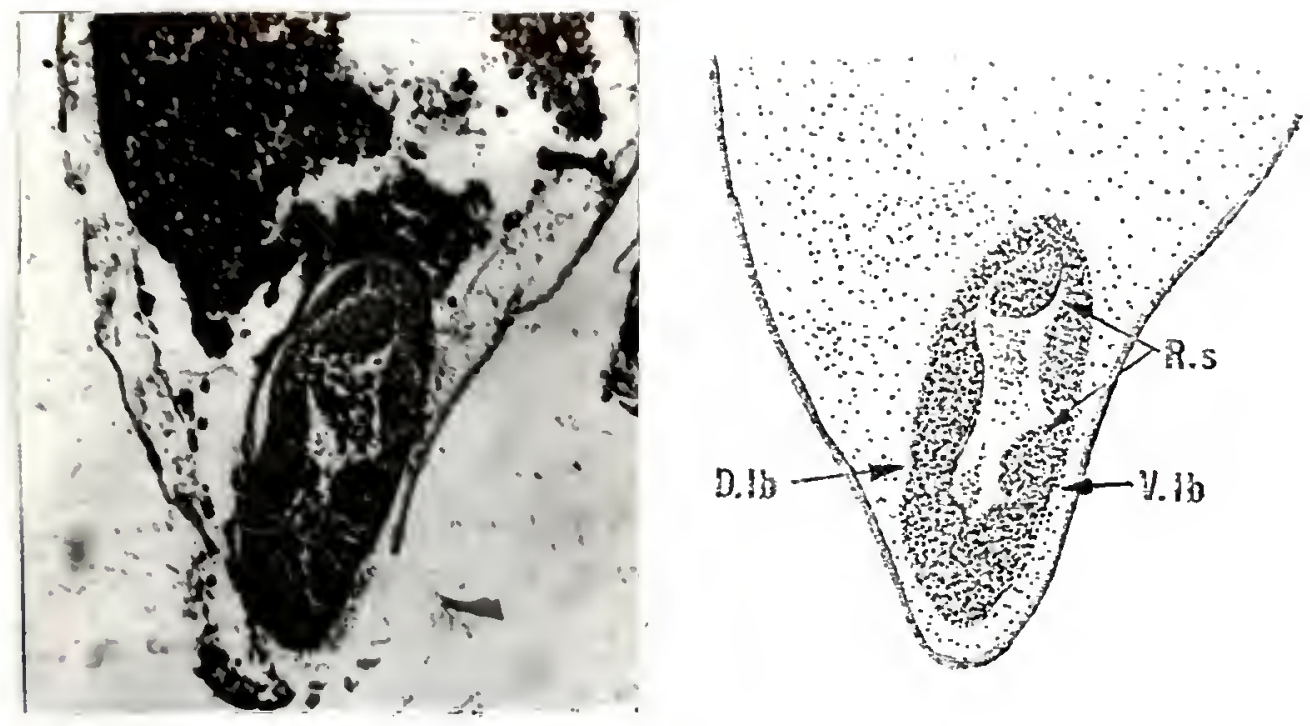

Fig. 12. Differentiation of the developing palpal organ at 24-36 hours into the penultimate instar.
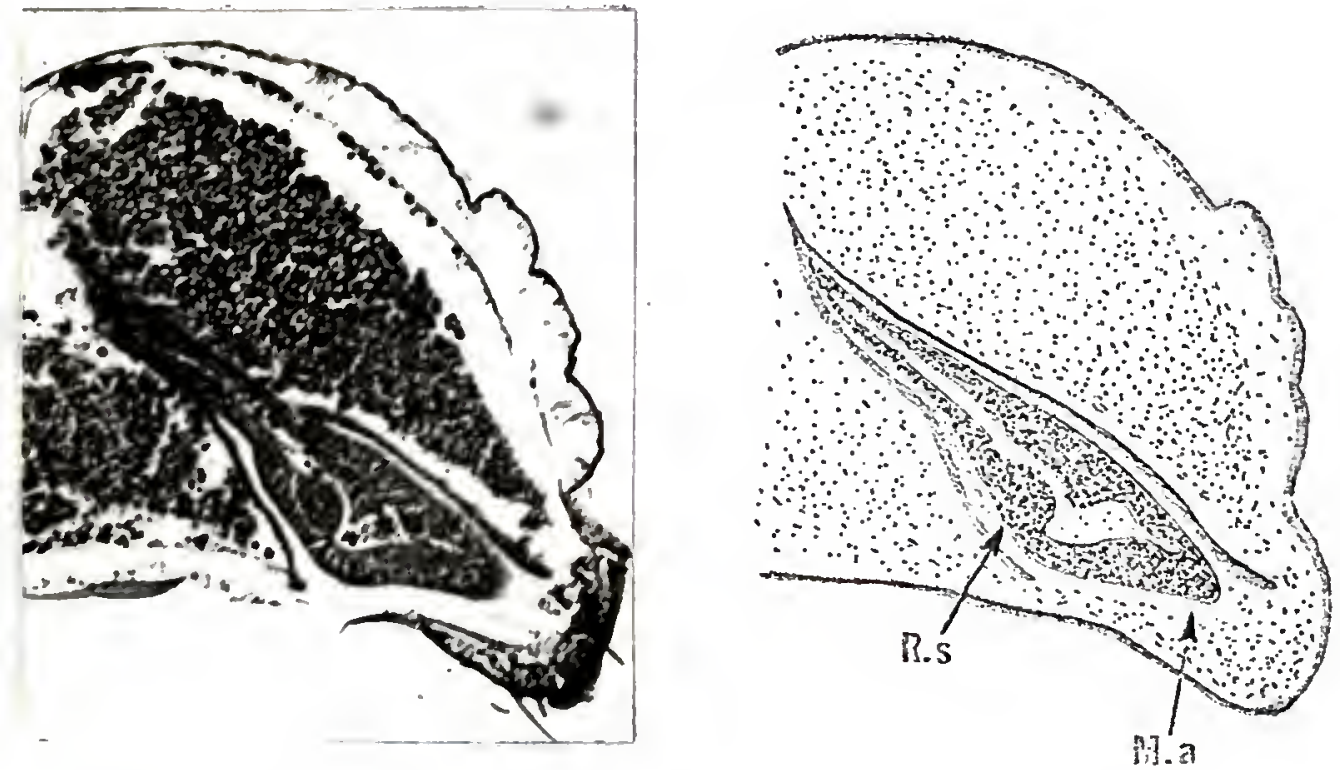

Fig. 13. Differentiation of the developing palpal organ at 48-72 hours into the penultimate instar. 


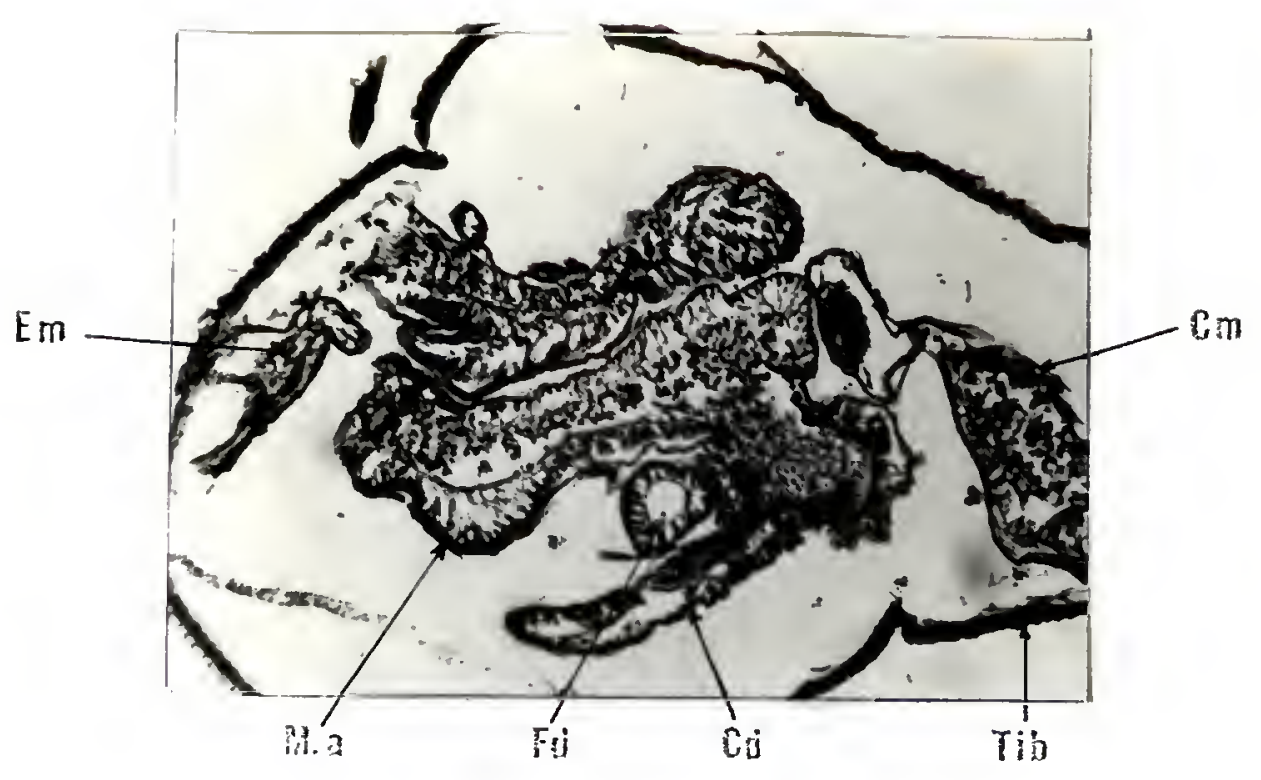

Fig. 14. Differentiation of the developing palpal organ approximately four days prior to the adult molt.

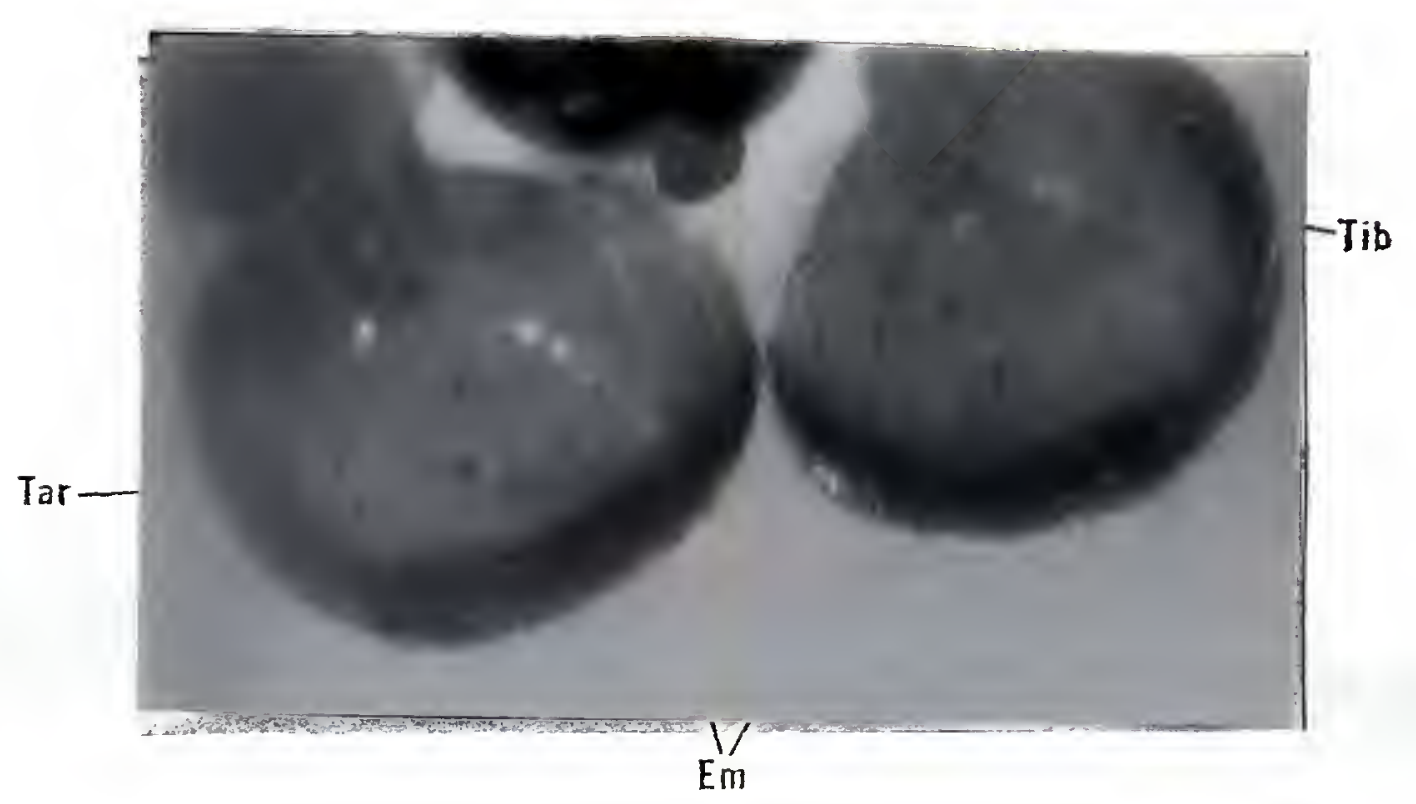

Fig. 15. Embolus of the developing palpal organ visible through the tarsal cuticle. 
and can be seen through the cuticle of the tarsus (Fig. 15). These results form the morphological basis by which the histology of regenerate palps resulting from the amputation experiments to follow can be compared.

Amputation of pre-penultimate palps

Pre-penultimate palps were amputated at various points to discover if palps injured during that stage would regenerate to normal penultimate palps and subsequently produce normal adult palps.

Amputation at the mid-tarsus

In 18 pre-penultimate male $\underline{L}$. variolus a palp was cut at the mid-point of the tarsus, eliminating the developing tissue of the developing palpal organ. Amputations were made when the spiders were an average of 30 days (range $=12-55$ days) into the instar. It took an average 15 (range $=9-19$ ) post-amputation days for the spiders to molt to the next instar. All of the specimens molted to the next instar and exhibited normal appearing penultimate palps. At the time of this report six had molted to the adult stage with normal adult palps (Fig. 16).

Amputation at the tibia-tarsus joint

The entire tarsus of one palp was removed from each of 18 spiders. The spiders were an average 28 days (range $=3-55$ days) into the instar at amputation. The spiders required an average of 22 (range $=14-39$ ) post-amputation days to molt. 

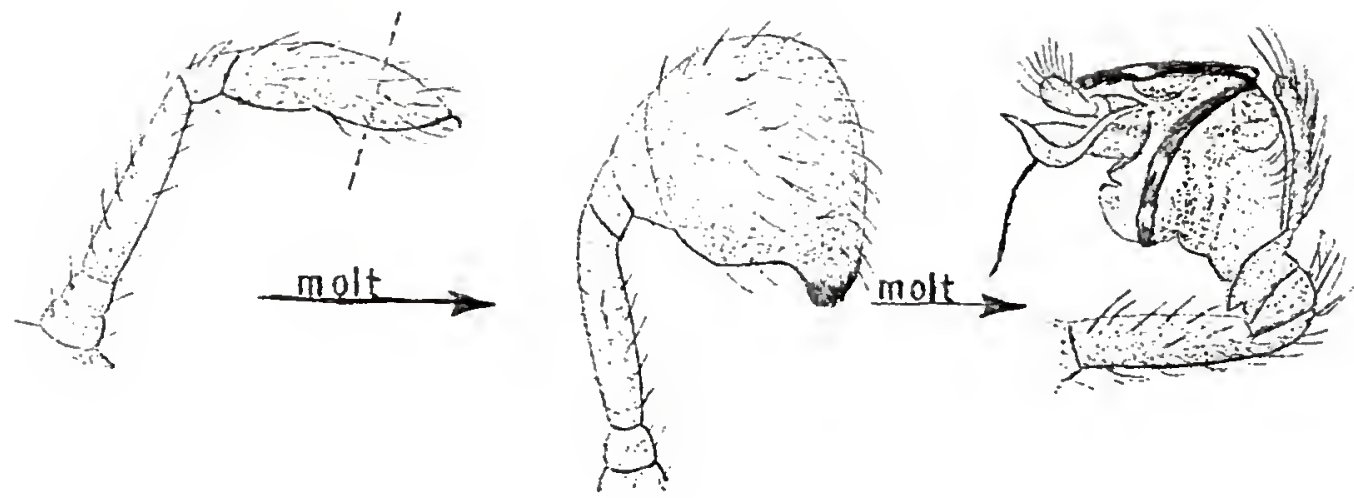

Fig. 16. Results of amputation of pre-penultimate palp at mid-tarsus.
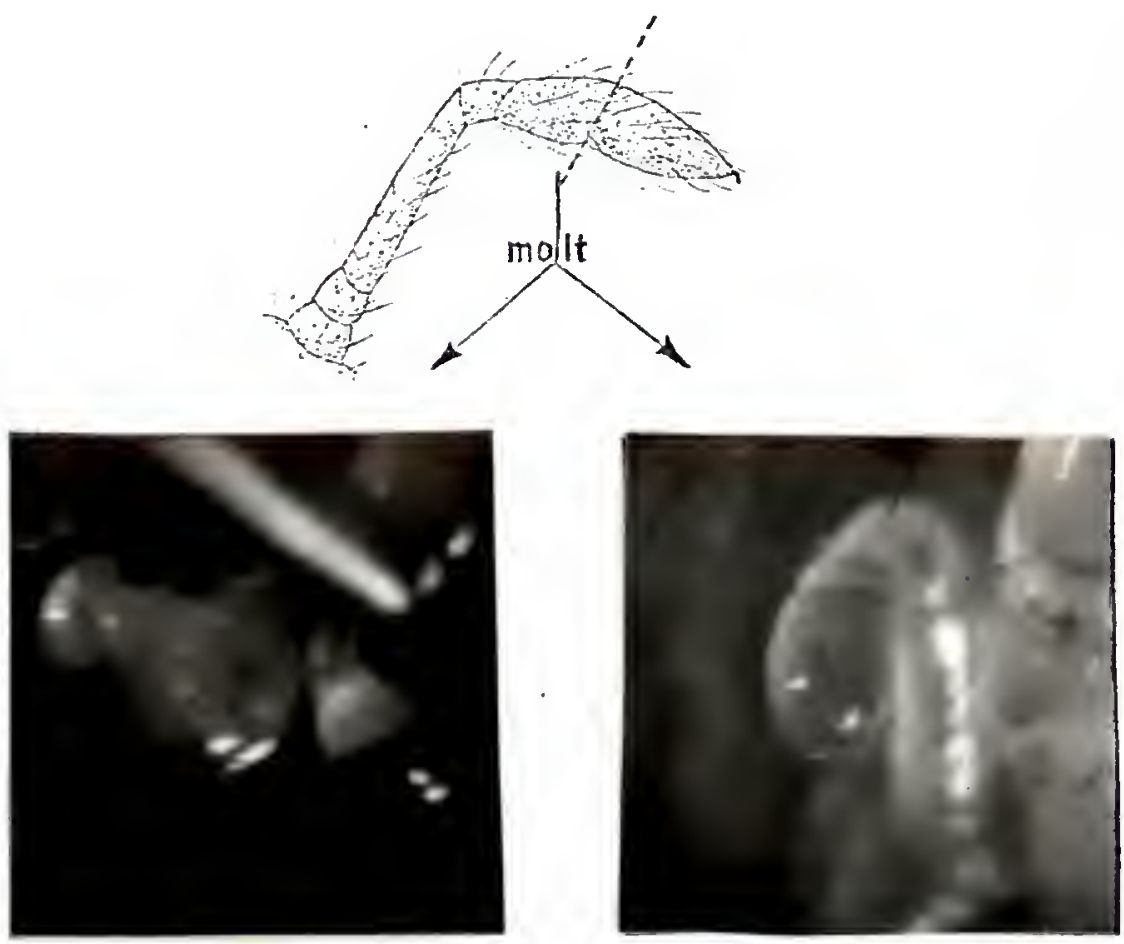

Fig. 17. Results of amputation of the pre-penultimate palp at the tibia-tarsus joint. 
One specimen displayed no regeneration after the post-amputation molt having only the coxa of the injured palp remaining. It is interesting that this spider spent the longest postamputation period (39 days) before molting yet did not regenerate.

The 17 remaining spiders exbibited imperfect regeneration in several modifications of the same general regenerate; the tarsus had regenerated much smaller than the normal corresponding penultimate palp. Examples of the different regenerates are shown in Figure 17. Histological examination of the regenerates indicated that the pretarsal primordia had been re-established and morphogenesis of the palpal organ was occurring but on a much smaller scale (Fig. 18). None of the eight spiders molting to the adult stage displayed any further regeneration of the injured palp.

Amputation at the patella-tibia joint

By amputating at the patella-tibia joint the entire tibia and tarsus were removed from one palp of 25 pre-penultimate male L. variolus an average of 23 days (range $=2-63$ days) into the instar. These spiders took an average of nine ( $r a n g e=$ 5-16) post-amputation days to molt to the penultimate instar. The regenerates from this experiment were similar in appearance to those of the preceding experiment. In 18 cases the regenerate appeared as a miniature penultimate palp one-third to one-fourth the size of the corresponding normal palp (Fig. 19). In six cases the regenerate was a small bud distal to 


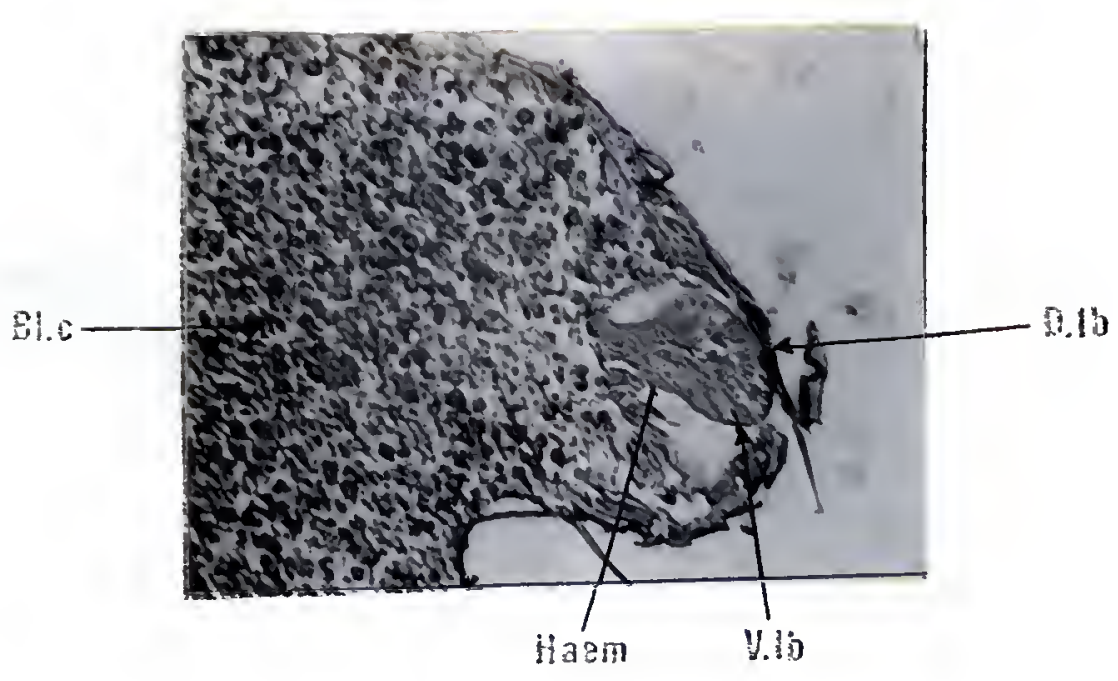

Fig. 18. Histology of regenerate palp following amputation at the tibia-tarsus joint.

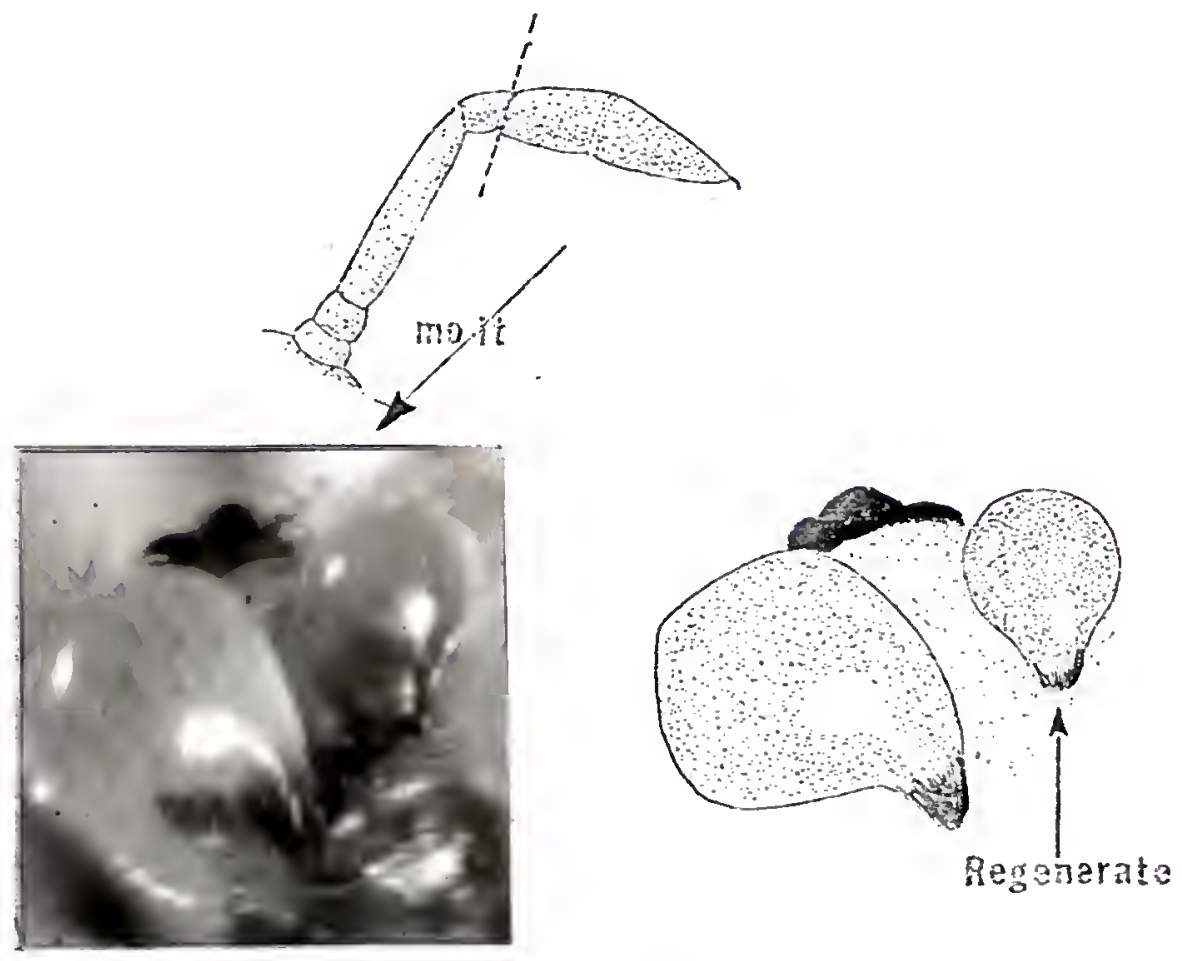

Fig. 19. Results of amputation of the pre-penultimate palp at the patella-tibia joint. 


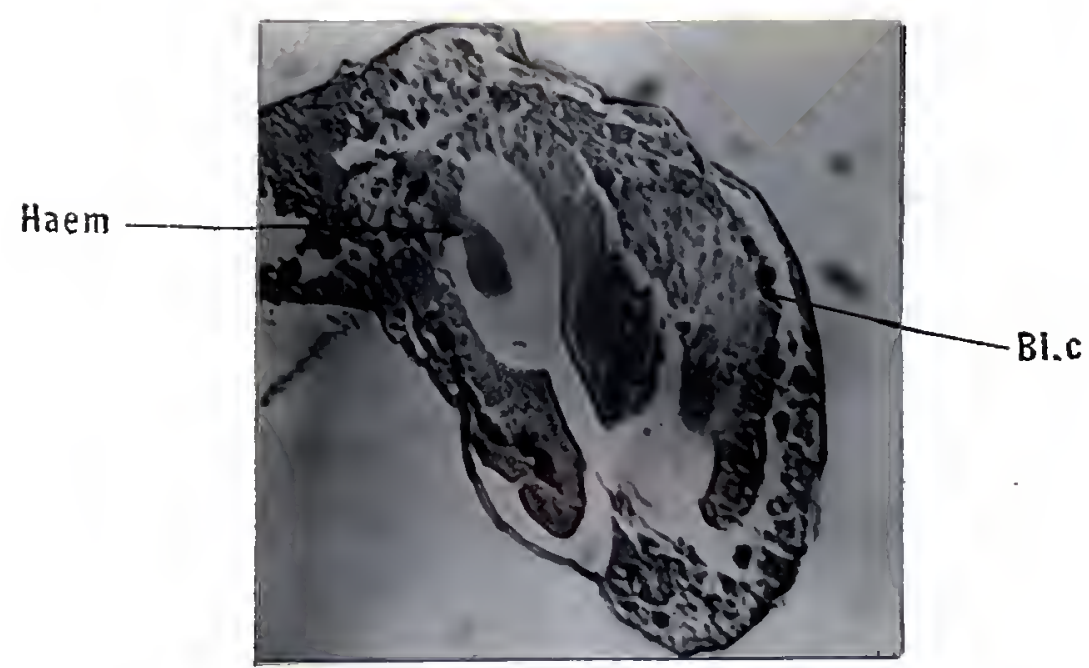

Fig. 20. Histology of regenerate palp following amputation at the patella-tibia joint. 
the palpal patella. One spider exhibited no regeneration having only the coxa of the injured palp remaining.

One specimen exhibiting the distal bud regenerate molted to a second penultimate stage where the uninjured palp remained unchanged and the regenerate palp had shrunk in size from the previous penultimate instar.

None of the eight spiders molting to the adult stage exhibited a normal palp following amputation of the tibia and tarsus during the pre-penultimate stage.

Again, histological examination of the regenerated palps indicated that morphogenesis of the palpal organ had been re-established but the developing organ was much smaller than the normal palp of the same age (Fig. 20).

Amputation at the femur-patella joint

In twelve spiders the palp was amputated at the femurpatella joint at an average of 37 (range $=1-47$ ) days into the instar. The spiders molted to the next instar in an average of 20 (18-21) days following amputation. Nine specimens displayed only healing of the femur. The remaining three spiders exhibited regeneration in the form of a small buib (Fig. 2I) attached to the distal end of the femur.

Amputation at the mid-femur and Trochanter-femur joint

In 14 pre-penultimate male $\mathrm{L}$. variolus the palpal femur was severed at its mid-point. In ten other specimens of the same stage one palp was amputated at the trochanter-femur 
joint. One specimen from the group cut at the mid-femur died three days after amputation without molting. Amputations were made an average of 24 days (range $=5-55$ days) into the instar and the 23 survivors took an average 20 (range $=5-47$ ) post-amputation days to molt to the penultimate instar.

Only three of the spiders (two from the trochanterfemur cut and one from the mid-femur cut) displayed any regeneration. The regenerates consisted of only the coxa, trochanter and femur. The regenerate femurs were one-third the size of theix normal counterparts (Fig. 22). The remaining 20 specimens, upon molting to the penultimate stage, had only the coxa and trochanter of the injured palp present and a normal palp in the corresponding position.

Amputation at the coxa-trochanter joint

Of the 16 pre-penultimate male $\underline{L}$ variolus used in this experiment ten had one palp cut at the coxa-trochanter joint and six had both palps removed by pulling with foreceps.

The palps removed by pulling all severed at the coxa-trochanter joint, establishing the plane of weakness for the palp.

All sixteen specimens molted to the next instar with no regeneration of injured palps. Only the coxa of each injured palp, whether cut or pulled remained (Fig. 23). Five spiders molted to the adult stage with only the palpal coxae present.

The amputation experiments performed on pre-penultimate

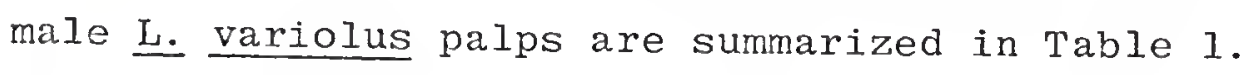




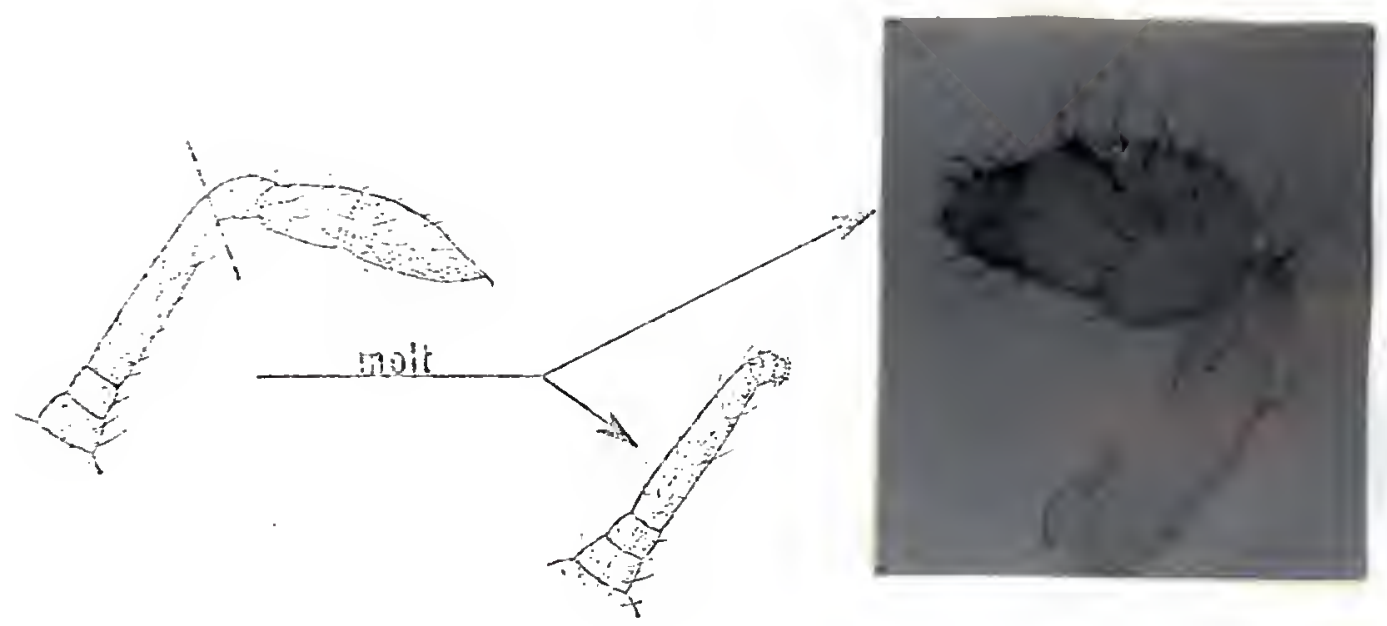

Fig. 21. Results of amputation of the pre-penultimate palp at the femur-patella joint.

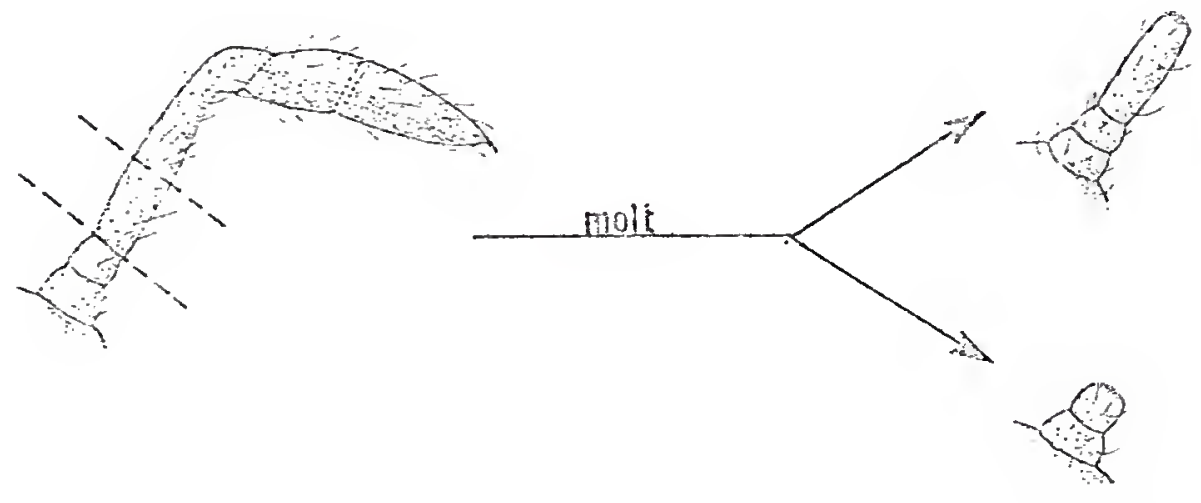

Fig. 22. Results of amputation of the pre-penultimate palp at the mid-femur and trochanter-femur joint.
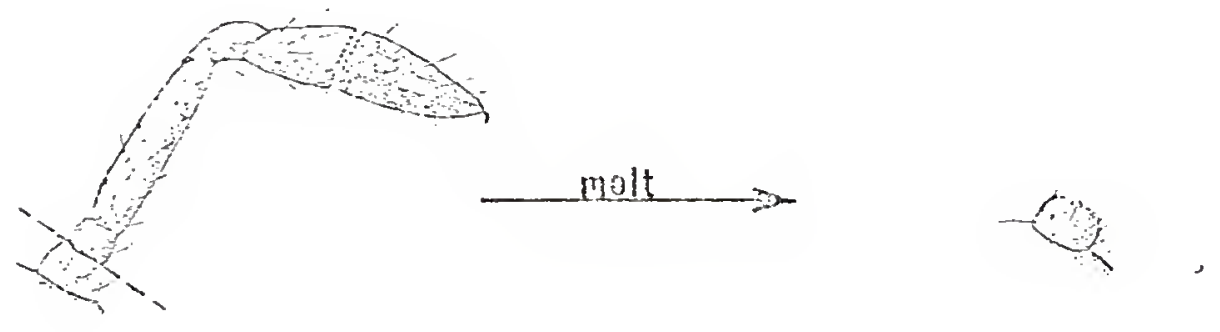

Fig. 23. Results of amputation of the pre-penultimate palp at the coxa-trochanter joint. 


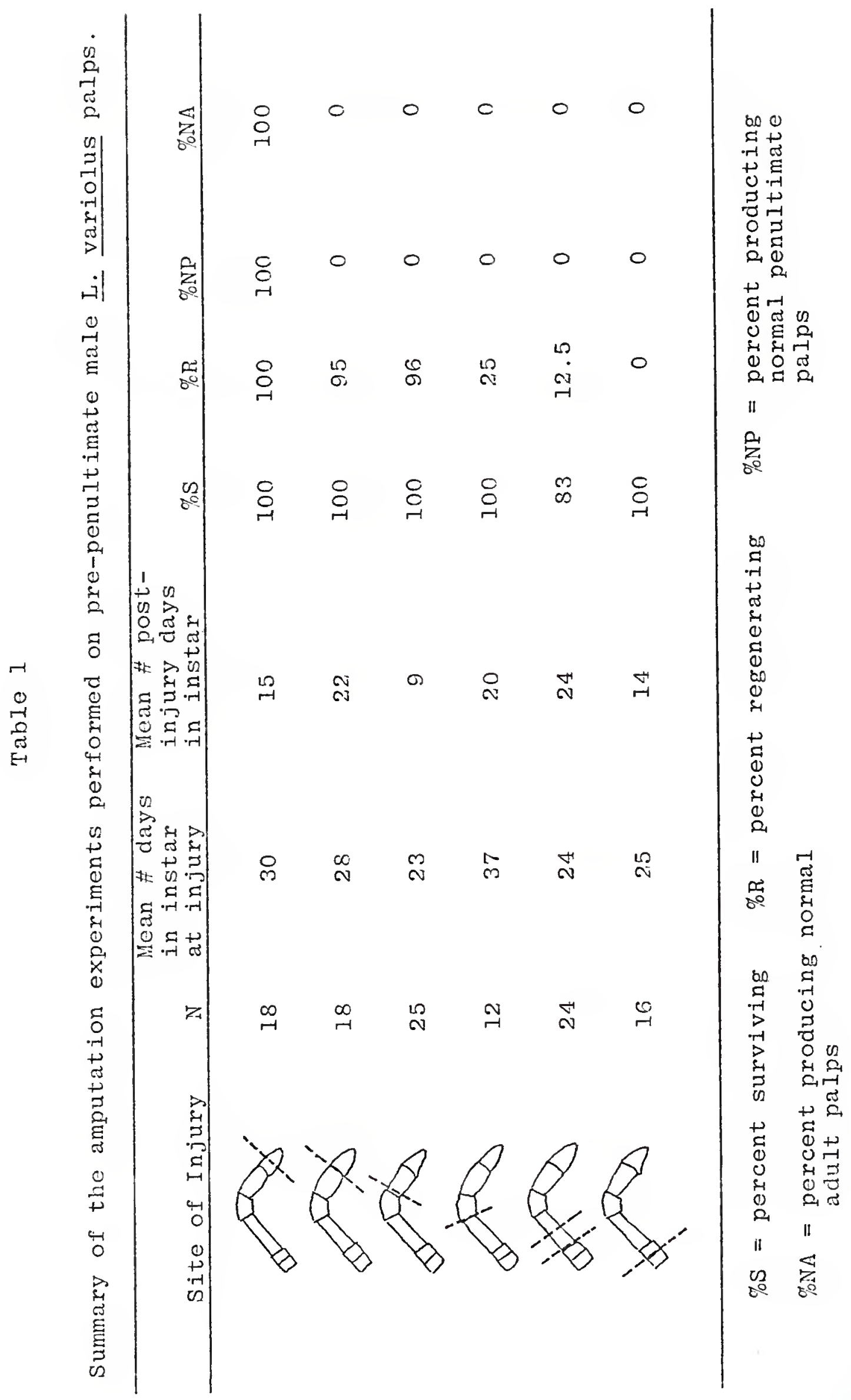


Amputation of penultimate palps

As in the previous series of experiments, it was desirable to discover the regenerative capacity of the penultimate palps. According to Bonnet's work on Dolomedes (1930) it would not be possible for either pre-penultimate or penultimate palps to produce normal adult structures after injury.

Amputation at the mid-point of the tarsus

In twelve penultimate male $\underline{L}$. variolus the distal half of the tarsus was removed from one palp an average of 17 days ( range $=9-25$ days) into the instar. Eight spiders died shortly after amputation without molting. The remaining four spiders molted to the adult instar in an average of twelve days (range $=4-17$ days) with no regeneration occurring. Coxae of the injured palps were the only structures present (Fig. 24).

Amputation at the tibia-tarsus joint

A palp of each of ten penultimate males was amputated at the tibia-tarsus joint an average of five days (range $=2$ 16 days) into the instar. All of the specimens died within two days of amputation without molting (Fig. 25).

Damage to the palpal tarsus

The tarsus of one palp of five penultimate males was damaged by puncture an average of twelve days ( range $=1-25$ days) into the instar. The only spider to survive molted to the adult instar 19 days after injury without any regeneration (Fig. 26). 


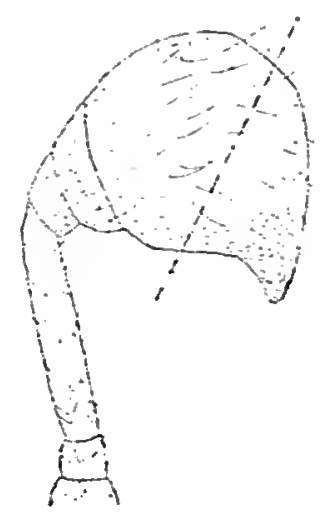

$$
\begin{gathered}
\text { D. } 34.4-30 \text { molk } \\
5 \%
\end{gathered}
$$
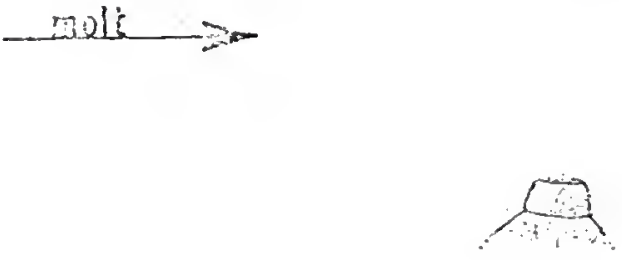

$33 \%$

Fig. 24. Results of amputation of the penultimate palp at the mid-tarsus.
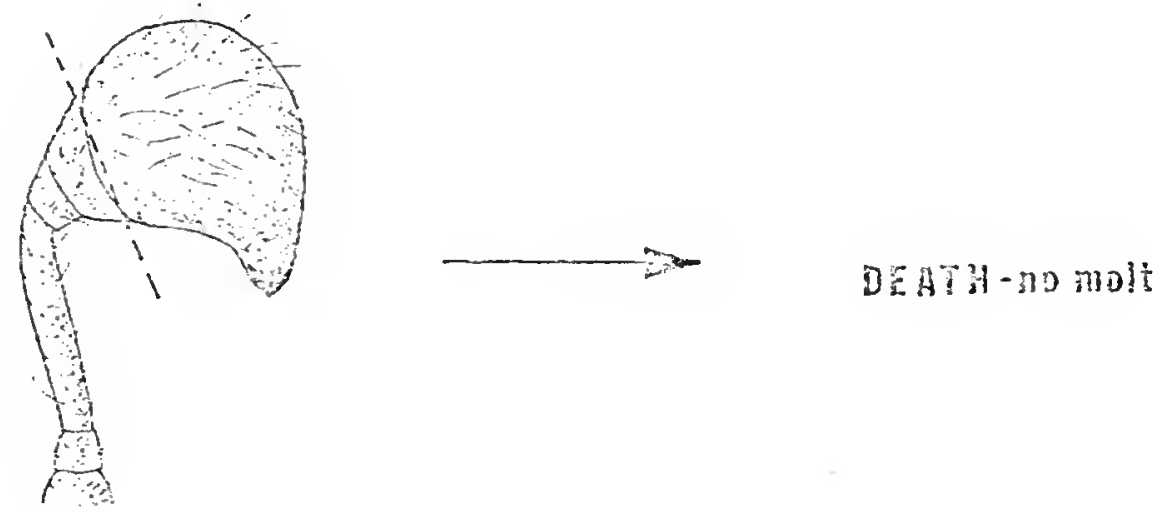

Fig. 25. Results of amputation of the penultimate palp at the tibia-tarsus joint.
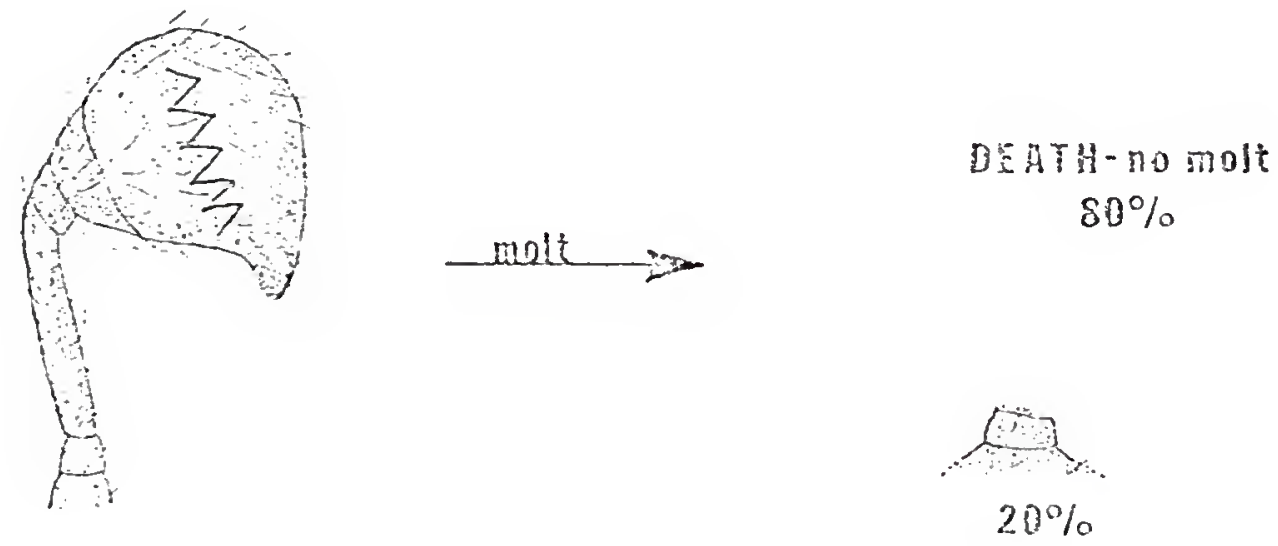

Fig. 26. Results of damage (puncture) to the tarsus of the penultimate palp. 
Amputation at the patella-tibia joint

The tibia and tarsus from each of ten penultimate males was amputated an average of two days (range $=1-2$ days) into instar. Two spiders died without molting. The remaining eight specimens molted to the adult instar an average of 41 (range $=30-61$ ) post-amputation days with no regeneration displayed by any spider. The injured palps appeared in the adult stage with a coxa, trochanter, femur and patella. The distal margin of the patella was healed over (Fig. 27).

Amputation at the coxa-trochanter joint

In twelve penultimate males a palp was amputated at the coxa-trochanter joint; eleven of which survived to the adult stage in an average of 15 days (range $=4-27$ ) after amputation. No regeneration of the injured palps was observed (Figi. 28).

The amputation experiments performed on the palps of penultimate male $\underline{L}$ variolus are summarized in Table 2.

\section{Ligature of Pre-penultimate and Penultimate Palps}

Ligation of pre-penultimate and penultimate palps was performed to discover if this type of injury would result in the autotomy of the palps.

\section{Ligature at mid-point of pre-penultimate palp}

In ten pre-penultimate males the mid-point of the palpal femur was ligated an average of nine days (range $=1-32$ ) into the instar. Two spiders died one day after ligation. Four of the remaining spiders apparently autotomized their injured palp one day after ligation. 

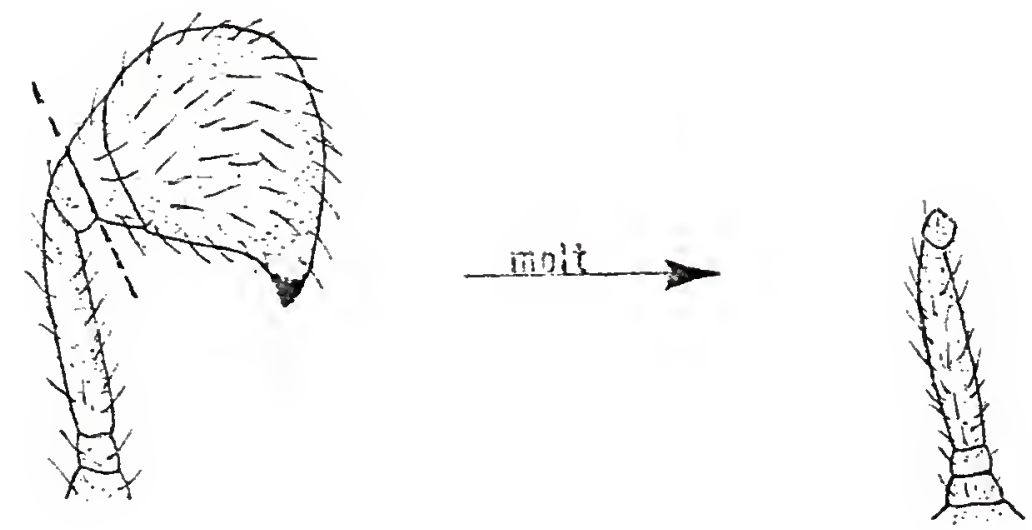

Fig. 27. Results of amputation of the penultimate palp at the patella-tibia joint.
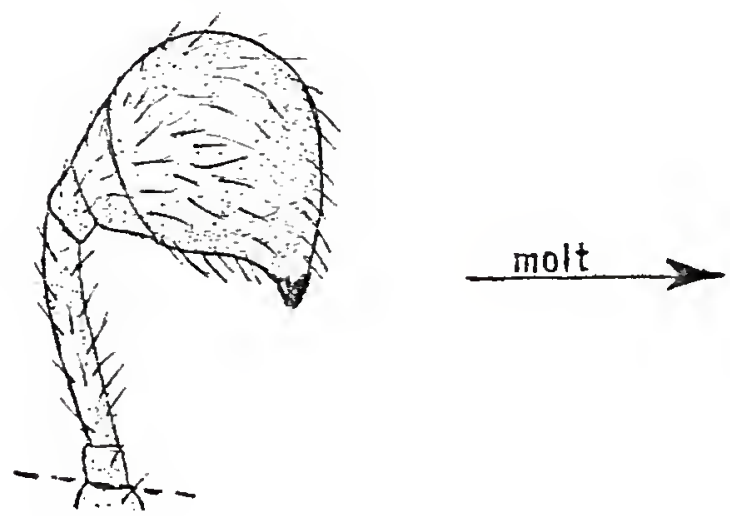

Fig. 28. Results of amputation of the penultimate palp at the coxa-trochanter joint. 


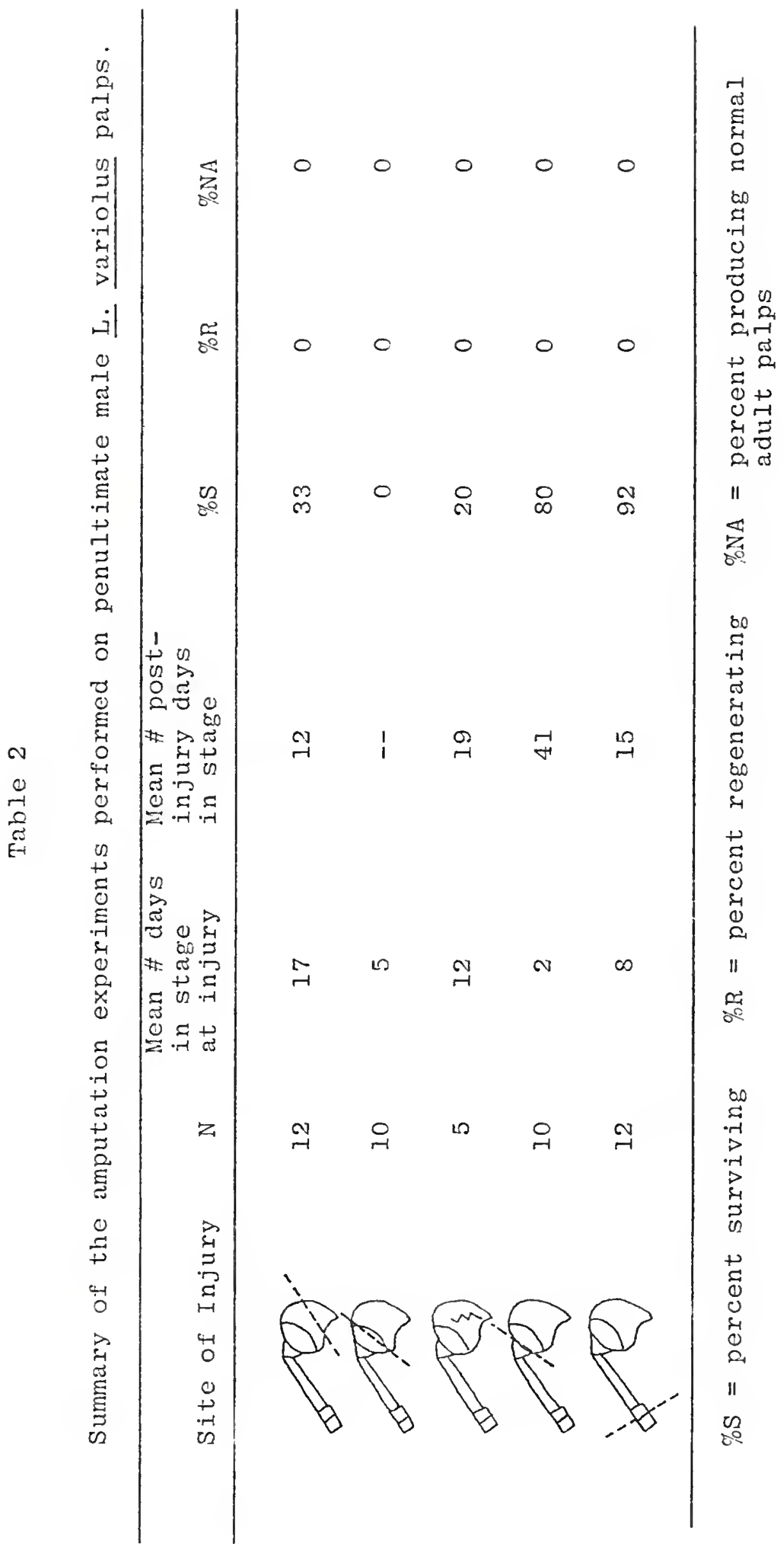


Ligature at the tibia-tarsus joint of penultimate palp

In five penultimate males, an average of 14 days (range $=1-20)$ into the instar, the tibia-tarsus joint of a palp was ligated. One spider died a day after ligation. One of the surviving four specimens exhibited the apparent autotomy of the palp two days after the application of the ligature.

Ligature at the mid-femur of the penultimate palp

In eight penultimate males the mid-femur of the palp was ligated an average of 48 days (range $=12-129$ ) into the instar. Six specimens died within two days of ligation. No autotomy was observed in the remaining two spiders.

The ligation experiments performed on the palps of prepenultimate and penultimate male $L_{\text {. }}$ variolus are.summarized in Table 3 .

Regeneration and Autotomy in the Legs of L. variolus

Regeneration and autotomy in the legs of L. variolus were studied using two types of injury, amputation and ligation. Amputation left an open wound requiring healing whereas ligation did not. The first leg on the left side of fourth and fifth instar female L. variolus was amputated at different points in an effort to determine the most proximal point from which amputation resulted in regeneration of the limb.

Amputation at the mid-point of the telotarsus

In six spiders the distal half of the telotarsus was removed two days into the instax. With the first post-ampu- 


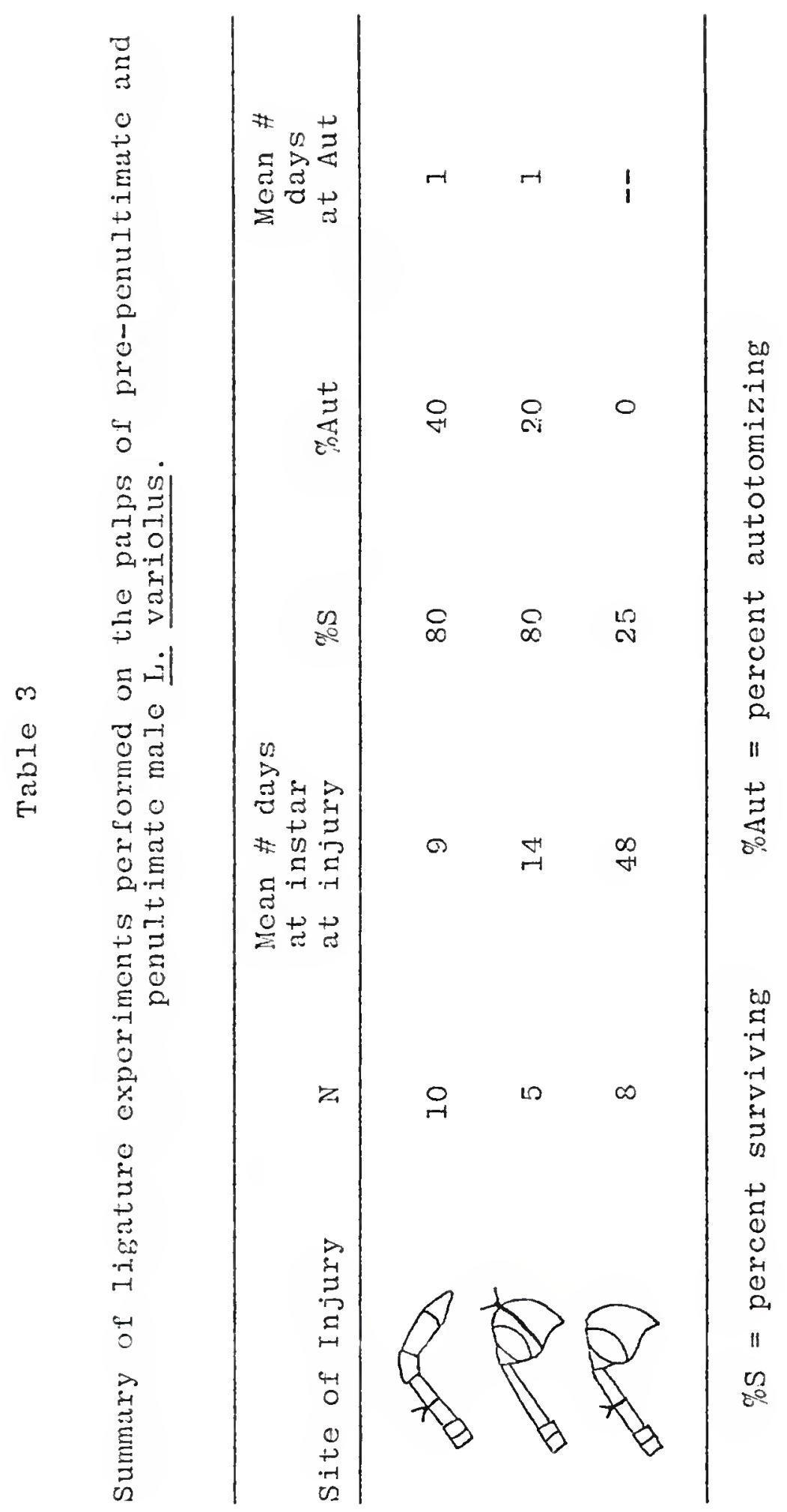


tation molt the injured telotarsi had regenerated to approximately $50 \%$ the size of the normal corresponding structure (Fig. 29). The tarsal claws were present and normal in appearance. With the second post-injury molt all injured legs were normal in size and appearance.

Amputation at the mid-point of the basitarsus

In ten immature female $L$. variolus a leg was amputated at the mid-point of the basitarsus an average of three days (range $=1-11)$ into the instar. Following the first postamputation molt all of the spiders exhibited regeneration where the basitarsus was 33-100\%, and the telotarsus 25-33\% normal by comparison to corresponding structures. By the second molt four had regained normal appearing legs. After the third post-injury molt all specimens displayed normal legs (Fig. 30).

Amputation at the mid-point of the tibia and at the patellatibia joint

In 14 specimens a leg was amputated at the mid-point of the tibia and ten other spiders had a leg amputated at the patella-tibia joint. Amputations were made when the spiders were an average of nine days (range $=1-45$ days) into the instar. All exhibited regeneration at the first post-amputation molt an average of 17 (range $=7-45$ ) days later with the tibia $33-50 \%$, basitarsus $20-50 \%$ and telotarsus $20-50 \%$ normal by comparison with normal corresponding structures (Fig. 31). Two spiders had regenerated a normal leg by their second postinjury molt and twelve had normal legs by the third molt following amputation. 


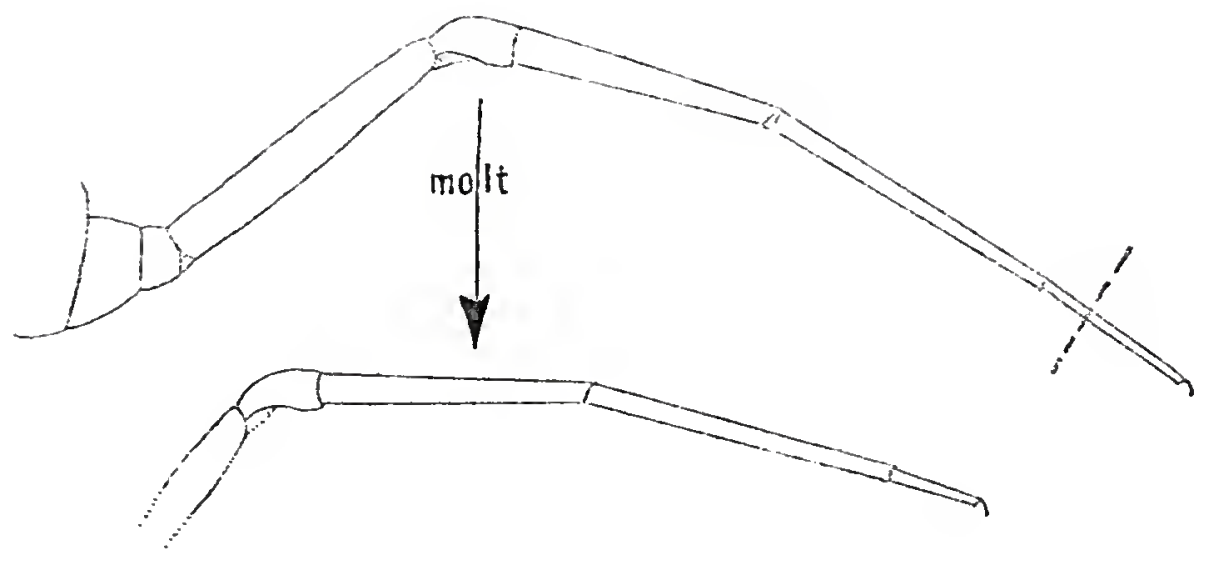

Fig. 29. Results of amputation of the leg at the mid-telotarsus.

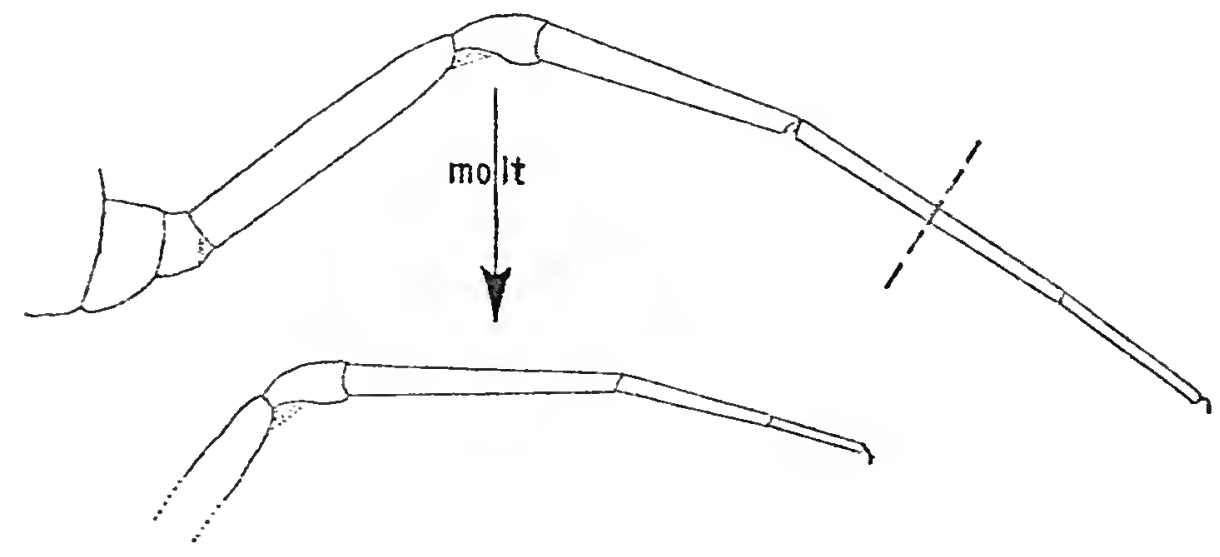

Fig. 30. Results of amputation of the leg at the midbasitarsus.

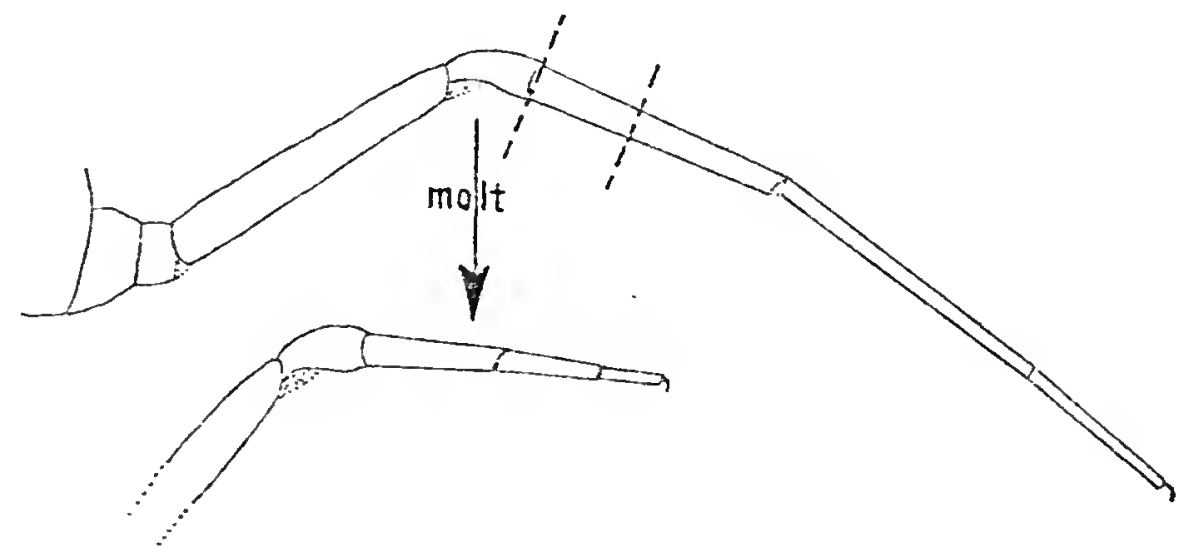

Fig. 31. Results of amputation of the leg at the midtibia and at the patella-tibia joint. 
Amputation at the femur-patella joint

In each of six spiders a leg was cut at the femur-patella joint one day into the instar. One specimen died two days after amputation without molting. Four of the remaining spiders molted in an average 25 (range $=18-39$ ) days later and regenerated the patella $50-100 \%$, tibia 50-75\%, basitarsus 33-50\% and telotarsus 20-33\% normal by comparison (Fig. 32). No spider had regenerated a normal leg by the second and only two had regenerated normal legs by the third post-amputation molt. One spider had only the coxa of the injured leg evident after two post-injury molts.

Amputation at the mid-point of the femur

In 20 spiders a leg was amputated at the mid-point of the femur an average of 18 (range $=1-35$ ) days into the instar. One spider died without molting. The first post-amputation molt came an average of 38 (range $=16-58$ ) days later with $70 \%$ of the survivors regenerating the femur $33-75 \%$, patella 33-50\%, tibia 20-50\%, basitarsus 20-33\% and telotarsus 20-25\% by comparison to normal structures (Fig. 33). None of the above had regenerated a normal leg by the second and only one spider had regenerated a normal leg after the third postamputation molt. The remaining $30 \%$ of the survivors displayed wound healing at the site of amputation with no subsequent regeneration. 


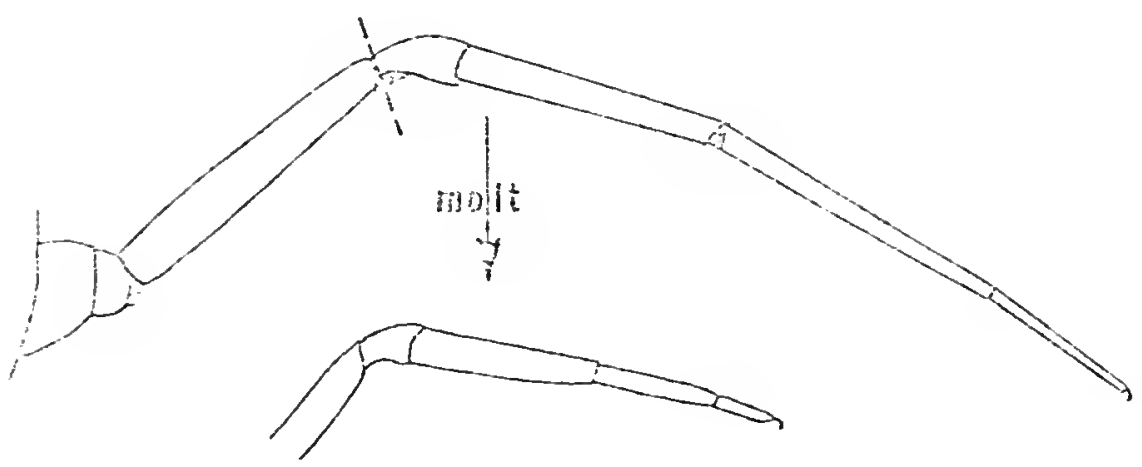

Fig. 32. Results of amputation of the leg at the femurpatella joint.

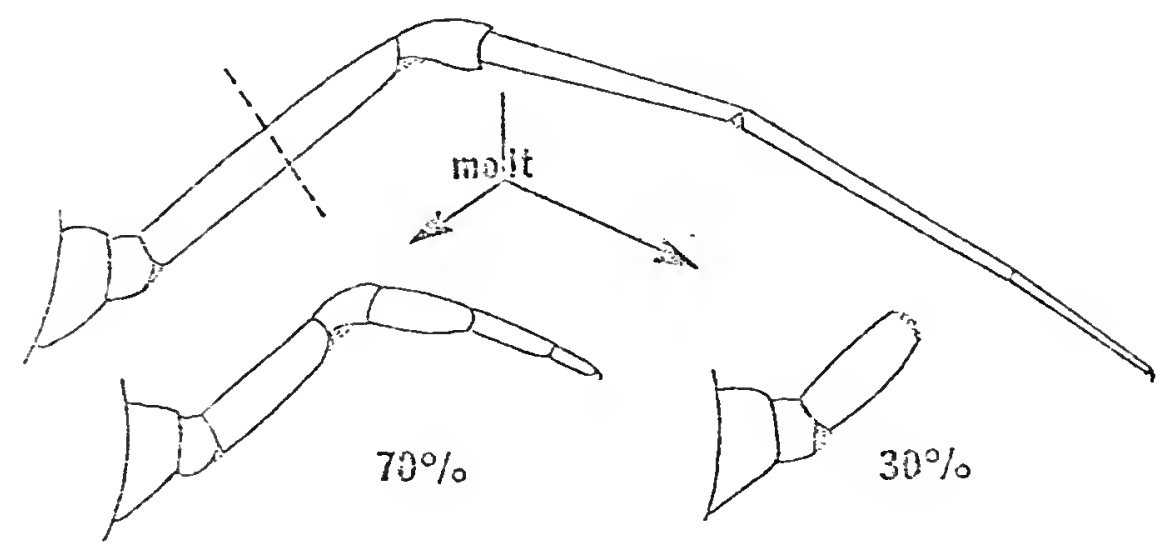

Fig. 33. Results of amputation of the leg at the mid-femur.

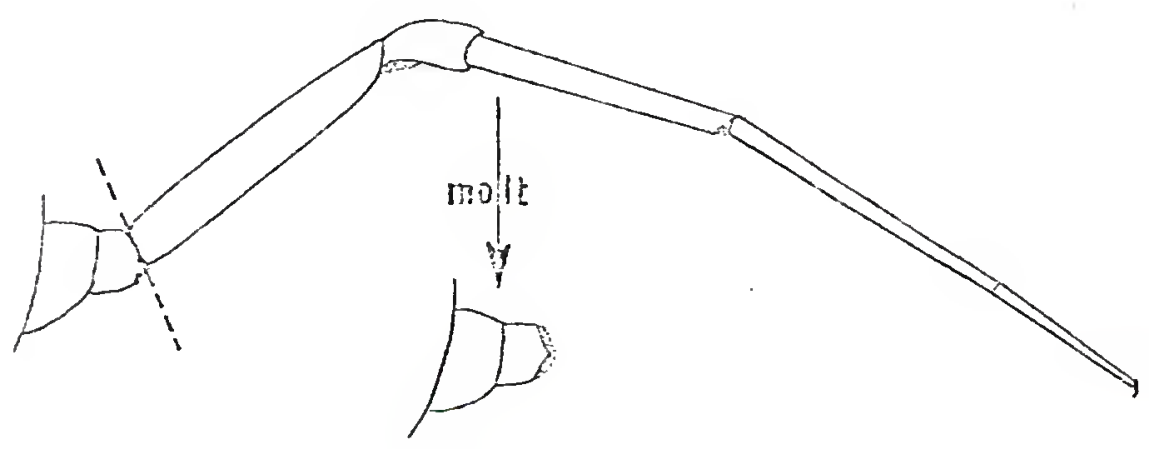

Fig. 34. Results of amputation of the leg at the trochanterfemur joint. 
Amputation at the trochanter-femur joint

In ten spiders a leg was amputated at the trochanterfemur joint an average of 27 (range $=5-48$ ) days into the instar. No specimen exhibited regeneration at any postamputation molts. In every case the trochanter had healed over (Fig. 34).

Amputation at the coxa-trochanter joint

A leg from each of 15 spiders was removed at the coxatrochanter joint by pulling on the leg with forceps. Amputation occurred an average of 12 (range $=1-39$ ) days into the instar. No regeneration occurred at any subsequent molts leaving only the coxae of injured legs (Fig. 35).

Amputation at the proximal margin of the coxa

In ten spiders one of the second pair of legs was removed by cutting around the proximal margin of the coxa. Only two spiders survived the injury and exhibited no regeneration of any leg structures. The wound healed over completely in the two survivors (Fig. 36).

The amputation experiments performed on the legs of $\underline{L}$. variolus are summarized in Table 4 .

\section{Localized Injury to the Femur}

This experiment was performed to discover if $\underline{L}$. variolus had the ability to regenerate a leg from a local injury to the femur. Bohn (1965) inflicted local injury to the tibia of a cockroach (L. maderae) by removing a V-shaped section of 


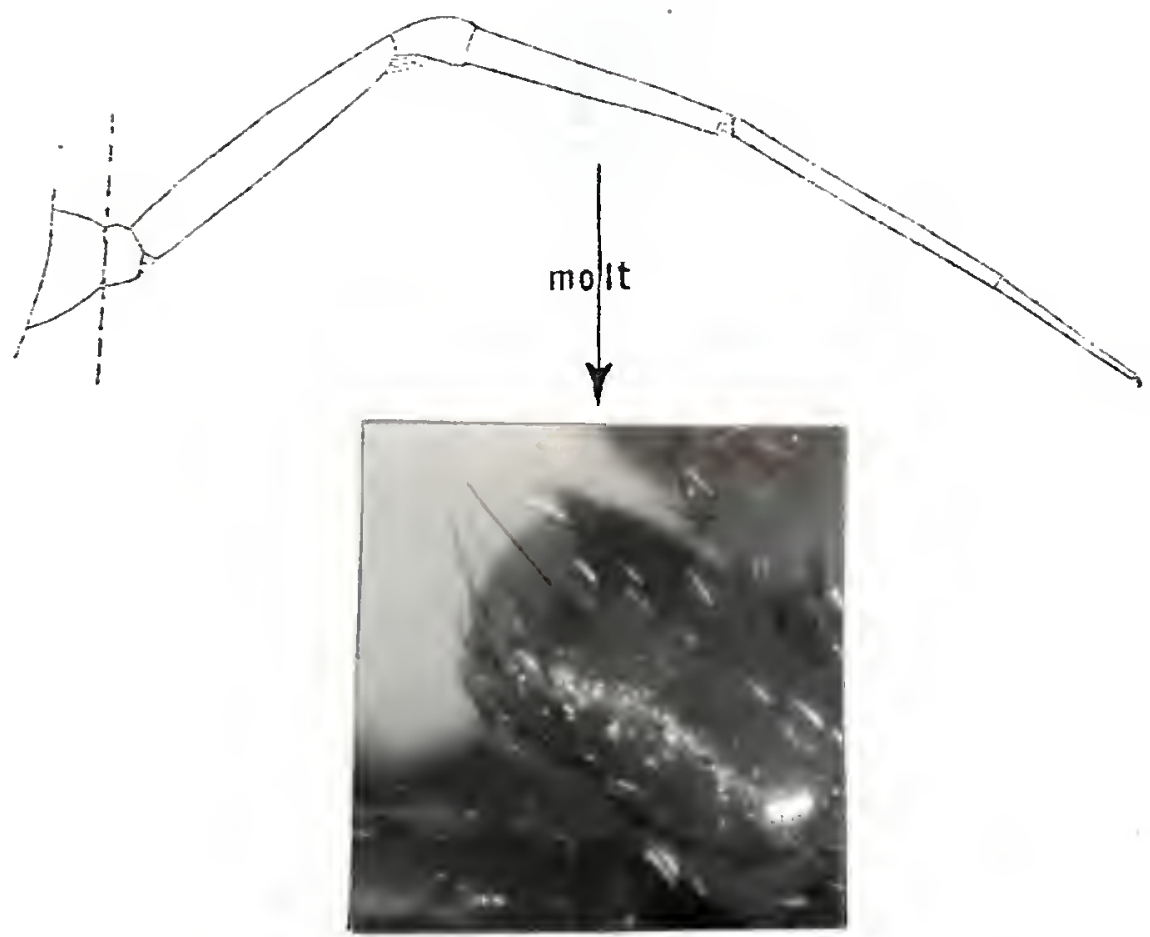

Fig. 35. Results of amputation of the leg at the coxatrochanter joint.

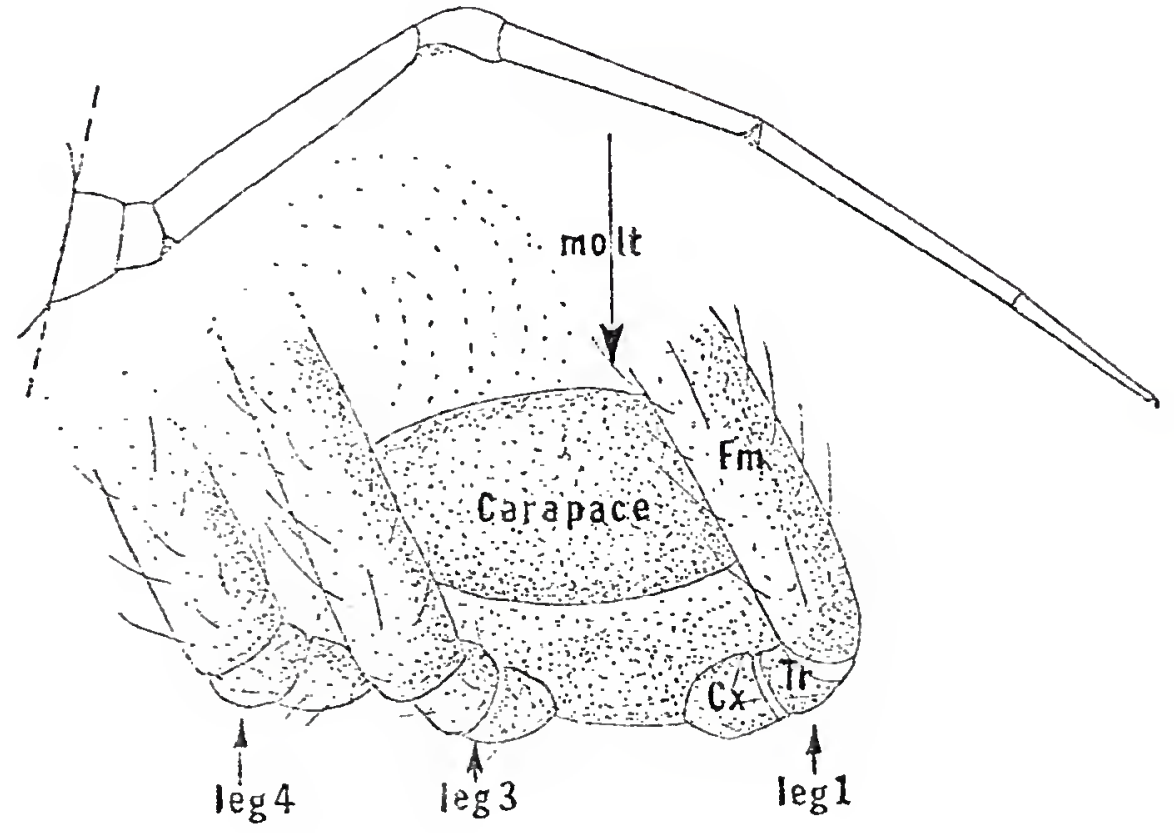

Fig. 36. Results of amputation of the leg at the proximal margin of the coxa. 


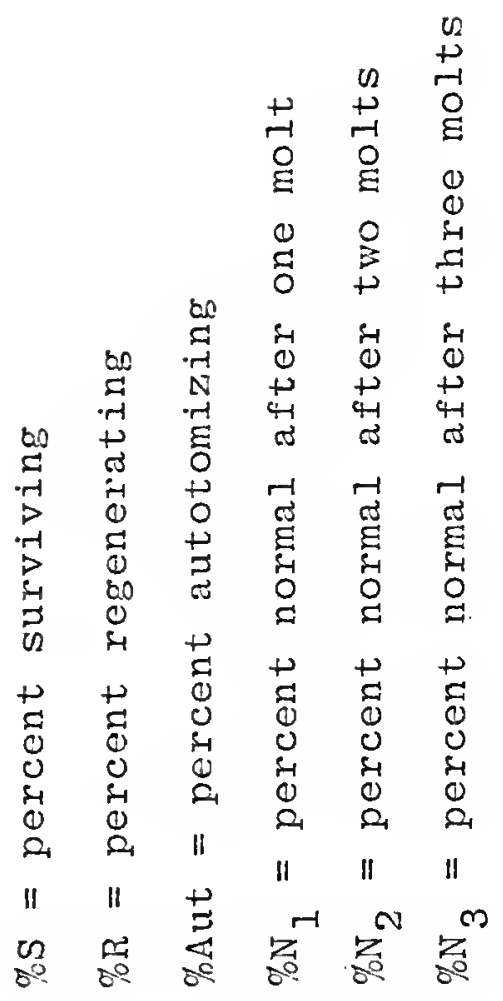




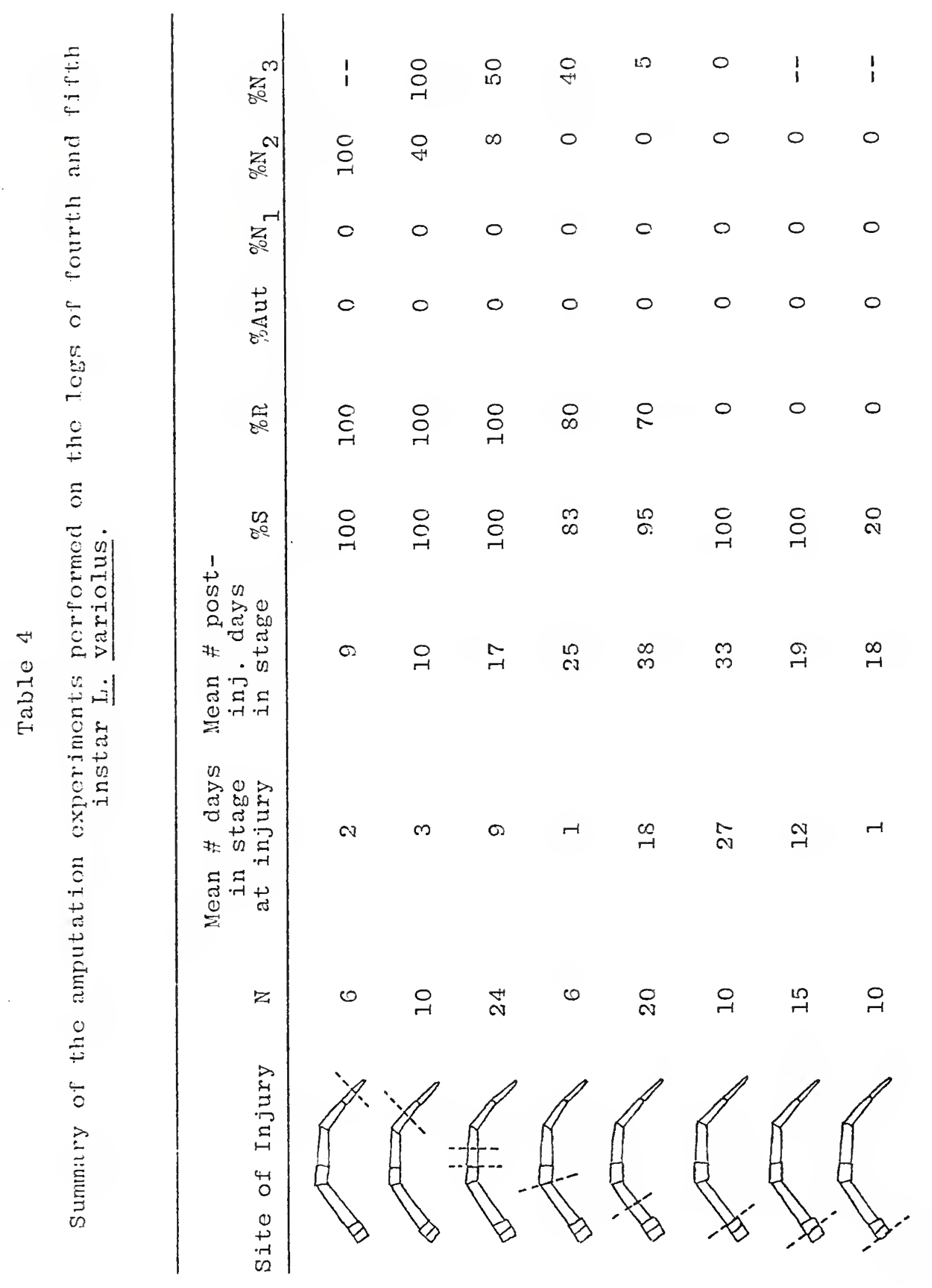


tissue. This resulted in a lateral regenerate, in the form of a leg, at the site of injury.

From each of 15 spiders a section of tissue was cut from the femur. One spider died without molting. Six specimens autotomized the injured limb at the coxa-trochanter joint in an average of four (range $=1-7$ ) days after injury (Fig. 37). Autotomized limbs did not regenerate with only the coxa remaining following subsequent molts. These results are comparable to those obtained by mechanical removal of the leg at the autotomy plane.

The other eight spiders exhibited healing of the wound following injury and a concave scar following the post-injury molt (Fig. 37). The scar area was characterized by a lack of setae. No lateral regenerates resulted from this type of injury to L. variolus.

\section{Ligature of the Legs}

Ligature was used to inflict injury to the leg without resulting in an open wound. Such an injury, however, is sustained for longer periods of time since the ligature is in place until discarded by some mechanical means or at the post-ligature ecdysis.

Ligature at the mid-point of the basitarsus

Ten spiders vere ligatured at the mid-point of the basitarsus an average of 49 (range $=36-67$ ) days into the instar. One day after ligature four spiders had lost, 


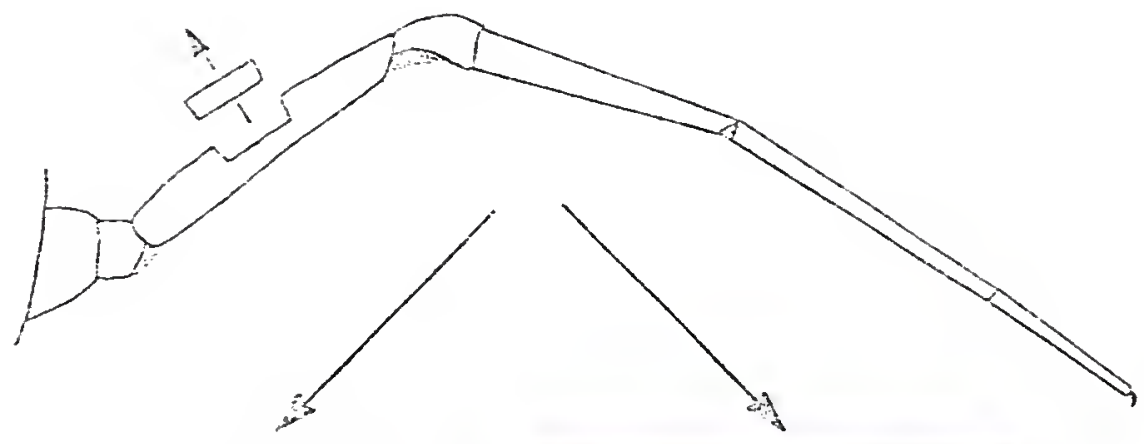

RUTOROMY An\%
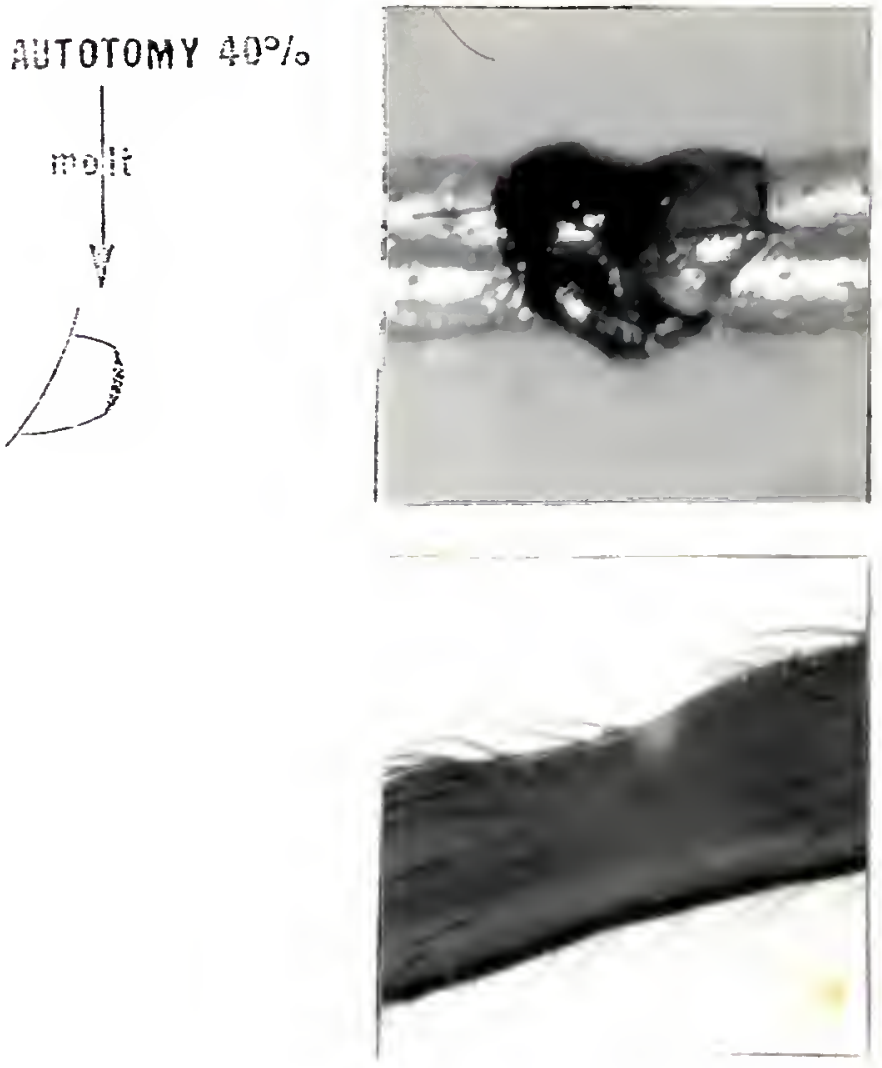

Fig. 37. Results of localized injury to the femur of the leg. 
apparently by a mechanical means, the portion of the injured leg distal to the ligature. The effect therefore was of amputation at that point. No autotomy was observed. All of the spiders regenerated at the next molt, an average of 20 (range $=17-40)$ days later, with the basitarsus 75-100\% and telotarsus 50\% normal (Fig. 38). Fifty percent of the spiders had regenerated a normal leg by the second molt.

Ligature at the mid-point of the tibia

A leg from each of 20 spiders was ligatured at the midpoint of the tibia an average of 19 (range $=16-22$ ) days into the instar. Fourteen specimens autotomized the injured limb at the coxa-trochanter joint in an average seven (range = 1-14) days after ligature. No post-autotomy regeneration was exhibited, leaving only the coxa of the ligatured/autotomized limb in evidence.

The six spiders that did not autotomize the ligatured limb did, however, remove the leg tissue distal to the ligature as described above in the preceding experiment in 2 to 23 days. These spiders did regenerate the tibia 50-67\%, basitarsus and telotarsus $25-33 \%$ at the first post-ligature ecdysis (Fig. 39).

\section{Ligature at the patella}

Six spiders were ligatured at the patella of one leg. Five spiders autotomized the injured leg in an average of seven (range $=1-12$ ) days after injury. The remaining specimen molted 20 days after ligation with the patella 50\%, tibia 50\%, basitarsus $33 \%$ and telotarsus $20 \%$ normal by comparison (Fig. 40). 


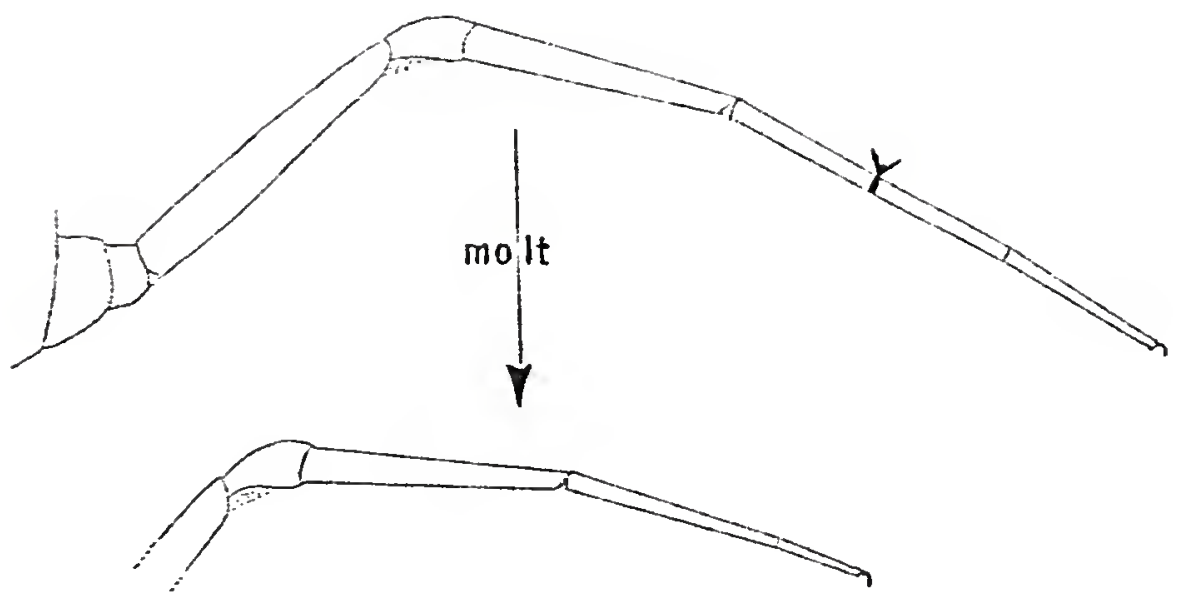

Fig. 38. Results of ligation of the leg at the midbasitarsus.

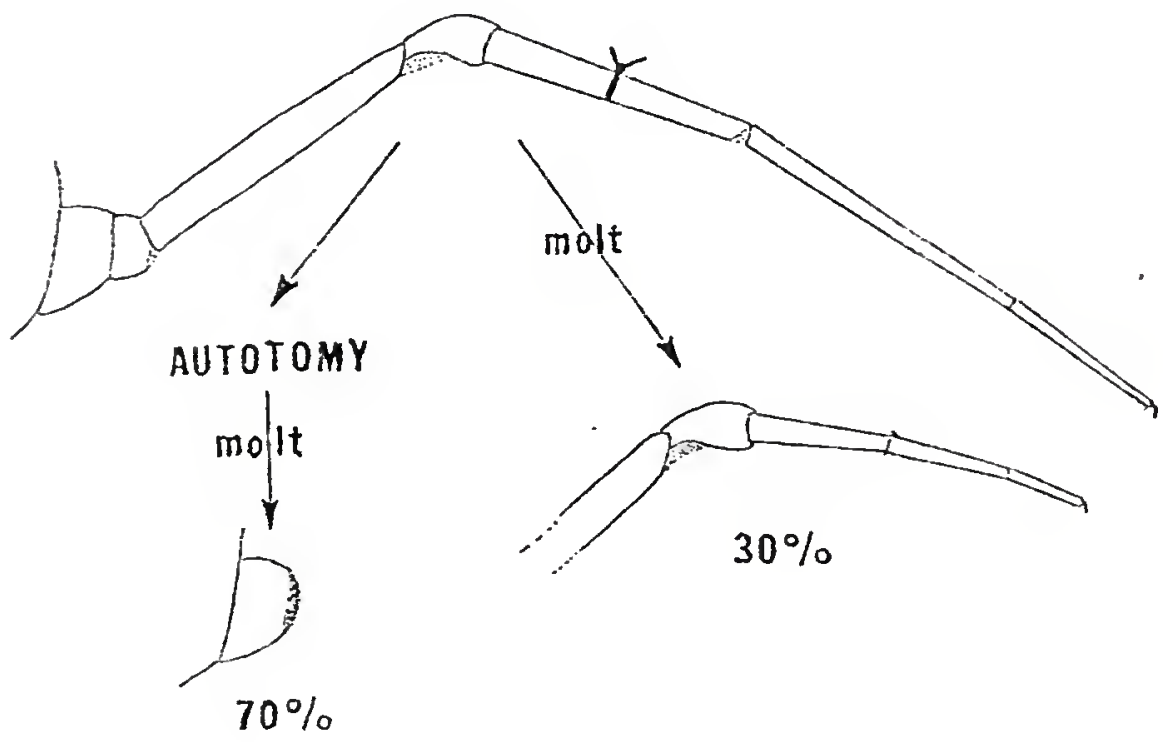

Fig. 39. Results of ligation of the leg at the mid-tibia. 
Ligature at the mid-point of the femur

One leg of each of ten spiders was ligatured at the midpoint of the femur an average of 38 (range $=1-59$ ) days into the instar. All ten specimens autotomized the ligatured limb at the coxa-trochanter joint within one day of injury. No regeneration of the limbs was observed. Only the coxa of ligatured/autotomized legs remained after subsequent molts (Fig. 41).

\section{External Force Applied at Autotomy Plane}

This experiment was performed to determine if an injury applied to the plane of weakness powerful enough to produce bleeding but mild enough not to cause severence of the limb, would result in autotomy. It was necessary to perform this experiment since the possibility existed that this type of injury may occur as a result of the manipulation of spiders for any of the previously described experiments.

In the 20 spiders tested in this manner at an average of 18 (range $=5-55$ ) days into the instar no autotomy resulted and all specimens molted to the next instar with no morphological anomalies observed.

The Iigature and external force experiments performed on the legs of $\underline{L}$ variolus are summarized in Table 5.

\section{Summary of Results}

Latrodectus variolus has the capacity to regenerate a normal adult male palp only if the injury occurs distal to the mid-point of the tarsus during or before the pre-penulti- 

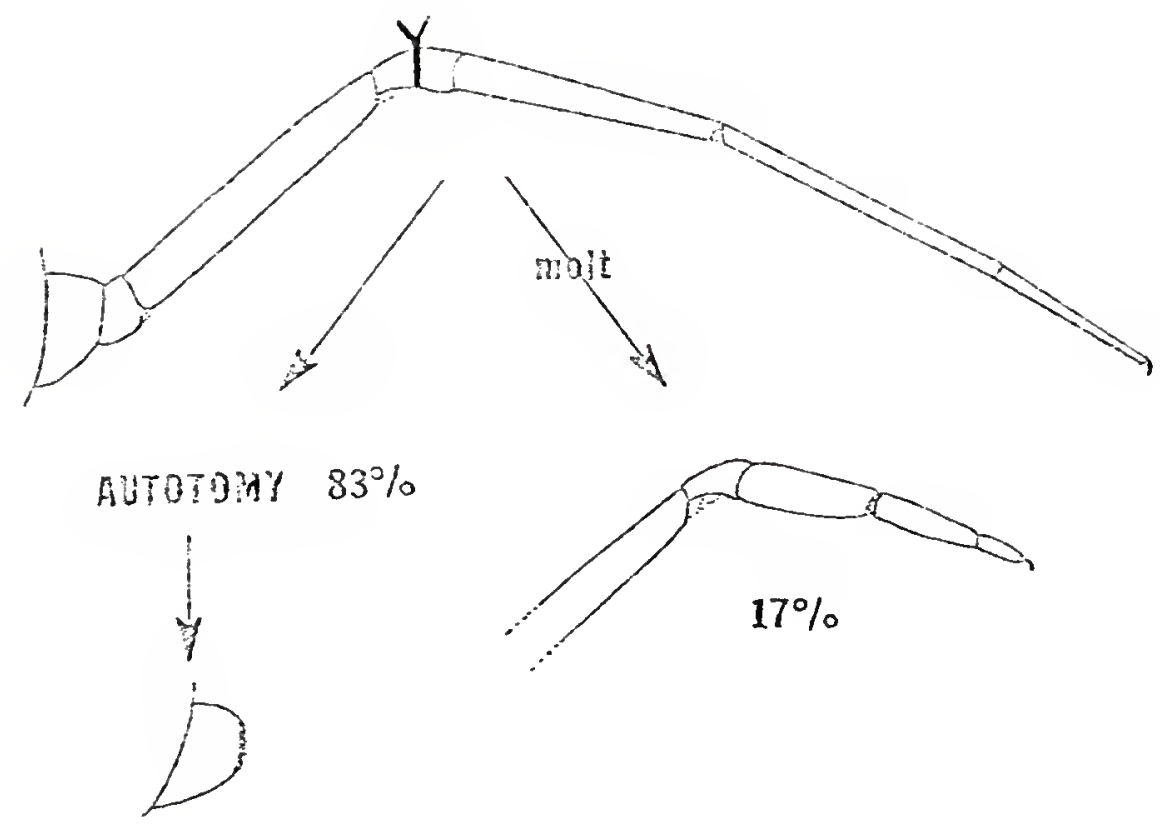

Fig. 40. Results of ligation of the leg at the patella.
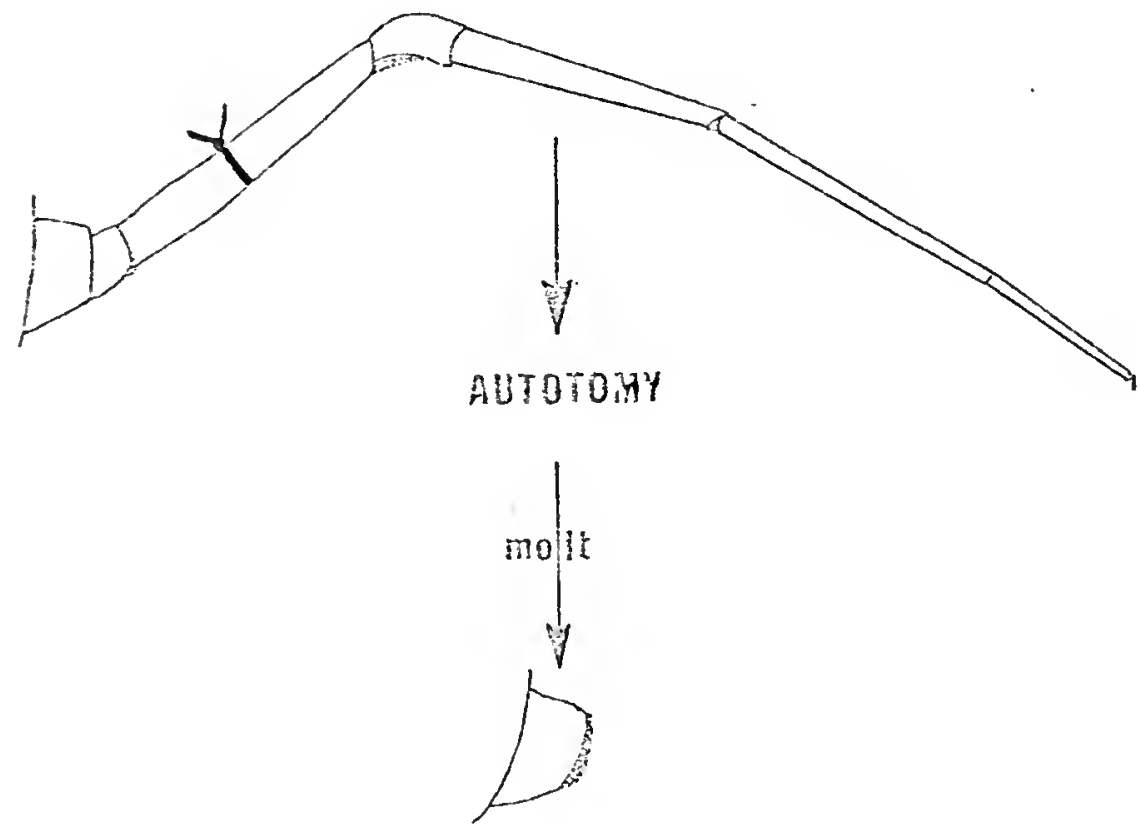

Fig. 4l. Results of ligation of the leg at the mid-femur. 


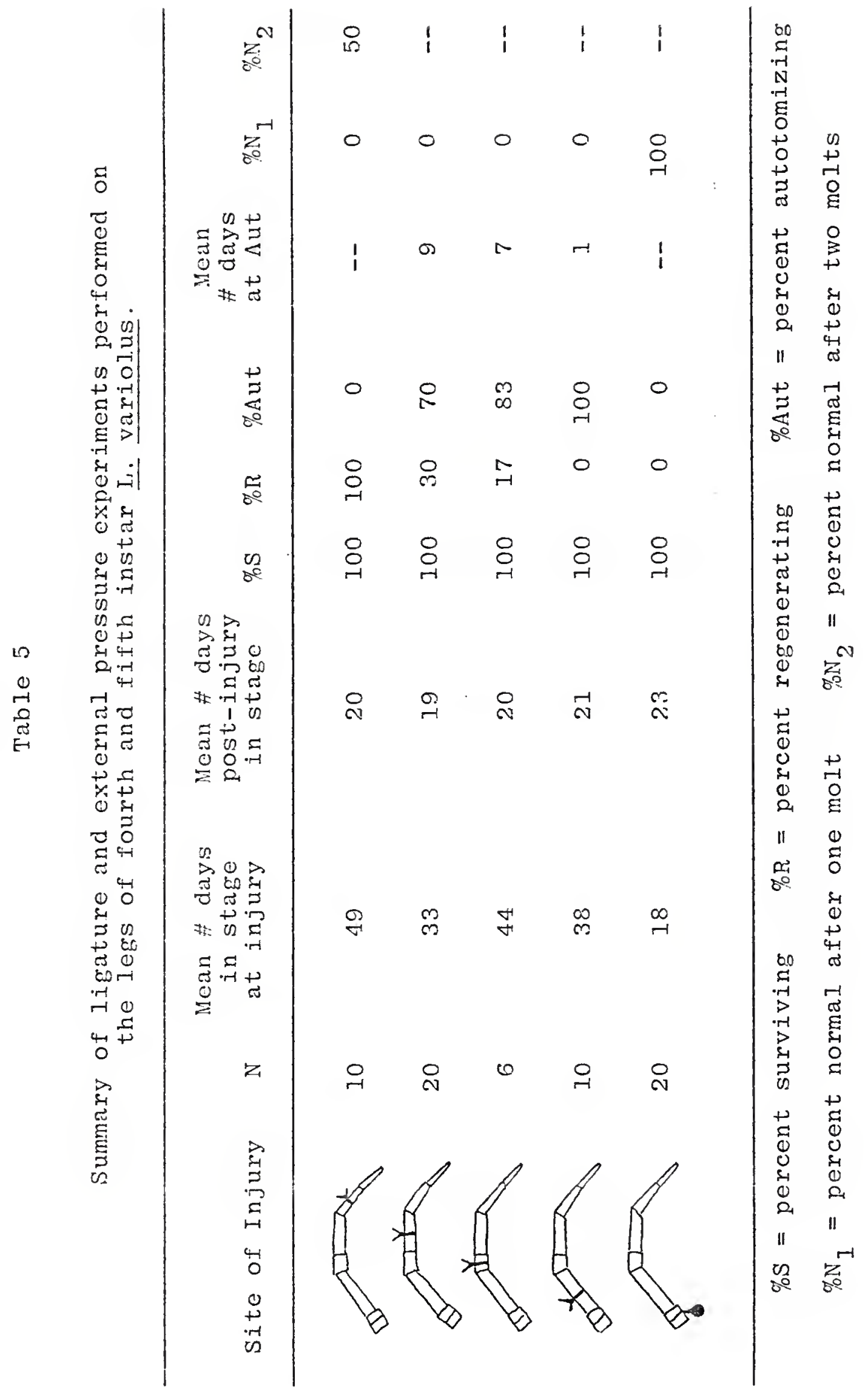


mate instar, thus allowing at least two more molts before maturation. Injury to the palp sustained proximal to the mid-point of the tarsus during the pre-penultimate instar did not result in normal regenerates. Ligation at the midfemur of the pre-penultimate palp resulted in apparent autotomy $40 \%$ of the time and in death $20 \%$ of the time.

Injury to the penultimate palps by ligation or amputation did not result in regeneration. Amputation of the tibia and/or tarsus of the penultimate palp frequently resulted in the death of the spider. Ligation at the tibiatarsus joint of the palp resulted in apparent autotomy in $20 \%$ of the cases and in death in $20 \%$ of the cases.

Amputation of the legs of immature I. variolus resulted in either regeneration or healing of the wound with no subsequent regeneration. Regeneration resulted when amputation occurred at or distal to the mid-point of the femur. Amputation at points proximal to the femoral mid-point to the proximal margin of the coxa resulted in the healing of the wound. Penultimate males (15) had legs amputated at various points and all exhibited regeneration or healing as described for immature females. Amputation of a leg of a penultimate male in no way interferred with palpal development.

Autotomy of the leg was first observed resulting from localized injury to the femur. Removal of a section of tissue from the femur resulted in either healing of the wound at the first post-injury molt or autotomy of the entire limb at the coxa-trochanter joint with no subsequent regeneration. 
Ligation at various points of the leg of $\underline{L}$. variolus resulted in either regeneration or autotomy. The more proximal the ligation the greater the frequency and earlier was the onset of autotomy. Ligature of the basitarsus never resulted in autotomy. Autotomy of the legs always occurred at the coxa-trochanter joint. 


\section{DISCUSSION}

\section{Regeneration}

This investigation has established the regenerative capacities for the legs and developing palpal organ of $\underline{L}$. variolus. The occurrence of autotomy in L. variolus was documented and compared to regeneration and healing as alternative responses to injury by amputation and ligature. This research has demonstrated that like other arthropods, L. variolus has the capacity to regenerate limbs injured by amputation or ligation. However, the black widow spider, L. variolus does not have the ability to regenerate a leg or palp following autotomy. This completely contradicts statements made by Goss (1969) and Needham (1965). Goss stated that the capacity for regeneration in arthropods was greatest at the autotomic breakage plane. Needham remarked that the specific rate of regeneration is greatest when amputation occurs at the autotomy plane. The evidence strongly suggests the capacity for regeneration is non-existent at the autotomic breakage plane of $\mathrm{L}$. variolus. In fact, the capacity for regeneration in the leg does not become apparent until some distance distal to the autotomy plane, at about the midpoint of the femur.

The palps of pre-penultimate male $\underline{L}$. variolus can regenerate to normal penultimate and subsequent adult paljs if 
the injury involves the loss of less than the distal half of the tarsus. When loss of more than the distal half of the pre-perultimate tarsus is sustained, there is tissue regeneration but insufficient to produce normal penultimate and adult palpal structures.

These results help to confirm the suspicions of Chrysanthus ( 1955 ) and Kaston (1963, 1968) that some malformations of penultimate and adult male spider palps could be attributed to imperfect regeneration following injury. Kaston (1968) reported a deformity in a penultimate palp of L. hesperus where one palpal tarsus was only half the size of the corresponding normal palp. This was observed in experimentation with $\underline{L}$. variolus when the tibia and tarsus of the pre-penultimate male palps were amputated.

In the current research amputations of penultimate palps never resulted in regeneration. Death occurred soon after the amputation of the distal half of the tarsus in $60 \%$ of the cases and in $100 \%$ of cases where the entire tarsus had been removed. Death did not occur when amputations were made at or proximal to the patella-tibia joint. In those cases the wound healed and the subsequent molt to the adult instar resulted in no regeneration.

Amputation and ligation of penultimate palps resulted only in the healing of the remaining portions of the palp or the death of the spider. Once the palp has reached the level of development seen in the penultimate palp damage is either fatal or repaired by healing since the evidence suggests that 
the tissue of the penultimate palp has lost the capacity to regenerate. The pre-penultimate palp retains the ability to regenerate the palpal organ as the histological examination of regenerate penultimate palps indicated. The regenerate cells in such a palp still form a developing palpal organ, although smaller than its normal counterpart, but has apparentIy lost the ability to react to the developmental hormones at the final molt. Palps injured during the pre-penultimate stage that regenerated a small penultimate palp never developed beyond that point even when the spiders involved molted to the adult stage.

A comparison of the regenerative capacities of prepenultimate and penultimate palps is presented in Figure 42 . Ligation of the femur of pre-penultimate palps resulted in death in $20 \%$ and apparent autotomy in $40 \%$ of the cases. Ligation at the tibia-tarsus joint and mid-femur of penultimate palps resulted in death $20 \%$ and $75 \%$ and apparent autotomy in $20 \%$ and $0 \%$ of the cases respectively. Due to the size and delicacy of the palps and the extreme difficulty in performing the ligation procedures I consider the data on ligation of the palps to be less than totally reliable. Further sophistication of the techniques for palpal ligation may yield more satisfactory results.

There seems a strong possibility that deaths resulting from amputation through the large cross-sectional areas of the penultimate palp may be related to the size of the wound. Cuts made through the bulbous portion leave a much greater 


\section{PRE-PENULTIMATE}

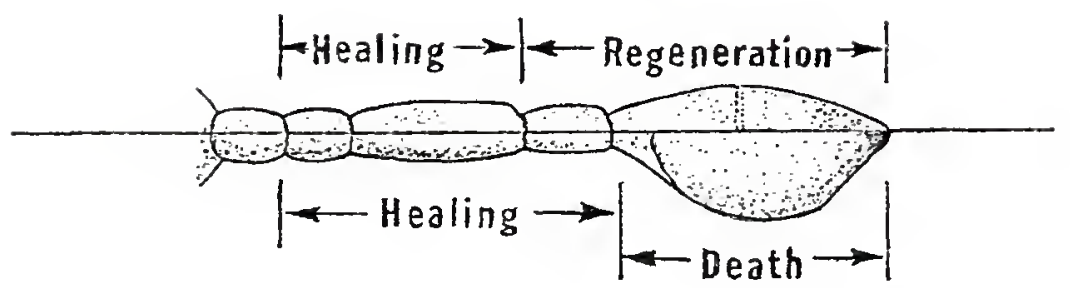

\section{PEHULTIMATE}

Fig. 42. Comparison of the regenerative capacities of the pre-penultimate and penultimate palps of the male L. variolus. 
wound than do cross-sectional cuts through the more proximal segments of the palp. Harvey and Williams (196I) reported that the "injury factor" in diapausing cecropia seemed to be released until the wound was sealed by blood cells. Amputation through the largest cross-sectional area of the prepenultimate palp, at the tibia-tarsus joint, is sealed by the healing process (Fig. 43) and the spiders survive to molt again. However, injury at the same point in the penultimate palp results in the death of the animal. The only perceivable difference is the size of the wound. Since the palps did not exhibit autotomy in response to amputation it may be possible that a larger amount of wound factor released from the larger wound, a wound that was not sealed by blood cells, may have resulted in the death of the spiders.

Amputation indicated that the regenerative capacity of the legs is greatest in the more distal segments. However, amputations as high on the leg as the patella-tibia joint resulted in some regeneration $100 \%$ of the time. No leg injured by amputation or ligature regenerated completely at the first post-injury molt. It is from the mid-point of the femur ( $30 \%$ of the time) to the proximal margin of the coxa that healing of the wound occurs with no subsequent regeneration .

The regeneration observed in the legs and palps of $\underline{L}$. variolus complies with the developmental gradient model for regeneration set forth by Bryant (Fig. I). Proximal structures left after amputation or ligature regenerate those portions lower (more distal) on the developmental gradient. 


\section{Autotomy}

Autotomy was first observed in the experiment where local injury of the leg resulted from removal of a section of tissue (Fig. 37) from the femur. Forty percent of the spiders thus injured exhibited autotomy of the entire limb at the coxa-trochanter joint not followed by any regeneration of the lost limb. A possible agent involved in the physiological "choice" between healing and autotomy may be the size of the wound and the corresponding release of wound factor. Autotomized legs in this experiment showed no signs of healing (Fig. 44) at the time the leg was released from the body, possibly indicating a wound too large to be sealed. Wound factor would then be released until the threshold for autotomy was reached, after which the leg would be severed from the body by the mechanism described by parry (1957).

Autotomy of the legs was a frequent result of ligation. A comparison of the autotomy, healing and regeneration of legs injured by amputation or ligature is presented in Figure 45. Ligature resulted in the autotomy of the entire leg $70 \%$ of the time when applied to the mid-point of the tibia. Amputation at the same point never resulted in autotomy. Autotomic reactions increased in frequency as more proximal segments of the leg vere ligatured.

Ligation distal to the mid-point of the tibia (at the mid-point of the basitarsus) did not result in autotomy. The lack of autotomy following injury to the dactyl of crustacea has been attributed to the fact that the leg nerve of those animals does not extend into that segment (Hodge, 1956; 

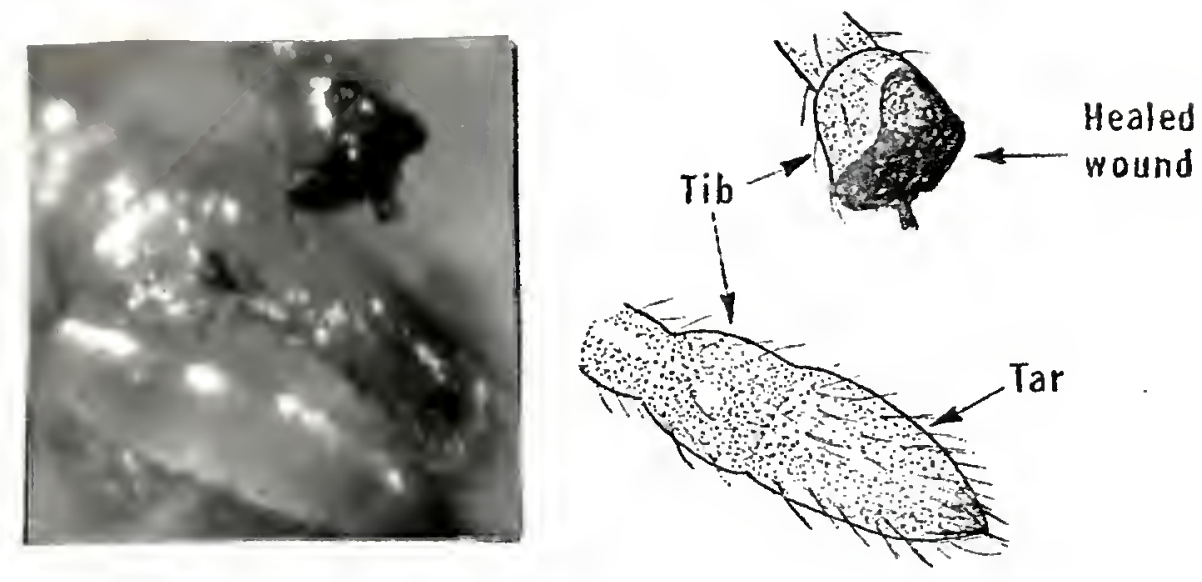

Fig. 43. Healing of the wound produced by amputation of the pre-penultimate palp at the tibia-tarsus joint.

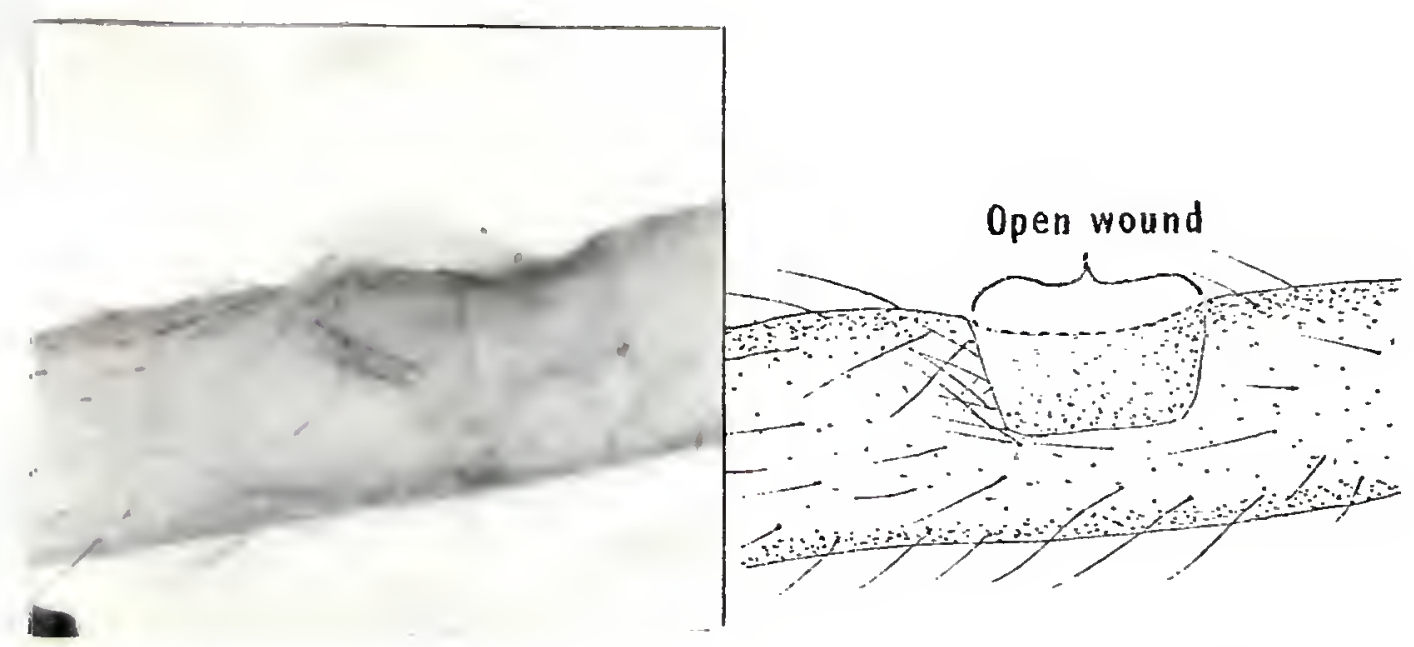

Fig. 44. The open wound of an autotomized leg after localized injury to the femur of the leg. 


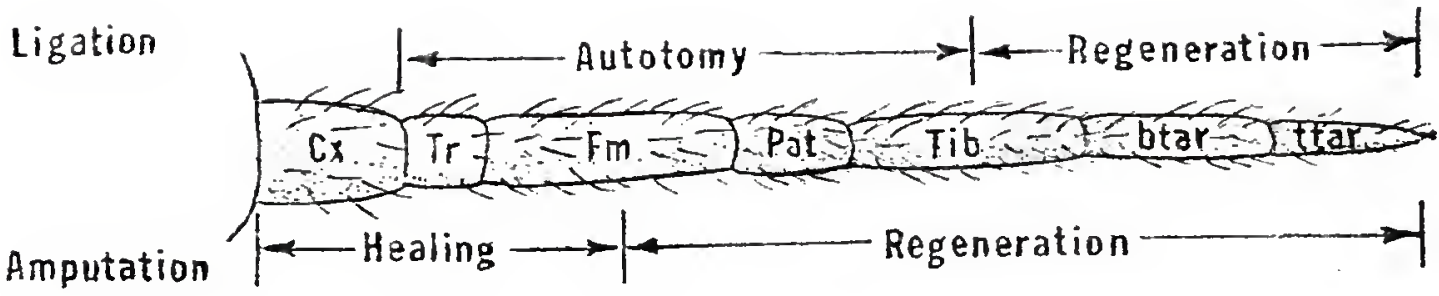

Fig. 45. A comparison of the autotomy, healing and regeneration of the legs injured by amputation and ligation.

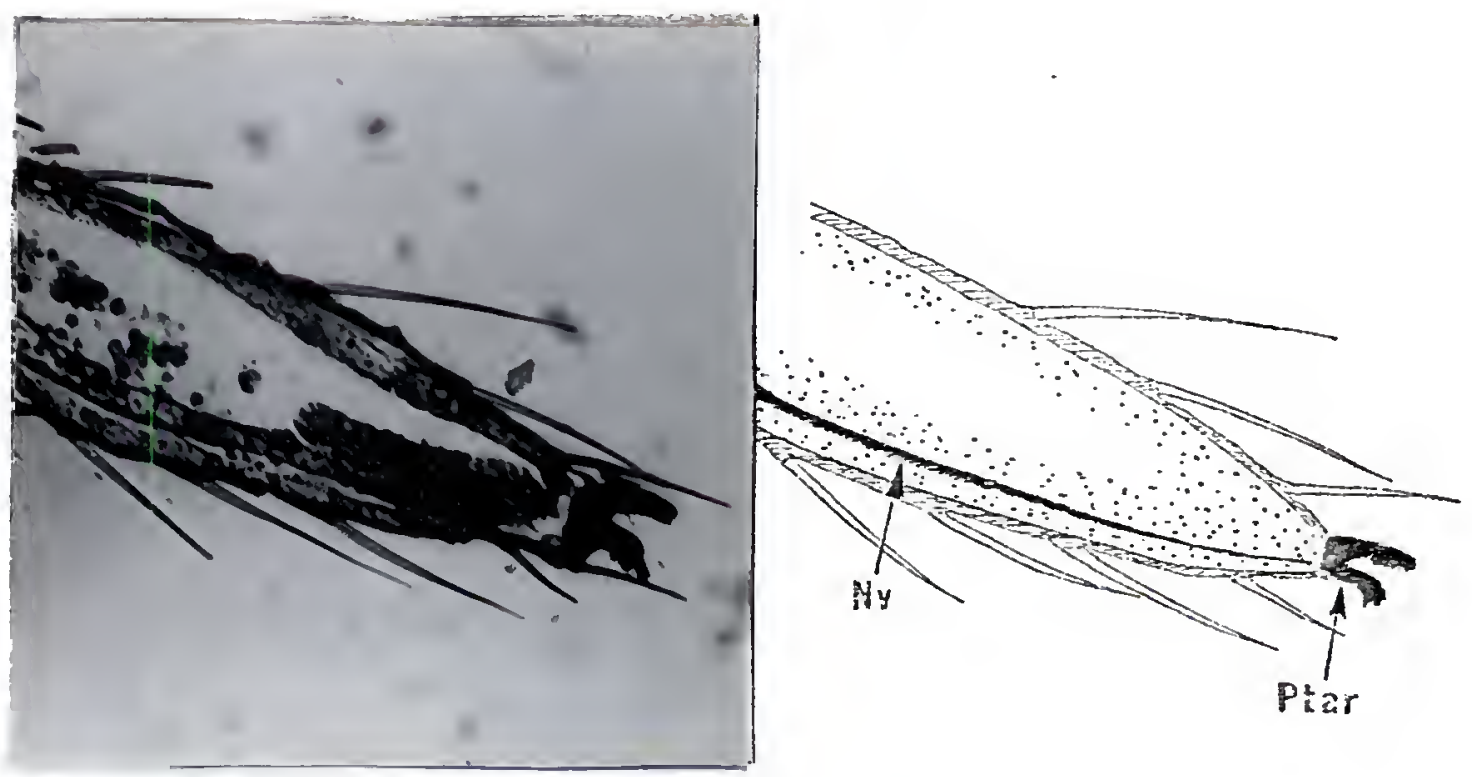

Fig. 46. Histology of the telotarsus of the leg of L. variolus showing the leg nerve present. 
Needham, 1947; and Wood, et al., 1932). No autotomy occurs when injury, either by amputation or ligation, is applied to the distal segments of the leg of $\mathrm{L}$. variolus even though the leg nerve is present to the tip of the telotarsus (Fig. 46). This fact argues against nervous reflex as a cause of autotomy, at least in the distal segments of the leg, in L. variolus.

It seems logical at this point to assume that ligation resultedin autotomy whereas amputation did not because of the greater duration of injury sustained with ligation. A cross-sectional cut of a leg leaves a wound capable of healing before the hypothetical wound factor threshold for autotomy is reached, thus no autotomy due to amputation was observed. Ligation is applied for longer periods of time, either until its mechanical removal or the first post-ligature molt. The greater duration of injury may result in wound factor production long enough to reach the autotomy threshold. This theory presupposes that wound factor is released in the absence of an open wound.

The argument that a wound factor contributes to the initiation of autotomy becomes stronger when the experiment taxing the autotomy plane is considered. Following theisplit of the articulating membrane at the coxa-trochanter joint caused by pulling, the release of hemolymph is proof the autotomy plane has been directly damaged. The pressure was not great enough to cause the direct loss of the leg. According to Harvey and Williams (1961) injury factor would have been released from such an injury but because the wound 
was quickly sealed when the split edges of the membrane came back into contact with each other the dose of wound factor would have been relatively small. Although the plane of weakness was injured directly and wound factor supposedly released, autotomy did not occur, presumably because the dose of wound factor did not reach the threshold and no reflex in response to the pressure applied caused the loss of the leg.

Autotomy has been demonstrated following injury to points on the leg distal to the plane of weakness where the injury was sustained for a longer period of time, either by duration of application (ligature) or by the failure of the wound to heal in some reasonable amount of time (local femoral injury). It seems possible that the duration and/or size of the injury, both related to the dose of wound factor released, contributes to the initiation of autotomy.

Autotomy is a costly alternative to regeneration in L. variolus since once a limb is autotomized regeneration of that limb is impossible. The adaptive advantage to a plane of weakness in a spider appendage is great. It is more advantageous for an animal to sacrifice a limb in order to escape than to be killed or fatally wounded in an encounter with a predator. Loss of a single leg to a web-dwelling spider may be of little consequence although no investigation of that phenomenon has been performed. In the black widow spider, I. variolus, the ability to escape or discard a badly injured limb outweighs the advantage of regenerating those limbs. 
The difference in the regenerative capacities of the legs and palpal organ may be related to the degrees of complexity of the two morphologically homologous appendages. The loss of one leg may be of little consequence since there are seven remaining. The palps of the male are at a relative premium since there are but two. Although only one palp is required for successful copulation, two palps would enhance the chances that a male spider's genes would be transmitted to. the next generation.

A physiological response gradient has been established for the legs and developing palpal organ of $\underline{L}$. variolus distinguishing between regeneration, healing, autotomy and death as responses to injury by amputation and ligation (Figs. 42 and 45).

In answering the questions posed earlier concerning the regenerative capacities of the legs and palps of $\underline{L}$. variolus a major question has been reopened. What is the "wound factor" and how is it related to regeneration, healing, autotomy and death, the alternative responses to injury? Is wound factor a universal agent found in all organisms in the same form or is it unique to each species?

The answers to those and other questions await discovery and discoverers. 
ADPENDIX 1

Fixation, Dehydration and Embedding Protocol

From fixation in alcoholic Bouin's fixative:

\begin{tabular}{ll}
$70 \%$ EtOH & $5-15 \mathrm{~min}$. \\
$70 \%$ EtOH & $5-15 \mathrm{~min}$. \\
$30 \%$ EtOH & $5-10 \mathrm{~min}$. \\
$50 \%$ EtOH & $5-10 \mathrm{~min}$. \\
$70 \%$ EtOH & $5-10 \mathrm{~min}$. \\
$80 \%$ EtOH & $5-10 \mathrm{~min}$. \\
$90 \%$ EtOH & $5-10 \mathrm{~min}$. \\
$95 \%$ EtOH & $5-10 \mathrm{~min}$. \\
$100 \%$ EtoH & $5-10 \mathrm{~min}$. \\
$1: 1$, 100\% EtoH:Acetone & $5-15 \mathrm{~min}$. \\
Acetone & $5-10 \mathrm{~min}$. \\
$1: 1$, Acetone:Terpineol & $10-15 \mathrm{~min}$. \\
Terpineol & 4 hours to overnight \\
& $($ can be stored in terpineol) \\
Benzene & $5 \mathrm{~min}$. \\
Benzene & $5 \mathrm{~min}$. \\
$1: 1$, Benzene:Paraplast & $15-30 \mathrm{~min}$. \\
Paraplast @ 55-60 & $15-45 \mathrm{~min}$. \\
Embed in Paraplast & \\
\hline
\end{tabular}


Paraffin blocks were trimmed and sectioned in rotary microtome.

Sections were mounted on standard glass microscope slides. 
APPENDIX 2

Mallory's Triple Stain Technique

$\begin{array}{ll}\text { Xylene } & 2-5 \mathrm{~min} . \\ \text { Xylene } & 2-5 \mathrm{~min} . \\ 100 \% \text { EtOH } & 2-5 \mathrm{~min} . \\ 95 \% \text { EtOH } & 2-5 \mathrm{~min} . \\ 80 \% \text { EtOH } & 2-5 \mathrm{~min} . \\ 70 \% \text { EtOH } & 2-5 \mathrm{~min} . \\ 50 \% \text { EtOH } & 2-5 \mathrm{~min} . \\ 30 \% \text { EtOH } & 2-5 \mathrm{~min} . \\ \text { Water } & 2-5 \mathrm{~min} .\end{array}$

Stain in $1 \%$ acid fuchsin for $2-5 \mathrm{~min}$. ( $t$ ime not critical)

Rinse in water for 1 min.

Transfer to $1 \%$ phosphotungstic acid for $2 \mathrm{~min}$. (time not critical)

Dip twice in water

Transfer to second staining solution (100 $\mathrm{ml}$ water, $0.5 \mathrm{~g}$ methylene blue, $2 \mathrm{~g}$ orange $\mathrm{G}$ and $2 \mathrm{~g}$ oxalic acid) for 5 min. (no more than 8 min.)

Wash in water - two 1 min. washes

Transfer to $100 \%$ alcohol for $1 \frac{1}{2} \mathrm{~min}$ - time is critical Place in xylene - can stay in xylene until ready to mount Pro-Tex or permount mounting medium are both good mountants. 


\section{LITERATURE CITED}

Agar, W. E. 1930. A statistical study of regeneration in two species of Crustacea. J. Expt. Biol. 7:349-369.

Baerg, W. J. 1923. The black widow: Its life history and effects of its poison. Sci. Monthly 17:535-547.

Bhatnagar, R. D. S. and J. G. Rempel. 1962. The structure, function and post-embryonic development of the male and female copulatory organs of the black widow spider Latrodectus curacaviensis (Muller). Can. J. Zool. 40:465510 .

BIiss, D. E. 1960. Autotomy and regeneration. Pages 561-589 in T. H. Waterman, ed. The physiology of crustacea. Academic Press, N. Y.

Bodenstein, D. 1933. Beintransplantationen an lepidopterenraupen II. Zur analyse der regeneration der brustbeine von Vanessa urticae - Raupen. Wilhelm Roux Arch. Entwiech. Org. 165:303-341.

Bodenstein, D. 1955. Contributions to the problem of regeneration in insects. J. Expt. Zool. 129:209-224.

Bohn, H. 1965. Analyse der regenerationsfahigkeit der insektenextremitat durch amputations - und transplantationsversuche an laven der Afrikanischen schabe Leucophaea maderae Fabr. (Blattaria). II. Achsendetermination. Wilhelm Roux Arch. EntwMech. Org. 156:449-503.

Bohn, H. 1972. The origin of the epidermis in the supernumerary regenerates of triple legs in cockroaches (Blattaria). J. Embryol. exp. Morph. 32(1):81-98.

Bohn, H. 1974a. Extent and properties of the regeneration field in the larval legs of cockroaches (Ieucophaea maderae). I. Extirpation experiments. J. Embryol. exp. Morph. 3I( 3 ): 557-572.

Bohn, H. 1974b. Extent and properties of the regeneration field in the larval legs of cockroaches (Leucophaea maderae). II. Confirmation by transplantation experiments. J. Embryol. exp. Morph. 32(1):69-79. 
Bohn, H. 1974c. Extent and properties of the regeneration field in the larval legs of cockroaches (Jeucophaea maderae). III. Origin of the tissues and determination of symmetry properties in the regenerates. J. Embryol. exp. Horph. 32(1):81-98.

Bonnet, P. 1930. La mue, l'autotomie, et le regeneration chez les Araignees. Bull. soc. hist. nat. Toulouse $59(2): 613-939$.

Brousse-Gaury, P. 1958. Contribution a l'etude de I'autotomie chez Acheta domestica L. Bull. biol. France et Belg. $92: 5 \overline{5-85}$.

Bryant, P. J. 1971. Regeneration and duplication following operations in situ on imaginal discs of Drosphila melanogaster. Devel. Biol. 26:606-615.

Bryant, P. J. 1975. Pattern formation in the imaginal wing disc of Drosophila melanogaster: Fate map, regeneration and duplication. J. Expt. Zool. 193:49-78.

Bulliere, D. 1967. Etude de la regeneration chez un insecte Blattopteroide, Blabera craniifer Burm. (Dictyoptere). I. Influence du niveau de la section sur la regeneration de la patte metathoracique. Bull. Soc. Zool. Fr. $92: 523-536$.

Bulliere, D. 197I. Utilization of intercalary regeneration for the study of cellular determination in the course of morphogenesis of Blabera craniffer. Devel. Biol. $25: 672-710$.

Burt, C. E. 1935. A review of the biology and distribution of the hourglass spider. J. Kan. Entomol. Soc. 8:117130 .

Chamberlin, R. V. and W. Ivie. 1935. The black widow spider and its variations in the United States. Bull. Univ. Utah 25(8):Biol. Ser. 3(1):1-18.

Chrysanthus, Fr. 1955. On defectively regenerated palps in male spiders. Natuurhist. Mnbld. 44:56-59.

Deevey, G. B. 1919. The developmental history of Latrodectus mactans at different rates of feeding. Amer. Midl. Nat. $\overline{42: 189-219 .}$

Emme1, V. E. 1910. Differentiation of tissues in the regenerating crustacean limb. Am. J. Anat. 10:109-156. 
French, T., P. J. Bryant and S. V. Bryant. 1975. Pattern regulation in epimorphic fields. Sci. 193:969-981.

Friedrich, P. 1906. Regeneration der beine und autotomie bei spinnen. Arch. f. Entwm. Bd. 20.

Goss, R. J. 1965. The functional demand theory of growth regulation. Pages $445-451$ in $V$. Kiortsis and H. A. L. Trampusch, eds. Regeneration in animals and related problems. North-Holland Publ. Co., Amsterdam.

Goss, R. J. 1969. Principles of regeneration. Academic Press, N. Y. 287 pp.

Hagstrum, D. W. 1968. Molting behavior of the black widow spider Latrodectus mactans. Ann. Entomol. Soc. Amer. $61: 591-\overline{593}$.

Harvey, W. R. and C. M. Williams. 1961. The injury metabolism of the cecropia silkmoth - I. Biological amplification of the effects of localized injury... J. Insect physiol. 7:81-99.

Hodge, M. H. 1956. Autotomy and regeneration in Gecarcinus lateralis. Anat. Rec. 125:633.

Jellison, W. L. and C. B. Philip. 1935. The biology of the black widow spider Latrodectus mactans. Sci. 81:71-72.

Kaston, B. J. 1937. The distribution of black widow spiders. Sci. $85: 74$.

Kaston, B. J. 1954. Is the Black Widow Spider invading New England? Sci. 119:192-193.

Kaston, B. J. 1963. Deformities of external genitalia in spiders. J. N. Y. Entomol. Soc. 21:30-39.

Kaston, B. J. 1968. Remarks on Black widow Spiders, with an account of some anomalies. Entomol. News. 79(2):113-124.

Kaston, B. J. 1970. Comparative biology of American Black Widow Spiders. Trans. San Diego Soc. Nat. Hist. 16(3): $33-82$.

Lawson, P. B. 1933. Notes on the life history of the hourglass spider. Ann. Entomol. Soc. Amer. 26:568-574.

Levi, II. W. 1958. Number of species of black widow spider. Sci. 127:1055. 
Luscher, 1. 1948. The regeneration of legs in Rhodnius prolixus (Hemiptera). J. Expt. Biol. 25:3 $\overline{34-343 .}$

McCrone, J. D. 1968. Biochemical differentiation of the sibling black widow spiders, Latrodectus mactans and I. variolus. Psyche 74:212-217.

Needham, A. E. 1945. Peripheral nerve and regeneration in crustacea. J. Expt. Biol. 21:144-146.

Needham, A. E. 1947. Local factors and regeneration in crustacea. J. Expt. Biol. 24:220-226.

Needham, A. E. 1949. Growth and regeneration in Asellus aquaticus (L.) in relation to age, sex, and season. J. Expt. Zool. 112:49-78.

Needham, A. E. 1950. Determination of the form of regenerating limbs in Asellus aquaticus. Quart. J. Microscop. Sci. $91: 401-41 \overline{8}$.

Needham, A. E. 1953. The central nervous system and regeneration in crustacea. J. Expt. Biol. 30:151-159.

Needham, A. E. 1965. Regeneration in arthopoda and its endocrine control. Pages 283-323 in V. Kiortsis and H.A.L. Trampusch, eds. Regeneration in animals and related problems. North-Holland Publ. Co., Amsterdam.

O'Farrell, A. F. and A. Stock. 1953. Regeneration and the molting cycle in Blattella germanica L. I. Single regeneration initiated during the first instar. Aust. J. Biol. Sci. 6:485-500.

O'Farrell, A. F. and A. Stock. 1954. Regeneration and the molting cycle in Blattella germanica L. III. Successive regeneration of both metathoracic legs. Aust. J. Biol. Sci. 7:525-536.

O'Farrell, A. F., A. Stock and J. Morgan. 1956. Regeneration and the molting cycle in Blattella germanica L. IV. Single and repeated regeneration and metamorphosis. Aust. J. Biol. Sci. 9:406-422.

Parry, D. A. 1957. Spider leg muscles and the autotomy mechanism. Quart. J. Microscop. Sci. 98:331-340.

Paul, J. H. 1914. Regeneration of the legs of decapod crustacea from the preformed breaking plane. Proc. Roy. Soc. Edinburgh 35:78-91. 
Paul, J.H. 1915. A comparative study of the reflexes of autotomy in decapod crustacea. Proc. Roy. Soc. Edinburgh 35: 232-262.

Penzlin, H. 1963. Uber die regeneration bei schaben (Biattaria). I. Das regenerations-vermogen und die genese des regenerats. Wilhelm Roux Arch. EntwMech. Org. $154: 434-465$.

Rempel, J.G. 1957. The embryology of the black widow spider, Latrodectus mactans (Fabr.). Can. J. Zool. 35:35-74.

Ross, K. and R. L. Smith. 1979. Aspects of the courtship behavior of the black widow spider, Latrodectus hesperus (Araneae: Theridiidae), with evidence for the existence of a contact sex pheromone. J. Arachnol. 7:69-77.

Savory, T. 1977. Arachnida. Academic Press, N. Y. 340 pp.

Schultz, E. 1898. Uber regeneration von spinnenfussen. Trav. Soc. Nat. petersbourg, XXIX L. 1, (2). Comptes Rendus Seances, 94-95.

Snodgrass, R. E. 1965. A textbook of arthropod anatomy. Hafner Publ. Co., N. Y. 363 pp.

Urvoy, J. 1963. Etude anatomo-functionnelle de la patte et de l'antenne de la blatte Blabera cranifier Burmeister. Ann. Sci. nat. Zool. Ser. XII $\frac{1}{5: 287}-413$.

Vachon, M. 1941. Chthonius tetrachelatus et ses formes immatures. Bull. Mus. Hist. Nat., Paris 13:442-449.

Wagner, W. 1887. Le regeneration des organes perdus chez les araignees. Sci. Imp. Nat. de Moscou.

Wilson, E. B. 1903. Notes on the renewal of asymmetry in the regeneration of chelae in Alpheus heterochelis. Biol. Bul1. 4:197-210.

Wolpert, I. 1974. The development of pattern and form in animals. Oxford Biology Readers $\# 51$, Oxford Univ. Press.

Wood, F. D. 1926. Autotomy in arachnida. J. Morph. $42(1): 143-195$.

Wood, F. D. and H. E. Wood. 1932. Autotomy in decapod crustacea. J. Expt. Zool. 62:1-55.

Woodruff, L. C. 1937. Autospasy and regeneration in the roach Blattella germanica (L.). J. Kan. Entomol. Soc. I0(1): $1-9$. 


\section{SUPPLEMENTARY BIBLIOGRAPHY}

Barbosa, P. 1974. Manual of basic techniques in insect histology. Autumn Press, Amgerst, Mass. 244 pp.

Bodenstein, D. 1959. The role of hormones in the regeneration of insect organs. Scientia 94:19-23.

Bryant, P. J. 1979. Pattern formation, growth control and cell interactions in Drosophila imaginal discs. Pages 295-316. Determinants of spatial organization. S. Subtelny and I. R. Konigsberg, ed. Academic Press, N. Y.

Bryant, P. J., S. V. Bryant and V. French. 1977. Biological regeneration and pattern formation. Sci. Amer. 237(1): 66-81.

Caveney, S. 1978. Intercellular communication in insect development is hormonally controlled. Sci. 199:192195.

Dewes, E. 1973. Regeneration in transplanted halves of male genital disks and its influence upon duration of development in Ephestia kuhniella Z. Wilhelm Roux Archiv. $172: 349-354$.

Edwards, J.S. and J. Palka. 1971. Neural regeneration: Delayed formation of central contacts by insect sensory cells. Sci. 172:591-594.

Ehn, A. 1964. Aspects of determination in the spider embryo. Zool. Bidr: Uppsala 37:3-20.

Etkin, W. and L. I. Gilbert. 1968. Metamorphosis. AppletonCentury-Crofts, N. Y. 459 pp.

Furukawa, H. 1937. Reduplication experimentally produced in the earwig, Anisolabis maritima (Dermaptera). III. Transplantation of forceps. Jap. J. Zool. 8:510-535.

Garcia-Bellido, A., P. A. Lawerance, and G. Morata. 1979. Compartments in animal development. Sci. Amer. 241(1): 102-110. 
Gordon, R. and A. G. Jacobson. 1978. The shaping of tissues in embryos. Sci. Amer. 23S(6):106-113.

Grant, P. 1978. Biology of developing systems. Holt, Reinhart and Winston, N. Y. $720 \mathrm{pp}$.

Hadorn, E. 1968. Transdetermination in cells. Sci. Amer. $219(5): 110-120$.

Krishnakumaran, A. 1961. A comparative study of the arachnid cuticle. II. Chemical nature. Zeitz. Physiol. $44: 478-486$.

Krishnakumaran, A. 1962. A comparative study of the cuticle in arachnida. I. Structure and staining properties. Zool. Jb. Anat. Bd. 80:49-64.

Krishnakumaran, A. 1972. Injury induced molting in Galleria mellonella larvae. Biol. Bull. 142:281-292.

Kunkel, J. G. 1977. Cockroach molting. II. The nature of regeneration-induced delay of molting hormone secretion. Biol. Bull. 153:145-162.

Lawerence, P. A. and G. Morata. 1979. Pattern formation and compartments in the tarsus of Drosophila. Pages 317-324 in Determinants of spatial organization.

S. Subte $\overline{l n} y$ and I. R. Konigsberg, ed., Academic Press, N. Y.

Madhavan, K. and H. A. Schneiderman. 1969. Hormonal control of imaginal disc regeneration in Galleria mellonella (Lepidoptera). Biol. Bull. 137( $\overline{2): 321-3} 3 \overline{1}$.

Markert, C. L. and H. Ursprung. 1971. Developmental genetics. Prentice-Hall, Inc., Englewood Cliffs, N. J. 214 pp.

Parry, D. A. 1960. Spider hydraulics. Endeavor 19:156-162.

Parry, D. A. and R. H. J. Brown. 1959. The hydraulic mechanism of the spider leg. J. Expt. Biol. 36:423-433.

Parry, D. A. and R. H. J. Brown. 1959. The jumping mechanism of salticid spiders. J. Expt. Biol. 36:654-664.

Pohley, H. J. 1965. Regeneration and the molting cycle in Ephestia kuhniella. Pages 324-330 in V. Kiortsis and H. A. L. Trampusch, eds. Regeneration in animals and related problems. North-Holland Publ. Co., Amsterdam. 
Schubiger, G. 1971. Regeneration, duplication and transdetermination in fragments of the leg disc of Drosophila melanogaster. Devel. Biol. 26:277-295.

Sewell, 1. T. 1955. The histology and histochemistry of the cuticle of a spider, Tegenaria domestica (L.). Ann. Entomol. Soc. Amer. $48(3): 107-\overline{118}$.

Shappirio, D. G. and W. R. Harvey. 1965. The injury metabolism of the cecropia silkworm - II. Injury induced alterations in oxidative enzyme systems and respiratory metabolism of the pupal wing epidermis. J. Insect Physiol. 11:305-327.

Waddington, C. H. 1966. Principle of development and differentiation. The Macmillan Co., N. Y. $115 \mathrm{pp}$.

Wilson, R. S. 1970. Some comments on the hydrostatic system of spiders (Chelicerata, Araneae). Z. Morph. Tiere $68: 308-322$.

Wolpert, L. 1978. Pattern formation in biological development. Sci. Amer. 239(4):154-164.

Woodruff, L. C. and L. Seamans. 1939. The rate of regeneration in the German roach. Ann. Entomol. Soc. Amer. $32: 589-599$. 


\section{BIOGRAPHICAL SKETCH}

John Brookes Randall was born in Ft. Wayne, Indiana, on April 7, 1949. He moved to Connecticut a year and a half later, then to Maryland at age four. He attended high school in Severna park, Maryland, graduating in 1967. In September of the same year he entered Maryville College, Maryville, Tennessee, and received the Bachelor of Arts degree in Biology from that institution in 1971.

For nearly two years after graduating from college he worked as a physician's assjstant in clinical research at Johns Hopkins School of Medicine.

In September of 1973 he began graduate studies in Entomology at the University of Florida under the direction of Dr. Willard H. Whitcomb, during which time he served as a graduate research and teaching assistant. He was awarded a Visiting Graduate Student Fellowship to the Smithsonian Institute in 1974 to study scientific illustration in that museum's Department of Entomology. He received the Master of Science degree from the University of Florida in June, 1976.

He continued graduate work for the doctoral degree under the direction of Dr. Harvey L. Cromroy. He has recently accepted a post-doctoral position at the state University 
of New York at Buffalo where he will be investigating the regeneration of insect nerve cells.

He holds membership in the Society of Sigma Xi, The Entomological Society of America, The American Arachnological Society, The Cambridge Entomological Club, The Florida Intomological Society, The Guild of Natural Science Illustrators and the International Society of Artists.

He has been married to his wife Carol for eight years and they have a three-year-old daughter, Brooke Kathryn. 
I certify that I have read this study and that in my opinion it conforms to acceptabie standards of scholarly presentation and is fuIly adequate, in scope and quality, as a dissertation for the degree of Doctor of philosophy.

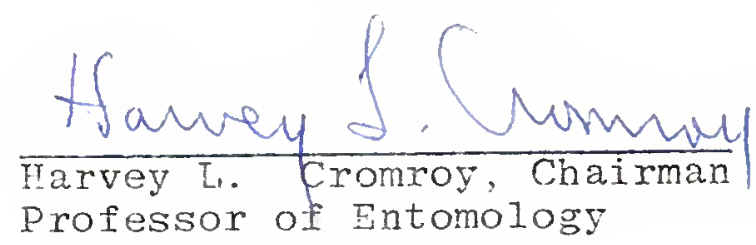

I certify that I have read this study and that in my opinion it conforms to acceptable standards of scholarly presentation and is fully adequate, in scope and quality, as a dissertation for the degree of Doctor of Philosophy.

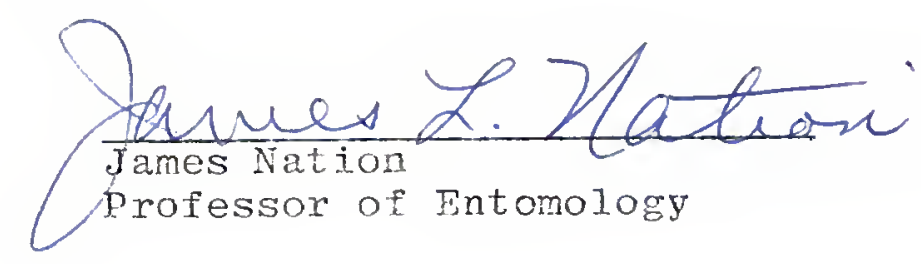

I certify that I have read this study and that in my opinion it conforms to acceptable standards of scholarly presentation and is fully adequate, in scope and quality, as a dissertation for the degree of Doctor of Philosophy.

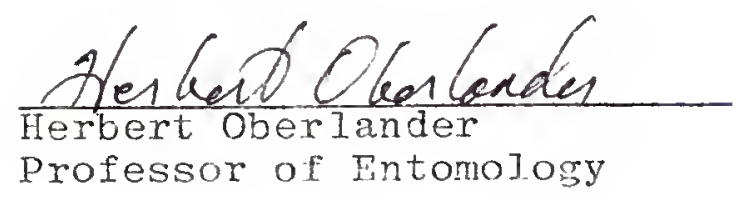


I certify that I have read this study and that in my opinion it conforms to acceptable standards of scholarly presentation and is fully adequate, in scope and quality, as a dissertation for the degree of Doctor of Philosophy.

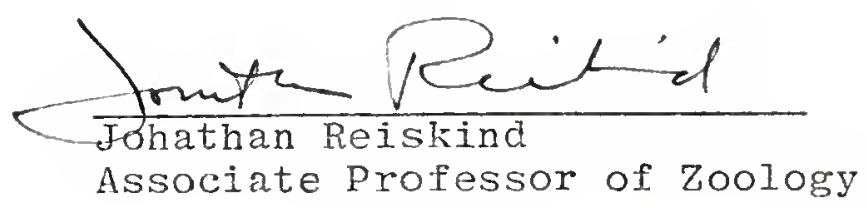

This dissertation was submitted to the Gracuate Faculty of the Collese of Agriculture and to the Graduate Council, and was accepted as partial fulfillment of the requirements for the degree of Doctor of Philosophy.

August 1979

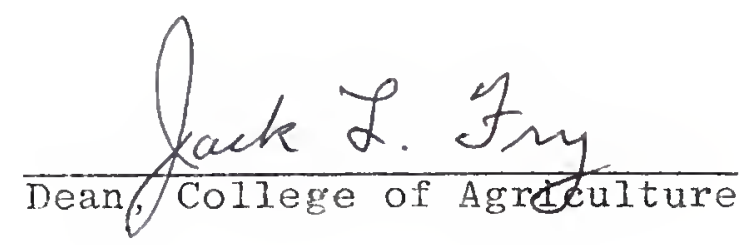

Dean, Graduate School 
UNIVERSITY OF FLORIDA

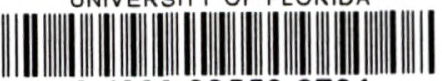

31262085539731 